\title{
Hans-Peter Hoelscher-Obermaier
}

\author{
Das lyrische Werk \\ Antoni Langes
}

\section{Untersuchungen zur Dichtungssprache eines "jungpolnischen" Autors}

Verlag Otto Sagner München · Berlin - Washington D.C.

Digitalisiert im Rahmen der Kooperation mit dem DFG-Projekt „Digi20“

der Bayerischen Staatsbibliothek, München. OCR-Bearbeitung und Erstellung des eBooks durch den Verlag Otto Sagner:

http://verlag.kubon-sagner.de

() bei Verlag Otto Sagner. Eine Verwertung oder Weitergabe der Texte und Abbildungen, insbesondere durch Vervielfältigung, ist ohne vorherige schriftliche Genehmigung des Verlages unzulässig. 


\title{
SlaVistische BEITRÄGE
}

\author{
BEGRÜNDET VON \\ ALOIS SCHMAUS \\ HERAUSGEGEBEN VON \\ JOHANNES HOLTHUSEN - HEINRICH KUNSTMANN \\ PETER REHDER - JOSEF SCHRENK \\ REDAKTION \\ PETER REHDER
}

Band 174

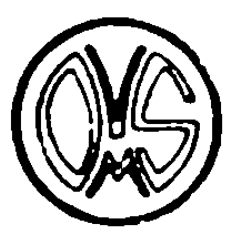

VERLAG OTTO SAGNER

MÜNCHEN 


\section{HANS-PETER HOELSCHER-OBERMAIER DAS LYRISCHE WERK ANTONI LANGES}

Untersuchungen zur Dichtungssprache eines ,jungpolnischen' Autors

\section{VERLAG OTTO SAGNER · MÜNCHEN 1983}


ISBN 3.8769 9 ).270.3

(C) Verlag Otto Sagner. München 1983

Abtellung der Firma Kuboin \& Sagner München

Druck D Gräbmesr Altenoorf

\section{Bayerlsictine}

Staatsbibliiorthok

Münchiem 


\section{Vorbemerkung}

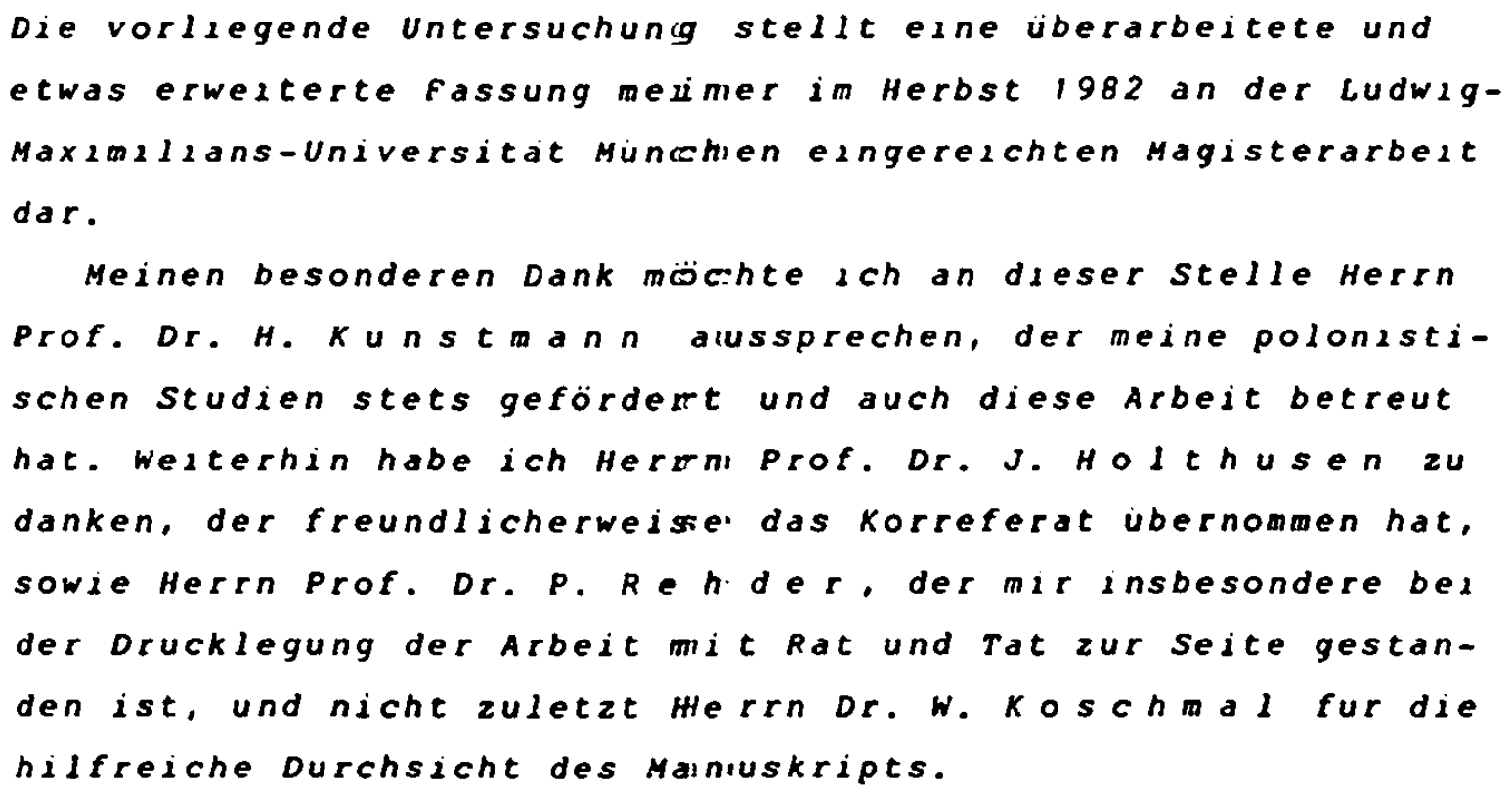


Inhal tsverzeichnis

1. Einleitung..................... 9

1.1. Forschungsstand..................... 10

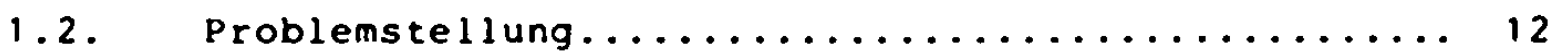

1.3. Untersuchungsgegenstand................. 14

1.4. Themenbereiche in LANGES Lyrik.............. 15

2. Gestaltungen des lyrischen Monologs........... 17

2.1. Typen der Monologgestaltung................ 17

2.2. Die Standardfunktionen der Monologgestaltungen.... 18

2.2.1. Die Standardfunktionen des Gestaltungstyps [a..... 18

2.2.2. Die Standardfunktionen der an einen Adressaten gerichteten Gestaltungen................ 20

2.2.3. Die Standardfunktionen der 'mittelbaren' Gestal-

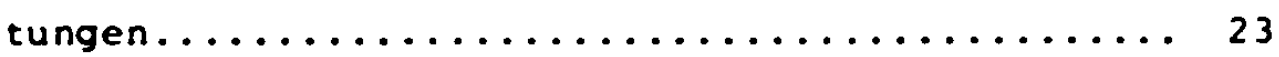

2.3. Besondere Funktionen der Monologgestaltung....... 27

2.3.1. Besondere Gestaltungen der phllosophischreflexiven Lyrik................... 27

2.3.2. Besondere Gestaltungen der politischsozialen Lyrik...................... 31

2.3.3. Besondere Gestaltungen der 'Liebeslyrik ........ 31

2.3.4. Besondere Gestaltungen der Naturlyrik ........ 32

2.4. Zusammenfassung................... 33

3. versbau......................... 36

3.1. Stark 'markierte Versgestaltungen........... 38

3.1.1. "Vers libres"...................... 39

3.1.2. Der 'modernisierte' Hexameter............... 43

3.2. Schwächer 'markierte' Versgestaltungen.......... 45

3.2.1. Syllabotonische versmaße................. 46

3.2.2. Syllabische versmaße.................. 51

3.3. Schwach 'markierte' Versgestaltungen........... 54

3.3.1. Häufiger gebrauchte Versmaße................ 55

3.3.2. Standardversmaße $\ldots \ldots \ldots \ldots \ldots \ldots \ldots \ldots \ldots \ldots \ldots$

3.4. Die innere Gestaltung des einzelnen Gedichts..... 58; 
3.4.1. Metrische Besonderheiten................. 59

3.4.2. Rhythmische Besonderheiten............... 63

3.5. zusammenfassung.................... 66

4. Schlüsselwörter.................... 68

4.1. Phllosophisch und religlös geprägte

Grundbegriffe.................... 70

4.1.1. Die geistige sphäre $1 m$ Menschen............... 70

4.1.2. Kategorien des Absoluten $\ldots \ldots \ldots \ldots \ldots \ldots \ldots \ldots$

4.1.3. 'Raum' und 'Ferne'..................... 74

4.1.4. 'Ende', 'Grenze', 'Ufer'.................. 75

4.1.5. Begriffe aus dem religiösen Bereich............ 76

4.2. Zentralbegriffe der persönlichen Reflexion....... 78

4.2 .1 . Tod' vs. 'Leben'..................... 78

4.2.2. 'Geheimnis' und 'Abgrund'................ 81

4.2.3. 'Finsternis' und 'Chaos'................ 84

4.2.4. 'Leiden' und 'Schmer 2 ', 'Tränen' und 'Trauer'.... 85

4.2.5. Weitere Folgen von 'Chaos' und 'Finsternis'..... 86

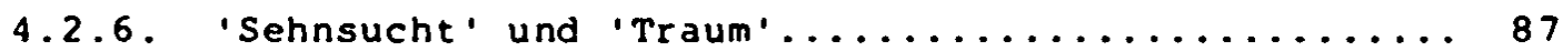

4.2.7. Inhalt der 'Sehnsüchte' und 'Träume' .......... 88

4.3. Bildhafte Naturelemente und Farbsymbolik......... 91

4.3.1. Blumen.............................. 91

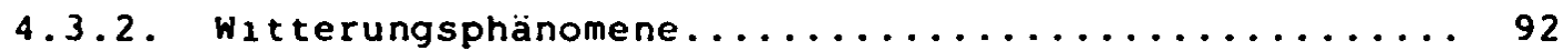

4.3.3. 'Meer' und 'Wellen', 'Fließen' oder 'Schwimmen'.... 93

4.3.4. Himmelskörper und mit ihnen verbundene

Naturphänomene..................... 96

4.3.5. Farbsymbolik...................... 98

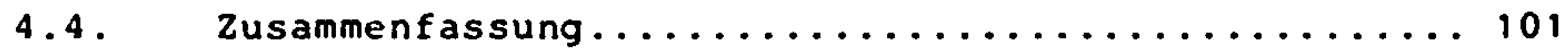

5. Literarische Bezugnahmen................ 104

5.1. Die griechisch-römische Antike............ 106

5.2. Die Welt der Bibel.................... 109

5.3. Christliches Mittelalter und europäische Neuzeit... 111

5.4. Der polnische Kulturbereich............... 114

5.5. Bezugnahmen innerhalb von LANGES Gesamtwerk...... 118

5.6. zusammenfassung.....................120

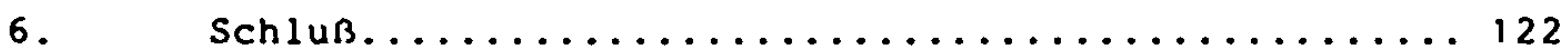


7. Literaturverzeichnis................... 123

7.1. Verwendete Ausgaben von LANGES werken.......... 123

7.2. Quellen der zitierten Gedichte.............. 123

7.3. Weitere $2 i t i e r t e$ Literatur................. 125 


\section{Einleitung}

Antoni LANGE (186)-1929) gehorte zu den interessanteren Personlichkelten in der Lyrikerplejade des polnischen Modernismus, wle $T$. WEISS aus dem zeltlichen Abstand von nunmehr fast einem Jahrhundert feststellt. Er war ein ungewohnlich vielseitiges ralent, ein fast renassancehaftes Geistesphanomen (1978:341)2. J. KRZYŻANOWSKI bezeichnet $\mathrm{ihn}$ sogar als bedeutenden Dichter ("znakomitego poety": "1979:488) und ungewohnlich subtlien Lyriker (1963:57). Die Richtigkeit dieser Urteile zu untermauern, soll - quasi en passant - elnes der Anliegen dieser Arbeit sein.

Angesichts solcher Einschatzungen muß es umso mehr verwundern, daß LANGES Schaffen wenı bekannt ast, und das sogar in Kressen der lateraturhistorker, und daß sein dichterssches Schaffen keshe grundlichen analysen erfahren habe, wie J. PORADECKI noch in der Einleitung 24 einem 1979 erschienenen Auswahlband (RIIW) konstatzeren mußte (1979:13 f.).2

$1 \mathrm{Zu}$ den in der Arbelt grundsatzlich verkürzt angeführten blbliographischen Angaben vgl. das Literaturverzeichnis (Kapitel 7). Den polnischen Orlginaltext fuhre lch bei allen 2 itaten aus LANGES lyrischem Werk an: ansonsten nur, wenn die deutsche Ubersetzung die Bedeutungsfülle des Originals nicht genau wiedergeben kann. Hervorhebungen durch Fettdruck in Zltaten stammen von mir: meine Zusatze innerhalb von zitaten sowie von (stets kursiven) zitatubersetzungen werden zwischen spitze Klammern gesetzt und nicht-kursiv geschrieben.

2 Eine der Ursachen hierfur mag darin zu suchen sein, daß nach den zu LANGES Lebzeiten bzw. kurz nach seinem Tode erschienenen und tellweise sehr schwer zuganglichen Gedichtbanden - abgesehen von elner kleineren Auswahlausgabe (PW) $1 \mathrm{~m}$ Jahre 1960 - erst das letztgenannte Werk wleder etwas ausfuhr licher an ihn erinnert hat. Da die Textsituation in Deutschland naturgemaß noch sehr viel schwleriger ist, werde ich in der vorliegenden Arbelt nicht umhinkönnen, meine Argumentation mit ausfuhrlichem Beisplelmaterlal zu belegen, zumal der leichter zugangliche neuere Auswahlband RIIW durch sinnentstellende Druckfehler tellweise seine Brauchbarkelt elnbüßt (vgl. dort z.B. R 40, v. 16: "umiejetnośc" statt richtiq "obojetnośc": R 42, v. 3: "czasów" statt "czarów": K 58, v. 3: "nieustannym" statt "nieustannych": $R$ 60, v. 20: "gdzie sloneczna" statt "gdzle zycia sloneczna": R 63 , v. 8 fehlt: "I w czeluście otwartych sienl h mrok spozleram": Wenecja 3, v. 7: "chclalby" statt "chclalaby": Chclalbym..., v. 19: "piersi" statt "plesni": u.a.l. 


\subsection{Forschungsstand}

Einiges Interesse im Rahmen von LANGES umfangrelchem und vielfaltigem Gesamtwerk haben in der forschungsliteratur lediglich selne theoretischen, insbesondere philosophischen und literaturkritıschen Arbeiten gefunden, wie die langere Abhandlung von M. PODRAZA-KWIATKOWSKA (1969) und die Monographie von B. SZYMANSKA (1979) zeigen. Auch seine imposante Leistung als Übersetzer ist unter verschiedenen Gesichtspunkten gewürigt worden (MACHALSKI 1937:81-136; DRZEWICKA 1971:75-98).

Dagegen füht LANGES literarisches Origlnalwerk (auch in neuerer Ze1t) $1 \mathrm{~m}$ Bewußtsein der Literaturhistoriker ein Schattendase $n$. Seınem umfangrelchen Prosaschaffen sowle seinen drel veroffentlichten Dramen "Wenedzi". "Atylla" und "Malczewski" wurden allenfalls in einigen Abrissen uber sein Gesamtwerk wenige pauschale Zellen gewldmet lam ausführlichsten PROKOP 1968: 428-430: unter dem speziellen Aspekt des Orientalismus MACHALSKI 1937:48-52, 59-64; dazu seit kurzem im Rahmen einer Gesamtdarstellung der polnischen 'science fiction' SMUSZKIEVICZ 1982: $138-146,153-158)$.

Mag dies noch tellweise damit zu begründen sein. daß die belden genannten Bereiche am wenlgsten bedeutungsvoll innerhalb LANGES Gesamtwerk zu sein scheinen, wie M. PODRAZA-KWIATKOWSKA melnt (1971:487), so muß die Vernachlässigung selnes poetischen Schaffens vollkommen unverständich blelben, zumal wenn man bedenkt, daß einigen selner - gewlß nicht interessanteren - jungpolnischen Dichterkollegen sogar monographische Untersuchungen gewldmet wurden.'

Die wenıgen erwähnenswerten Skizzen, die slch mit LANGES dichterischem Werk beschäfigen, seien 1 m folgenden kurz charakterisiert:

Als erster hat sich $w$. BOROWY (1934) eingehender mit diesem Schaffensberelch auseinandergesetzt. Er arbeitet vor allem die best 1 mmenden Hauptmotive und Themenkomplexe heraus: Tod (Abschnitt 1), Wanderschaft und Veranderung (2), das Leiden an

\footnotetext{
- Man vergleiche z.B. M. WOLSKA (SIEROTWINSKI 1963 ) oder $W$. ROLICZ-LIEDER (NAPIERSKI 1936: PODRAZA-KWIATKOWSKA 1966).
} 
dieser welt (3) und schließlich die Einsamke1t (6). Daneben verwelst er auf LANGES formale Neuerungen (4), betont aber zu Recht, wle zu zeigen sein wlrd-, daß seine sprachliche virtuoserie niemals zu inhaltsleerer Wortspielerei wird (5).

Ebenfalls noch vor dem 2. Weltkrieg ist F. MACHALSKIS Abhandlung über östliches Kulturgut in LANGES Gesamtwerk erschlenen. In einigen Abschnitten untersucht er auch LANGES Lyrik auf diesen Aspekt hin (1937:30-48,53-58,65-78), wobel deutlich wird, welch großen Einfluß gerade die Indische Geisteswelt auf diesen Bereich seines Werks ausgeubt hat. In manchen Fällen können MACHALSKIS Hinweise die Interpretation von LANGES Gedichten erleichtern, auch wenn mir nicht alle seine Deutungen begründet erscheinen, wor auf an gegebener Stelle zu verweisen sein wird, und sie des öfteren den Blick fur das Wesentliche verstellen. Der Intention des Autors entsprechend lst das Buch vor allem als Beitrag zur Gelstesgeschichte interessant.

Im Jahre 1960 hat $J$. Z. JAKUBOWSKI mit einem Auswahlband aus LANGES Dichtungs- und Ubersetzungswerk (PW) wieder an den - Inzwlschen fast ganz vergessenen (vgl. ebd.:5) - Jungpolen erinnert. In seiner Einleitung weist er (ähnlich wie schon LORENTOWICZ 1908) vor allem auf zwei Hauptinsplrationsquellen für LANGES Lyrik hin: die europäische wle polnische Romantik, deren Elnfluß in seinem polltischen Lyrikschaffen zum Ausdruck komme (ebd.:8-10), und die aktuelle französische Literatur (Baudelalre, Parnasse, Symbolismus), deren Rezeption eine wichtige Etappe in seiner künstlerischen Entwlcklung gewesen sei, die schließlich in seinem reifsten zyklus "Rozmyślania" (Betrachtungen oder Meditationen) ihren Höhepunkt erreicht habe (ebd.:(10-14).

Vor allem den gelstesgeschichtlichen Entwicklungsgang, der sich in LANGES poetischem Schaffen manifestiert, verfolgt $\mathrm{J}$. PROKOP Im Rahmen selner Wüdıgung des schriftstellerischen Gesamtwerks (1968:422-428). In elner abschließenden Betrachtung hebt er zu Recht die Tatsache hervor, daß LANGE einem gedanklichen Lyriktyp zuzurechnen sei, was sich in elner banalen und ungegenständlichen Bildsprache äußere. F.r habe den elgentülichen Reiz des Wortmaterials als solchem nicht empfunden, obwohl er sich um formale Virtuoserle bemüht habe (ebd.:431 f.). 
Der schon erwahnte J. PORADECK (1979) versucht, den Dichter zunachst in den Rahmen der polnischen Literaturtradition des 19. Jahrhunderts zu stellen: LANGE habe das Dilemma der polnischen Dichter selner Zelt, die zwischen elnem von der übermächtzgen Romantiktradition diktierten Patriotismus und den neuen, wirkungsmachtıgen allgemeineuropalschen Llteraturströmungen $z u$ wahlen hatten. (wie elnige vor $1 \mathrm{hm}$ ) dadurch zu lösen versucht. daß er sich diese Tradition uminterpretierend aneignete und sie in den Rahmen der alteren polnischen Literaturtradition stellte, um auf diesem Umweg den Anschluß an die Weltilteratur wiederzufinden (ebd.:5-11, 15, 20-22, 25). Daneben skizziert PORADECKI LANGES zyklischen Evolutionismus lebd.:16 f.: vgl. dazu PODRAZA-KWIATKOWSKA 1969:78-88 und SZYMANSKA 1979, besonders Kapltel I und III und versucht, divergierende Tendenzen in seinem Werk. einerselts die fixierung aut das Problem des indi$v i d u e l i e n$ Reifens mit seinem Kulminationspunkt im lod (PORADECKI 1979:17-19), andererseits die polltisch-gesellschaftskrit1sche Thematik (ebd.:19 f.), von dieser gemeinsamen Grundlage abzulelten. Schließlich fürt er auch LANGES unorlginelle. trotz starken Elnflusses von MALLARMES symbolistischer Theorle sehr traditionelle Dichtungssprache auf diese geschichtsphilosophische Konzeptzon zurück (ebd.:23-25).

Insgesamt also wurden in den bisherigen - sehr skizzenhaften - Untersuchungen zu LANGES dichterischem werk vor allem Themenberelche, geistesgeschichtliche Grundlagen, literariscne Einflüse sowie die Stellung des Werks innerhalb der polnischen Literatur diskutiert. Die zentrale Kategorie elnes literarischen Kunstwerks im allgemeinen und von Lyrik $1 \mathrm{~m}$ besonderen. die poetisch gestaltete Sprache, ist kaum beachtet und allenfalls pauschal abgehandelt worden.

\subsection{Problemstellung}

Die vorliegende Arbeit versucht an diesem Punkt anzusetzen und elne Charakteristik wesentlicher Berelche der - im weitesten Sinne definierten - Dichtungssprache im lyrischen Werk Anton 1 LANGES zu erarbelten.

Dies erscheint umso sinnvoller, als damit zuglelch ein Beitrạ zur Untersuchung 'jungpolnischer' Dichtungssprache uber- 
haupt geleistet werden kann, die bisher kaum zum Gegenstand spezl.ller Forschungen wurde. Die wenigen Versuche in dieser Rlchtung beschränken sich auf kleine Teilbereiche des Gesamtproblems. So läßt es etwa M. JASTRUN bei seinen überlegungen zur sprache des Jungen Polen (1967:LXVI-LXIX) mit einer kurzen Charakteristik der lexikalischen Besonderhelten des Epochenstils sein Bewenden haben oder widmet sich M. PODRAZA-KWIATKOWSKA In elner grundleqenden Abhandlung (1975) speziell der Bildsprache der jungpolnischen Dichtung. Andererseits bleiben die sporadischen Aussagen zum Gesamtkomplex der "poetischen" Sprache einzelner Dichter. wie etwa J. KRZYżANOWSKIS Bemerkungen viber den wortkunstler TETMAJER (1968:LXXIX-XCI), recht pauschal und sind wenig systematisch aufgebaut.

Vor diesem Hintergrund muß es eln weiteres Ziel dieser Arbelt sein, am konkreten Fall Antoni LANGE eine systematische Vorgehensweise bei der Analyse einer individuellen Dichtungssprache zu entwickeln und zur Diskussion zu stellen. Das hierbei zugrunde gelegte 'Modell' elner Vorgehenswelse beruht auf folgenden einfachen überlegungen:

Die 'Poetisierung' der Sprache in einem literarischen Kunstwerk erfolgt - schematisch ausgedrückt - dadurch, daß das zu verwendende Sprachmaterial nach bes $1 \mathrm{~mm}$ e $\mathrm{n}$ Kriterien ausgewahlt und angeordnet wird. Eine Beschreibung dieser poetisierten 'Sprache erfolgt deshalb am sinnvollsten durch die Beschreibung eben dieser Kriterien. d.h. der sprachlichen Gestaltungsprinzipien, die im Text wirksam werden.

Die erschöpfende Charakteristik elnes poetischen 'Sprachsystems", die alle relevanten Gestaltungsprinzipien sowle die Interdependenzen zwischen diesen berükslchtıgen müßte, ist - solite sie überhaupt möglich oder notwendig sein - im Rahmen elner Arbelt wie der vorliegenden nicht durchfuhrbar. Die Analyse muß sich deshalb auf elnige, für die poetische Gesamtwirkung besonders wichtige Gestaltungsprinziplen beschranken. Als solche habe ich Im Falle LANGE die Bereiche 'Gestaltungen des lyrischen Monologs'. 'Versbau'. 'Schlüsselwörter' und 'literarische Bezugnahmen ausgewahlt, was an den entsprechenden stellen $1 \mathrm{~m}$ einzelnen $z u$ begrüden sein wird.

Die zur Untersuchung dieser Grundformen der Textgestaltung notwendigen methodischen Schritte (Erstellung und Einordnung 
des reinen Faktenmaterials: Interpretation dieses Materials in seinem inneren Gefüge und im konkreten Textzusammenhang) werde ich im Darstellungstell nicht getrennt abhandeln, um unnölge Wlederholungen zu vermelden, zumal das Hauptgewicht der Betrachtungen auf einer funktionalen Analyse des Faktenmaterials liegen muß, da nur eine solche die entscheidenden Mechanismen einer 'Poetisierung' der Sprache bloßlegen kann. Um dles an elnem einfachen Beispiel zu illustrieren: Die reine Feststellung. welche Versmaße LANGE verwendet, ist in erster linie für elne (äußerlich verstandene) Geschichte der polnischen Versifikation und LANGES stellung in ihr von Interesse. Erst die Frage, warum er bestimmte Versmaße in bestimmten Kontexten gebraucht, fuhrt zu einer Charakterisierung des Versbaus als Gestaltungsmittel seiner poetischen Texte.

Dabel muß die konkrete Ausformung dieser funktionalen Interpretation naturgemäß dem jewells untersuchten Bereich angepaßt werden. Die Analyse geht aber in jedem Fall von der Relation: Gestaltungselement - Einzeltext (dann auch: - Textgruppe) aus und versucht erst in einem methodisch letzten Schritt die konkreten Detailergebnisse auf einen gemeinsamen Nenner zu bringen. Nur bei einer solchen Vorgehensweise sehe ich das Eigengewicht jedes Einzelgedichts als - zunächst - in sich geschlossene Einheit, der alle Gestaltungselemente untergeordnet sind, in angemessener Weise berücksichtigt.

Dieser interne Funktionszusammenhang führt im übrıgen nicht selten dazu, daß bel der Analyse elnes bestimmten Gestaltungselements ausfürlichere Interpretationen anderer Textebenen erforderlich werden, daß sich aber auch umgekehrt aus der Analyse des isolierten Gestaltungselements ubergreifende Interpretationen für das Gesamtgedicht ergeben. Solche an gegebener Stelle exemplarisch zu erarbeiten, soll ein welteres (Neben-)ziel der vorllegenden Arbelt sein, da sich hieran die Bedeutung der untersuchten Elemente am klarsten zeigen laßt.

\subsection{Untersuchungsgegenstand}

Hauptzlel der Arbeit ist Jedoch, wle gesagt, die Beschreibung der angefuhrten Gestaltungselemente, und zwar in LANGES ilyrischem Werk. Ich grenze also den Untersuchungsgegenstand in 
zwei Richtungen ab: Auf der einen Seite wird die Sprache von LANGES künstlerischer Prosa nicht berücksichtigt, auf der anderen muß innerhalb des Bereichs der gebundenen Rede die sprachliche Gestaltung von Versepik und Versdramatik außer Betracht bleiben.

Dies bedeutet nicht, daß einige der für die 'Lyrik' zu beschreibenden Gestaltungsprinzipien in anderen literarischen Schaffensbereichen nicht analog zum Tragen kommen könnten. Doch erfahren diese dort oft abweichende Ausgestaltungen und erfullen vor allem grundlegend andere Funktionen als unter den spezifischen Bedingungen 'Lyrischer' Aussagegestaltung, so daß also die genannten 'nichtlyrischen' Gattungen auch in Hinblick auf die gleichen Gestaltungsprinzipien eigener Untersuchungen bedürten.

Den Bereich der hier zur Diskussion stehenden 'Lyrik' fasse ich indes nicht $z u$ eng und berücksichtige auch verschiedene zweifelhafte, insbesondere in den Bereich der Didaktik ubergehende (vgl.u. 2.3.1.) Randerschernungen.

\subsection{Themenbere Iche In LANGES Lyrik}

Die in dieser Arbeit unternommene Charakterisierung einiger in LANGES lyrischem Werk wirksamer Gestaltungselemente muß gelegentlich (vgl. besonders Kapitel 2) auf eine inhaltliche Grobgliederung dieses Werks zurückgreifen. Da eine solche Einteilung, so provisorisch und lückenhaft sie auch bleiben muß, zugleich einen ersten überblick über LANGES Lyrikschaffen ermöglicht, soll sie an dieser stelle vorweggenommen werden:

Die größte Gruppe bilden Gedichte, deren Thematik als "philosophisch-reflexiv $v^{\circ}$ charakterisieren ist (im weiteren als Gruppe A bezeichnet). Sie nimmt schon in LANGES ersten Gedichtbänden, "Poezje I" (1895) und "Poezje II" (1898), eine wichtige stellung ein und erreicht ihren intellektuellen Höhepunkt in den "Rozmyślania" (1906) sowie im 1. Band des posthum erschienenen "Ostatni zbiór poezyj" (1931).

Ebenfalls stark vertreten sind 'politisch-sozial' engagierte Gedichte (B). gesammelt vor allem in den Bänden "Pogrobowcom" (1901). "Pierwszy dzień stworzenıa. Piéśni spoleczne" (1907) und "Trzeci dzień" (1925). 
Die im weitesten Sinne dem Bereich der 'Liebeslyrik' (C) zuzurechnenden Werke verteilen sich auf die Bände "Poezje I". "Poezje II", "XXVII sonetów" (1914), "Pocalunki" (1925) und den 2. Band des "Ostatni zbiór poezyj" (1931).

Größere Gruppen von 'Naturgedichten' (D) schließlich sind in "Poezje I" und vor allem in "Poezje II" erschienen. 
2. Gestaltungen des lyrischen Monologs

Sehr viel größere Aussagekraft gewinnt eine solche grobthematische Gliederung des lyrischen Gesamtwerks durch Einbeziehung struktureller Kriterien des Textaufbaus. Insbesondere bietet sich hierfür die Kategorie des 'lyrischen Monologs' an, der eines der grundlegenden Bauprinzipien von Lyrik als solcher darstellt und geradezu ihr Wesen im Vergleich $z$ den anderen Gattungen bestimmt.

Zudem prägt die jeweilige konkrete Ausgestaltungsvariante des lyrischen Monologs die Gesamtwirkung eines Gedichts auf grundsätzlicher Ebene, stellt also ein für die Charakterisierung der poetischen Sprache wesentliches Kriterium dar.

Dieses Kapltel stellt sich somit die Aufgabe, die Verwendungsweise des Gestaltungsfaktors 'lyrischer Monolog' bei LANGE genauer zu untersuchen, einerseits in Hinblick auf eine adäquate Einteilung und Charakteristik seines lyrischen Gesamtschaffens, andererseits mit dem Ziel, die Wirkungsmechanismen dieses Elements seiner Dichtungssprache deutlich zu machen.

\subsection{Typen der Monologgestal tung}

Zur Analyse von LANGES Monologgestaltung verwende ich ein vor allem an Vorschlägen von H. MARKIEWICZ ("1980:171) sowie B. CHRZĄSTOWSKA und S. WYSKOUCH (1974, besonders: $277 \mathrm{f}$.) orientiertes theoretisches Modell, das im folgenden kurz skizziert sein soll:

Zunächst muß zwischen Gedichten unterschieden werden, in denen sich das lyrische Ich durch ein unmetelbares Bekenntnis selbst ausdrückt ("liryka bezpośrednia"), und solchen, in denen das Subjekt nur mittelbar zum Ausdruck kommt ("liryka pośrednia").

Das unmittelbare Bekenntnis des lyrischen Subjekts kann einerseits als quasi innerer Monolog nur auf sich selbst gerichtet sein (im folgenden bezeichnet als Typ la); es kann sich andererseits an einen bestımmten Adressaten ('Du'-Lyrik) rıchten. sel dieser nun rein rhetorischer Natur (Ib) oder ein 'realer' Ansprechpartner (IC). 
In elner weiteren Gruppe von 'Du'-Gedichten tritt das lyrische Ich in den Hintergrund, und das Aussageinteresse verlagert sich zum Adressaten hin. Diese Gruppe der Appell-oder Invokations-Lyrik (II) stellt somit den ubergang zu den mittelbaren Aussageformen dar (CHRZALSTOWSKA/WYSKOUCH 1974:232).

Bei diesen mittelbaren Formen (III) kann es sich um narrative (IIIa) oder beschreibende (IIIb) Lyrik handeln, in der eine dynamische bzw. statische Wirklichkeit subjektiv oder symbolisch dargestellt wird (MARKIEWICZ "1980:171). Gelegentich findet sich auch elne dialogische Gestaltung der lyrischen Aussage (IIIC). Schließlich dient elne unpersönliche Form der begrifflichen verallgemeinerumg ("uogolnienle pojeciowe": II Id) zur Darlegung abstrakter Gedankengänge.

Neben den angefürten $T$ y $p$ e des Monologs spielt in einigen Gruppen, insbesondere in Ia und III, auch die Art des lyrischen Subjekts eine wlchtige Rolle: Neben die persönliche Aussage kann die kollektive treten ( wl $^{\circ}$ ). (Zur Verdeutlichung des skizzierten Modells vgl. die folgenden konkretisierten Ausführungen und insbesondere die zugehörigen Textbeispiele:)

Grundsätzlich ist $z u$ beachten, daß die angefürten Gestaltungen des lyrischen Monologs in der Praxis tellweise nicht klar gegeneinander abgrenzbar sind. Außerdem treten sie in manchen Gedichten in verschiedenen Kombinationen miteinander ge koppelt auf.

\subsection{Die Standardfunktionen der Monologgestal tungen}

In diesem Abschnitt ist darzustellen, mit welchen inhaltichthematischen Komplexen sich bel LANGE die einzelnen Gestaltungstypen des lyrischen Monologs vor $z$ ug we is e verbinden. Diese "Standardgestaltungen" sollen zugleich auf ihre knnkrete Funktion im Rahmen der Einzeltexte hin untersucht werden.

\subsubsection{Die Standardfunktionen des Gestaltungstyps la}

Die bei LANGE stark vertretene unmittelbare Bekenntnislyrik des Typs Ia ist fast ausschließlich philosophisch-reflexiven Charakters (A). Sie herrscht insbesondere im Zyklus "Rozmyślania" deutlich vor. 
Es sind dies Reflexionen iber die eigene (seelische) Lebenslage, quasi geistige Bilanzen seines Daseins $(R 3,4,24,25$, 31. 50: Sonet [1]; Exegi...). Schilderungen von Wunschvorstellungen ( $R$ 10,56, 64-1) und spezifischen geistigen Erlebnissen ( $R 11,26,49,62$ ) sowie vor allem von wichtigen Elementen der eigenen Geisteswelt, des inneren Fühlens $(R 7,8,14,16,27$, 28, 35, 39-42, 48, 50, 63; DP 12; Mogila):

Kiedy o sobie mówie, nie mówię o sobie, Bo obcy sobie jestem, jakby rozdwojony:

Cialem zyje w tym czasie, na tutejszym globie. Ale duch zamieszkuje odmienne regiony.

Osoba moja wlasna jest mi obojętna I ludzie obojetni mi sa i nieznani. Ale jest we mnie jakas melodia odświętna. Co plynie we mnie $z$ owej dalekiej otchlani.

$z$ tej otchlani mi plyna niewiadome glosy. które nieraz powtarzam jako piéśn aniolów. Pelna gwiezdnej muzyki i niebieskiej rosy: Glos mój jest glosem owych nieznanych zywiolów. (R 39)

[wenn ich von mir spreche, spreche ich nicht von mir, Denn ich bin mir fremd, gleichsam entzwei geteilt: Mit dem Körper lebe ich in dieser zeit, auf dem hiesigen GloAber der Geist bewohnt andere Regionen. [bus,

Meine eigene Person ist mir gleichgültig -

Und die Laute sind mir gleichgültig und unbekannt, Aber es ist in mir so eine feierliche Melodie, Die in mir aus jenem fernen Abgrund fliebt.

Aus diesem Abgrund flieBen mir unbekannte stimmen, Die ich manchmal wiederhole wie ein Engelslied, Voll von sternenmusik und Himmelstau:

Meine stimme ist die stimme jener unbekannten Elemente.]

Die Gestaltung des lyrischen Monologs verleiht all diesen Gedichten naturgemäß einen ausgesprochen persönlichen, teilweise intimen Charakter; sie sind als betont subjektive Aussagen des lyrischen Ichs konstruiert.

Die kollektiv gestalteten Aussagen dieses Monologtyps (Iak) beziehen sich hingegen auf politisch-gesellschaftliche Fragestellungen ( $B$ ) und unterstreichen hier das zugehörigkeitsgefül des Subjekts zu einer bestimmten geistig-sozialen Gruppe, meist seiner ideellen 'Generation' (Pog 1, 2, 7: Prz 12; z poza chmury: Boska komedia) oder (vor allem in späteren Gedichten) zum polnischen Volk insgesamt (Dies illa; Nowa pieśn; Inwokacja; Pochwala zycial: 
Myśmy przybyli na śwlat w straszliwe godziny. Gdy ciezarne kobiety - w zmlennych walk kolei. Drzaly pod wirem uczuc trwogi i nadziei

I w nasza krew wlewaly boleśc krwi matczynej.

Wiec w macierzyńskich lonach, nie zrodzeni jeszcze, Myśmy znali zyjacych buntownicze drzenia:

Gniew i rozpacz, i zemsty straszliwe pragnienia,

I milośc, i okrutne nienawiści dreszcze -

I zalobny dzwon kleski, i rozczarowania, Które wlalo nam wyly jadowite czerwie,

I niemoc zaszczepilo w schorowanym nerwie,

I nie dalo nam ciszy, co serca ochrania. (Pog 1)

[wir sind in schrecklichen stunden aut die welt gekommen, Als die schwangeren fraven - 1 m verlaufe wechselvoller rämpfe Unter dem strudelnden Andrang von Gefuhlen der sorge und der

[Hoffnung zitterten

Und in unser blut den schmerz des müterlichen Blutes gossen.

Also kannten wir schon im MutterschoB, noch ungeboren. Der lebenden rebellisches beben:

zorn und Verzwelflung, und schrecklichen Rachedurst, und sowohl liebe als auch den grausamen schauer des Hasses.

Und das Travergeldute der Naderlage und der Ent tauschuag.

Die uns giftige wurmer in die Adern gegossen

Und Kraftlosigkest im kranken Nerv eingepflanzt hat,

Und uns keine Ruhe gab, die die Herzen schutzt.]

\subsubsection{Die Standardfunktionen der an einen Adressaten gerichte- ten Gestal tungen}

Mit rhetorischen Apostrophen (Ib) sollen vor allem philosophische Reflexionen in ihrer Eindringlichkelt verstärkt werden. Insbesondere gilt dies für die mehrfache scheinbare $z w i e s p r a c h e$ mit dem personifizierten Tod (R 32,64-2; DP 21), wodurcl die zentrale Bedeutung dieses Themas für LANGES Lyrik zusatzich unterstrichen wird (vgl. BOROWY 1934:196-200):

Najgoretsze moje pienia -

o wielmozna, tajemnicza

Pani święta bez oblicza -

Tobiem skladal, gwiazdo cienia!

Ty, aniele bez imienia,

Bialoskrzydla mglo dziewicza.

Której szept mie rozslodycza -

Srebrna rzeko zapomnienia!

Pani czysta, pani smutna -

Nieugieta - absolutna -

Cześć cl za twe biale plótna...

Cześć cl, pani, za te cisze,

Która slodko nas kolysze -

$u$ twych stóp w bezmiärach wisze... (DP 21. Smierć) 
[Meine glühendsten Gesänge -

o gnädige, geheimnisvolle

Heilige Herrin ohne Antlitz -

Habe ich dir dargebracht, Herrin des schattens!

Du, Engel ohne Namen,

Weibgeflügelter, jungfräulicher Nebel,

Dessen Geflüster mich verzückt -

silberner flub des Vergessens!

Reine Herrin, traurige Herrin -

Unbeugsame - absolute -

Heil dir für dein weibes leinen...

Heil Dir, Herrin, für die stille,

Die uns süB wiegt -

zu deinen füBen hänge ich in den Unermeblichkeiten...]

Neben dem Tod werden aber auch ein unbekannter cott, ein

Herr neuer Morgendammerungen (DP Epi. Nieznanemu Bogu) oder die für eine bestimmte Lebenshaltung stehende Hamletgestalt apostrophiert ( $R$ 55), es wird dem eigenen Herzen Mut zugesprochen ( $R$ 47-2) oder einer xiefer dargelegt, welche Reflexionen sich dem lyrischen Ich mit ihr verbinden (Sosna).

Eine quasi 'reale' Bekenntnissituation schaffen dagegen die Konstruktionen des Typs Ic, die sich fast ausschließlich an die Geliebte richten (C), sei es mit einfachen Liebesgeständnissen (Chcialbym...: Pieśni o pocalunkach; Mlynareczka; BP 4) oder mit Reflexionen über das Verhältnis zwischen den beiden Liebenden (Fragment [2]; Przebacz...; z erotyków) bzw. über das eigene Erleben der Liebe (R 17; DP 11; "Pamietasz te noc cicha - i ten lazur czysty"; Rien que pour vous) oder aber mit weitergehenden Gedanken, die sich an das Liebeserleben knüpfen (Pytanie: R 12, 34; DP 10; "Starozytnym Gallów obyczajem"). Insbesondere der zyklus "XXVII sonetów" ist zum überwiegenden Teil aus solchen 'Geständnissen' an die Geliebte aufgebaut, die das Erleben dieser Liebe vor dem Hintergrund seines nun schon langen Lebensweges reflektieren (Son 1,4-5, 11-20,22, 24-27):

Kocham cie, czy jak senna zjawiasz mi sie mara -

Czyli jestem przy tobie, u nóg twoich, blisko,

I zapach twej istoty - czarowne zjawisko -

Upaja mnie, jak wina cypryjskiego czara.

Kocham cie, gdy twe oczy, gwiazd promiennych para,

Swieca mi, jakby niebo swiecilo mi wszystko:

Zda mi sie, zem w baśniowe wstapil uroczysko,

Gdzie sie odbywa wielkich zmartwychwstań ofiara.

Kocham cie, gdy zastygle duszy mojej rany

Balsamujesz pieszczota swej dloni siostrzanej.

Budzac nowego zycia jutrznie i promienie. 
Kocham cie, gdy marzenie twoich ust szkarlatu Snuje wcią wobec śmierci bliskiej majestatu -

Chcac je mieć, jako ziemi ostatnie wspomnienie. (Son 13)

[Ich liebe dich, ob du mir als traum erscheinst ob ich bei dir bin, zu deinen fuBen, nahe,

Und der Duft deines Wesens, e $2 n$ zauberphänomen, Mich berauscht wle ein Becher zypernweins.

Ich liebe dich, wenn deine Augen, ein pad strahlender sterne, Mir leuchten, als ob mir der ganze Himmel leuchtete:

Es scheint mir, daB ich in eine märchenhafte Kultstäte eingeWo das opfer groBer Auferstehungen stattfindet. [treten bin.

Ich liebe dich, wenn du auf die geronnenen wunden meiner seele Durch die Liebkosung deiner schwesterlichen Hand Balsam streichsit, Und damit Morgenröten und strahlen eines neuen lebens weckst.

Ich liebe dich, wenn ich den Traum vom Scharlach deines Mundes Angesichts des rodes naher Majestät stänig spinne

Und ihn haben will als letzte Erinnerung an die Erde.]

Die Konstruktionstypen Ib und Ic gestalten ebenso wie Ia unmit te l bare persönliche Bekenntnisse des lyrischen Ichs. nur daß diese in bestimmte Kommunikationssituationen gestellt werden. In der dritten Gruppe der an einen Adressaten gerichteten Gedichte, der Appell-Lyrik (II), tritt hingegen das lyrische

'Ich' hinter dem 'Du' deutlich zurück. Diese Gestaltungen sind

bei LANGE vor allem politisch-gesellschaftlichen (Cezarom oddaj....: Prz 4: BP 1) oder geschichtsbetrachtenden Charakters (DP 18, 19 ; ZSL 9), entweder rein agitatorisch gefaßt oder mit reflexiven Elementen zusätzlich angereichert:

wy, którym losy daly dziewictwo bolesci I zaden zdrój nie gasil zracych jej plomieni:

wy, którym kazda czara trucizna sie piens -

I zadna was nadzıeja ni wiara nie pleści!

Wy, skazani na hańbe, zdeptani, zgnębieni!

Wy, którym rdza zelaza zgięty kark bezczésci

I miecz nosicie w gardle az do rękojesci:

Wy, pragnacy i glodni! wy, wydziedziczenı!

Wy, rzuceni na wieki w ciemności posępne, Którym jasne krainy myśli niedostepne,

Wy, którym nakazano zagluszyć swa milóśc.

Iz musicie przez zywot iść - jako rzezańce!

Niewolnicy, nędzarze, tulacze. wygnańce -

Przeklinajcie!... (Prz 4$)$

[ Ihr, denen das schicksal die Jungfräulichkeit des schmerzes gab.. Dessen fressende flammen keine quelle loschte;

Ihr, denen jeder Becher vor Gift schäum -

und die euch weder Hoffnung noch Glauben kost!

Ihr, die zur schmach verurteilt, getreten, unterdruckt seid!

Ihr, denen der Rost des Elsens den gebeugten Nacken entehrt

Und die iht das Schwert bis zum Griff in der Kehle tragt;

Ihr Durstigen und Hungrigen! Ihr Enterbten! 
Ihr, die ihr für immer in düstere finsternisse geworfen seid, Denen die hellen Gefilde der Gedanken unzuganglich sind, Ihr, denen man befohlen hat, die eigene liebe zu ersticken, so daB ihr wie Kastraten durch das leben gehen must! sklaven, Bettler, Vagabunden, Verbannte verflucht!...]

\subsubsection{Die Standardfunktionen der 'mittelbaren' Gestaltungen}

Unter den 'mittelbaren" Darbietungsformen sind die narrativ geprägten (IIIa) ebenfalls in erster Linie inhaltlich der Gruppe B zuzuordnen. Es handelt sich hierbei in den meisten fällen um Parabeln mit politischem Hintersinn (DP 16; ZSL 1-4, 6, 8, 12: Nieboska komedia), manchmal auch um konkrete, subjektiv gefaßte Schilderungen politisch-historischer Abläufe (DP 17; We śnie: Blyskawice). Als Beispiel sei LANGES politisch-moralisch gedeutete Bibel-Paraphrase "Oblubieniec" (zSL 2; vgl. dazu unten Kapitel 5) angefüht:

Czekajace, boleściwe -

Przygotujciez, panny, wieniec -

Przygotujciez wy oliwe:

Idzie, idzie oblubieniec.

Plakaly go dyugie lata -

Czekaly go pelne troski -

Az ci nagle $z$ końca świata

Oblubieniec przyszedl boski.

Przyszedl jasny jako slońce -

Zmartwychwstaly przyszed $I$, zywy.

Panny, panny czekajace.

Maciez w lampach dość oliwy?

[Ihr wartenden, schmerzvollen

Jungfrauen, bereitet den Kranz -

Bereitet das 01 :

Es kommt, es kommt der Bräutigam.

Sie beweinten ihn lange Jahre -

Erwarteten ihn voller sorge -

Bis plötzlich vom Ende der Welt

Der gottliche Bräutigam kam.

Er kam hell wie die sonne -

Er kam auferstanden, lebendig.

Ihr wartenden Jungfraven,

Habt ihr denn genug 01 in den Lampen?]

Neben politisch-sozialen werden aber auch phllosophischreflexive Themen (A) auf bildhaft symbolische Weise narrativ gestaltet (R 21: DP 2, 4, 22: Akteon: Romantyczność).

Sogar die kleine Gruppe der 'Naturgedichte' (D) verwendet neben statischen Momentaufnahmen (IIIb: EZ 2; Skowronki: R 52-2) 
häufig den Monologtyp IIIa: Diese narrativen Gestaltungen (Ez 4. 5: Chrabaszcze; Dab; Sw 3, 4, 8) lassen sich in vielen Fällen auf die Tatsache zurückführen, daß die dargestellten Naturphanomene (wie etwa Sonnenaufgänge, Erwachen der Maikäfer, Erblühen der Eiche, etc.) auch als symbol für den dynamischen Prozeß der Wiedergeburt Polens interpretiert werden können, sich also den oben genannten politischen Parabeln anschließen lassen, wre etwa "Sw 8" (vgl. dazu unten Abschnitt 5.4.!):

Ogniem - zda sie - czerwonym gore cala puszcza.

Szczyt boru purpurowym plaszczem sie otula,

Niebo plonie jak pozar. Az ognista kula

Weszla na bór. Rakiete zlotych strzal wypuszcza.

I Switei purpurowa fala sie rozpluszcza,

Rzeklbys - ogreń po wodzie jak do stepie hula,

Srebrne mgly jak plonaca zdaja sie koszula -

I drzy serce kazdego nadbrzeznego kuszcza.

w wyzyny plynie zorza. Kuna krwi zagasa, Plomi ennozlotym kreglem zajaśnialo slońce

I wszystkie rzeczy zloci jego zlota krasa.

A oto wlelka tarcza w glebinach sie pali

Drugie slońce - I w kazdym kędziorze wód fall

Rozpryskuje sie w drobnych zlotych slońc tysiace.

[In rotem feuer - scheint es - brennt die ganze wlidnis.

Die spitze des waldes hüllt sich in einen purpurmantel,

Der Himmel flammt wie ein Brand. Bis sich die feurlge Kugel

Uber den wald erhoben hat. Sie läbt eine Rakete goldener

[Pfeile hervorschleben.

Und der swltei beglnnt mit purpurner welle zu platschern,

Glelchsam wutet ein feuer uber das wasser wie iber eine steppe

Die silbernen Nebel erscheinen wie ein flammenhemd - [hinweg.

und es zittert das Herz jedes strauchs am Ufer.

Die Morgenröte fliebt nach oben. Der Feuerschein des blutes

In flammendgoldenem Kreis hat die Sonne zu leuchten begonnen. und alle Dinge vergoldet lhre goldene schönheit.

und da brennt wie ein grober schild in den Tlefen Eine zweite sonne - und in jedem Wellengekrausel

zersplittert sie in Tausende kleiner goldener Sonnen.]

Die relativ seltenen Monologtypen IIIb und IIIC können nicht mit deutlich dominierenden Themenkomplexen in Verbindung gebracht werden.

Als begriffliche Verallgemelnerungen (III) werden vor allem philosophisch-reflexive Themen im engeren Sinne (A), seltener auch Betrachtungen politisch-sozialer Art (B) sowle Gedanken uber die Liebe $1 \mathrm{~m}$ allgemeinen (C) gestaltet, was den Gedichten aus diesen unterschiedlichen Bereichen ein einheltlich reflexi- 
ves Gepräge und deutlichen Anspruch auf Allgemeingültigkeit verleint.

Dabei sind streng unpersönliche Gestaltungen (Gruppe A: Samotnośc: DP 9, 20. Gruppe B: Prz 2, 6; Pog 11. Gruppe C: Sonet [1]: Fragment [3]; Son 9) und scheinbar 'gemildert" unpersönliche, in denen ein unspezifischer Adressat oszillierenden Charakters $\left({ }^{\prime} t y^{\prime}\right.$ ) vorhanden ist (Gruppe $A: R$ 1, 6, 30, 51 . Gruppe B: 2SL 10. Gruppe C: Son 21, von solchen zu trennen, in denen mehr oder weniger deutliche kollektive Konstruktionen (im Sinne von 'wir Menschen', etc.) das lyrische Subjekt miteinbeziehen (Gruppe A: R 13, 19,20,23,33,36, 38, 57; DP 7, 8. Gruppe B: ZSL 5: Prz 1) und so einerseits seine persönliche Betroffenheit unterstreichen, andererseits seinem Gefühl besonderen Ausdruck verleihen, gemeinsame Probleme einer größeren Gruppe abzuhandeln.

Als Beispiel für streng unpersönliche Gestaltung mag "Son 9" stehen:

W mi lości wszystko czystym jest i wszystko swiętem -

Bo milośc nad wszystkimi rzeczami jest wladna.

Ozlaca wszystko, noca niespetana zadna.

Sama sobie jest swiatla zywym elementem.

wszystko jest w niej krysztalem i wszystko diamentem -

I gdy na nia oszczercy z kamieniami wpadna.

Kamienie jej pokornie u nóg sie ukladna

I nietykalna stanie nad ludzkim odmętem.

Bo dusze, strojne w jasna milowania chwale, Przez ziemskie ida blota, nieskalanie biale Jak labedzie, co plyna przez Nilowe i $x y$.

Milość jest sama sobie zamknięta kraina.

Milośc jest sama sobie celem i przyczyna.

A w blasku jej znikaja wszystkie mroku py $y_{y}$.

[In der liebe lst alles rein und alles heilig-

Denn die liebe herrscht über alle Dinge.

sie vergoldet alles, von keiner Nacht gefesselt,

Aus sich selbst heraus ist sie das lebendige Element des Lichts.

Alles an ihr ist Kristall und alles Diamant -

und wenn Verleumder uber sie mit steinen herfallen,

Legen sich ihr die steine demütig zu füBen

und unantastbar steht sie über dem menschlichen abgrund.

Denn seelen, die mit dem hellen Ruhm des Liebens geschmuckt sind, schreiten durch irdischen Schmutz makellos weiB -

Wie Schwäne, die durch den Nilschlamm schwimmen.

Die liebe ist ein in sich geschlossenes Gefllde.

Die liebe ist sich selbst ziel und Ursache,

Und in ihrem Glanz vergeht aller staub der finsternis.] 
Das oszillierende ' $\mathrm{Du}$ ' (mit den möglichen Interpretationen: 'Leser'. 'Autor selbst', 'Mensch im allgemeinen', etc.l erscheint etwa in "R $30 "$ ":

życie zagadka ci jest, lecz za dni zywota żaden $c i$ duch tajemnicy owej nie rozmota, Bo jaki badi jest ten świat, zbyt go oko w oko Ogladasz, ze zda ci sie widmowa powloka. Roisz więc oto, ze śmierć zaslone odchyli I powie ci, co niepojete bylow owej chwlli.

Lecz nowa cie - któz wie - tam zagadka pochwyci:

Czym jest śmierć? Tajemniczych pelne nicl

otacza cie nieustajace w ruchu kolo...

I gdy sie w prochy juz rozpadnie twoje czolo, zapomnisz pytać, czym jest zycie - i na nowo:

Czym jest śmierć? pytać bẹdzlesz równie bezcelowo!

lDas leben ist dir ein Ratsel, doch zu lebzeiten Kann dir kein Geist jenes Geheimnis entwirren, Denn wie auch immer diese welt beschaffen ist, betrachtest du [sie zu sehr auge in Auge.

So dab sie dir als gespensterhafte Hulle erscheint. Also wahnst du, dab der tod den schleier luften Und dir sagen wird, was in jenem augenblick unverstandlich war. Aber ein neues Ratsel - wer wesb - wird dich dort erfassen: was ist der Tod? Voll geheimnisvoller faden Umkreist dich ein unaufhörlich in Bewegung befindliches Rad... Und wenn deine stirn schon zu staub zerfallen sein wird, wirst du vergessen zu fragen, was das leben sei - und von neuem Wirst du genauso nutzlos fragen: Was ist der rod?]

Eindeutig und explizit ist der Autor hingegen in den kollektiv geprägten Konstruktionen in die Aussage einbezogen. Dieser Art der Gestaltung bedient sich LANGE besonders häuf 19 , wobel mehrfacher Wechsel der Perspektive für inn typisch ist. Im folgenden Rondeau ( $R, 13)$ etwa wechselt die anfangs unpersönliche Konstruktion uber ' $t y^{\prime}$ und ' $w y^{\prime} z u$ ' $m y^{\prime}$. um schließlich abermals unpersönlich gestaltet $z u$ werden. Dadurch erhält die Aussage eine dem Inhalt angepaßte eigentümlich unruhige färbung:

Za wiele jest na ziemi nienawiści I zbyt ogromna rozczarowań rzeka Im dalej idziesz, tym ci plonie mgliściej

Swlatlo edeńskie. Które tam $z$ daleka $\mathrm{Na}$ umęczone twoje nogi czeka.

slyszycie poszum spadajacych liści? Jesień ordzawia marzenia czlowieka... zórz nam za wiele wrózyli psalmiści Za wiele!

Krwla nlenawlści pierś nam wciaz ocieka. Kiedyz zestapia owi promienniści. Których istote mi lość przyobleka? za wielez czasów, gdy świat sie oczyśc1, Królestwo Boze tu się na nim ziścl - 
[Es gibt auf Erden zuviel HaB -

Und zu gewaltig ist der strom der Enttauschungen -

Je weiter du schreitest, desto verschwommener brennt dir

Das licht von Eden, das dort in der Ferne

Auf deine müden Fübe wartet.

Hört ihr das Rascheln der abfallenden blatter?

Der Herbst farbt die Träume des Menschen rostigrot...

zu viele Morgenröten haben uns die psalmisten prophezeit zu vielel

Aus der Brust trieft uns immer noch das blut des Hasses.

wann werden denn jene strahlenden herniedersteigen.

Deren wesen die liebe umgibt?

wird sich das Königreich cottes erst nach langer zeit, wenn [sich die Erde gereinigt hat.

Hier auf ihr verwirklichen -

Nach langer zeit?]

\subsection{Besondere Funktionen der Monologgestaltung}

Neben den dargesteliten 'Standardverbindungen' einzelner Monologtypen mit meist einem oder doch nur einem Teil der Themenbereiche lassen sich weitere, seltenere Kombinationen feststellen, die dem Gedicht einen sehr spezifischen Gestaltungscharakter verleihen, wobei zudem ein Teil der Gedichte auch eine Verbindung von mehreren, deutlich voneinander abgehobenen Monologtypen aufweisen kann. Diese Gestaltungsformen könnte man aufgrund ihres Ausnahmecharakters (in Abwandlung eines sprachwissenschaftlichen Begriffsl als gewissermaßen stärker 'markiert im Vergleich zu den bisher dargestellten Fällen bezeichnen.

\subsubsection{Besondere Gestaltungen der 'phllosophisch-reflexiven'} Lyrik

Die große Mehrzahl der Gedichte "philosophisch-reflexiven" Gehalts (A) ist, wie gezeigt, auf der einen seite als persönliches Bekenntnis der Typen Ia und $I b$, auf der anderen als narrative (IIIa) oder abstrakt-verallgemeinernde (IIId) Aussage gefaßt. Dazu treten Gedichte, die diese Monologtypen miteinander oder mit anderen Gestaltungen verbinden:

Die kollektive Form innerhalb einer persönlichen Reflexion (Ia+Iak) veranschaulicht etwa die Gegenüberstellung von Individual- und Gemeinschaftsbewußtsein ( $R$ 61) oder den übergang von der persönlichen Reflexion zur allgemeingültigen Schlußfolgerung ( $R$ 58). 
Pathetische rhetorische Apostrophen an Sonne und Geist ( $R$ 47-1) oder den Tod ( $R$ 2) werden in das Bekenntnis geflochten (Ia+Ib) oder Gedichte mit Anrufungen des Herrn abgeschlossen (Bezsenna noc: $R$ 60), wobei insbesondere " $R$ 60" eine ungewöhnliche Konstruktion bietet: Nach vier strophen einer allgemein gefaßten Reflexion (IIId) wird Gott ("Panie") zum Zeugen dafür angerufen, daß der Inhalt dieser strophen auch für das lyrische Subjekt zutrifft, und schließlich um Abhilfe gebeten:

Panie! Ty, który serce me wldzisz, wiesz o tem,

Jako bylem $w$ przepaściach na samym dnie Hada:

Podnieś wzwyz moja istność: niech wejde $z$ powrotem

Tam, gdzie zycia sloneczna zloci sie biesiada. (vv. 17-20)

[Herr! Du, der du mein Herz siehst, weibt darum,

Wie lch in Abgrüden auf dem tiefsten Grund des Hades war: Hebe mein wesen empor: Möge ich wieder dort hinaufscigen. wo das sonnige Gelage des lebens golden strahlt.]

Häufiger wird das persönlıche Bekenntnis (Ia) mit begriffllchen Verallgemeinerungen' (IIId) kombiniert, wobel diese entweder den Ausgangspurkt zu Individuellen Betrachtungen darstellen (Strofa alcejska: Fragment [1]; R 15, 53: "Triumfalnie podlość się uśmiecha") oder diese Betrachtungen ins Allgemeingültige überführen $(R 29,37)$. Die konkretisierende oder individuell abwandelnde Funktion der hier nach Typ Ia gestalteten Gedichtteile können in Verbindung mit IIId aber auch 'mittelbare" Konstruktionen insbesondere narrativen Charakters (IIIa) ibernehmen (Kuk 1 arfa; DP 3; R 5).

Die besonders für Gedichte politisch-sozialen Inhalts charakteristısche 'appellative' Gestaltungsweise (II) findet sich auch in allgemeiner philosophisch gepragten Werken und dient hier zur Formulierung von gewissen Verhaltensmaßregeln ( $w$ imionniku R. D.: R 43, 44; manchmal auch als Schlußfolgerung aus einem narrativ gestalteten bildhaften Te11: DP 11 oder in Verbindung mit elnem allgemein formulierenden Gedichttei' (IIId) zur verehrenden Charakterisierung historischer Personlichkeiten (Sw 2: Kopernik).

Eine Sonderstellung kommt den dialogischen Konstruktionen (IIIC) innerhalb der philosophisch-reflexiven Lyrik LANGES zu. Sie dienen keiner echten Diskussion wie im (politischen) "Herakles i Achilles" (vgl. 2.3.2.), sondern lediglich zur Betonung der antikisierenden Gestaltung (Apollo 1 Muzy) oder der Herausarbeltung einer elnfachen Polnte in volkstumlich wirkenaen 
Zwiesprachen (mit einem jungen Fischer in "Sw 10" bzw. einem Blatt in "R 52-1"):

- Liściu mój zblakkany.

Dokad wiatr cie niesie?

- Lece przez tumany.

Szczéścia szukam w lesie.

- Czego szukasz blędnie

Na wsze strony świata?

- Nim ma zieleń zwiednie.

Szukam liścia brata.

- Brata? Mylnie sadzisz.

Że się sen twój ziści:

Prózno szukasz, bladzisz -

Nie ma bratnich liści. (R 52-1)

[- Mein verirrtes blatt,

Wohin trägt dich der wind?

- Ich fliege durch die Nebelschwaden.

suche das Gluck in walde.

- Was suchst du, umherirrend

In alle Himelsrichtungen?

- Bevor mein Grün verwelkt.

suche ich ein Bruder-Blatt.

- Einen Bruder? Fälschlich meinst du,

Dab sich dein Traum erfüllen kann:

Vergeblich suchst du, lrrst du - -

Es gibt keine Bruderblatter.]

Zweifelhaft muß bleiben, ob es sich in "R 64-3" um eine an die obigen volkstülichen Gestaltungsweisen erinnernde dialogische Konstruktion handelt (Partner A: vv. 1-32 und 53-56: Partner $B$ : $v v, 33-52)$, oder ob die verse 33-52 eine verallgemeinerung (IIId) mit oszillierendem Adressaten (streng unpersönlich bzw. allgemeines ' $\mathrm{Du}$ ') darstellen, wobei für die erstere Möglichkeit durchaus der Gesamtton und die äußere Gestaltung des Gedichts (Refrain, Versmaß) sprechen.

Eine besondere Gruppe innerhalb der philosophisch-reflexiven" Lyrik LANGES bilden schließlich auch die drei zyklen "Sonety wedyckie" (SW), "Ksiegi proroków" (KP) und "Logos" (L). Scheinbar nach verschiedenen Monologtypen 'mittelbaren' Charakters konstruiert, stellen sie doch Aussagen besonderer Art dar, da der Stoff quasi auf $z$ we $i$ 'Situationsebenen' verteilt ist:

In gewönnlichen 'mittelbaren' Gestaltungen ist ein vom Gedichtautor geschaffenes lyrisches Ich deutlich hinter dem - nur scheinbar subjektlosen - Text zu spüren, während hier sozusagen $z$ we 1 'lyrische Subjekte" vorhanden sind. Zum einen der historische Schöpfer der in diesen Werken dargestellten Gedankengänge (Religionsstifter. Dichter und Philosophen), zum anderen der 
diese Systeme auf seine Weise begreifende und darstellende "Autor' der konkreten Gedichte.

Dieses Verhaltnis wird entweder direkt zum Ausdruck gebracht durch Einführung des 'historischen Schöpfers' und anschließendes Quasi-zitat (vgl. das einfürende Gedicht der "Sonety wedyckie" sowle den Beginn des folgenden: "<... - prawi meadrzec bozy - [- spricht der göttliche weise-]; SW 2, v.1), oder der 'historische Schöpfer' wird lediglich durch die überschrift angedeutet, und die eigentliche werkstruktur erst verständlich durch Verknupfung von Titel und als ' $Z$ itat' erkannten Gedichtkörper (Logos):

Miej serce i patrz w serce. Mędrzec lodowaty Nie ujrzy cudu, zjawisk nie przeniknie rdzenia. Ale kto plonie ogniem bozego natchnienia Poprzez pozory - widzl niewldzialne swlaty.

$w$ Bogu jest iródlo natchnień. Zawsze on na czaty wybrańcze zsyla duchy, co znosza cierpienia za miliony, przez milość ludzkiego plemienia, By je uniéś na slowa górne Araraty.

slowo-moc, slowo-ogień, slowo-blyskawica A w nich czyn i of lara - to objawień zorze. Którymi Czlowlek wieczny duch ludów podsyca.

A wszystko to sie dzieje, by królestwo boze Wcielić wońcu na ziemi. Lecz nim sie to stanie. Dziś o wojnę wszechludów blagamy cie, Panie! (L 3 . Micklewlcz)

lHabe ein Herz und schau ins Herz. Der eisige Weise kann kein wunder erblicken, den kern der Erscheinungen nicht ldurchdringen.

Aber wer in Feuer der gottlichen Inspiration brennt, sieht - durch allen schein hindurch - unsichtbare welten.

In Gote ist die quelle der Inspirationen. Immer schickt Er Auserwahlte Geister auf die wacht hernieder, die Leiden ertra[gen können

Für Millionen, aus Liebe zum Menschengeschlecht, um es auf die hehren Ararate des logos zu erheben.

Das wort als Macht, als feuer, als Bl1tz-

und in ihnen $T$ at und opfer - das sind die Morgenröten der of l fenbarungen,

Mit denen der Ewige Mensch den Geist der Völker entfacht.

Und alles das geschieht, um das Königreich Gottes Schlieblich auf Erden zu verwirklichen. Aber bevor das geschieht, flehen wir dich heute um den Krieg aller völker an. Herr!]

Die drei zyklen nähern sich durch diese Art der Konstruktion stark der versifizierten Lehrdichtung, was aber ihrer zentralen Bedeutung für die gelstesgeschichtliche Einordnung von LANGES Lyrik keinen Abbruch tut (vgl. Kapltel 5). J. PROKOP zahlt sie 
- gerade aufgrund ihres unpersönlichen Charakters - sogar $2 u$ den literarisch gelungensten Werken LANGES (1968:432).

2.3.2. Besondere Gestaltungen der 'politisch-sozialen' Lyrik

Die 'politisch-soziale' Lyrik (B) LANGES ist, wie gezeigt, häufig als kollektive Aussage des Typs Ia gestaltet. In manchen fällen wird diese durch eine kollektive Konstruktion erweitert: durch eine rhetorische Apostrophe der eigenen Generation in "Swemu pokoleniu" (Iak+Ibk), eine bildhafte Erzählung in "ZSL $7 "$ und "ZSL $11 "$ (Iak+IIIa) oder eine "begriffliche Verallgemeinerung" in "Prz 5" (Iak+IIId).

Die Einbeziehung eines Adressaten erfolgt im allgemeinen auf 'appellativer' Ebene (II). Doch verwendet LANGE auch rhetorische Apostrophen oder quasi 'reale' Ansprechpartner (Ib bzW. Ic: manchmal in Verbindung mit anderen Konstruktionen), die der Aussage pathetischen Charakter verleihen (Prz 3: Mickiewicz: Iliada i Odyseja), eine anfängliche, dann grausam zerstörte Schein-Idylle zwischen den Verliebten (Sielanka) bzw. zwischen Mutter und Kind (Kolysanka) suggerieren oder ein Gedicht demonstrativ in die aktuelle Realität einbinden (List do redaktora).

Eine Ausnahmeerscheinung im 'politisch-sozialen' Themenbereich stellt die schon erwähnte dialogische Gestaltung (IIIC) von "Herakles i Achilles" dar, die - neben der antikisierenden wirkung - vor allem den Konflikt zweier standpunkte veranschaulichen soll.

\subsubsection{Besondere Gestaltungen der 'Llebeslyrik'}

LANGES 'Liebeslyrik' (C) ist vor allem als persönliches Geständnis an die Geliebte gestaltet (IC). Davon heben sich einige Konstruktionen ab, in denen der Partner zusätzlich stärker ins Blickfeld tritt (IC+II: Son 7, 8, 10, 23), oder sich begrifflich verallgemeinernde Konstruktionen - deutlich abgehoben - mit dem persönlichen Bekenntnis verbinden (Ic+IIId: Impromptu: "Bywaja czasem slowa, które - rzeklbys - plyna").

Dagegen verwendet LANGE den Typ Ia in Fallen, in denen kein (fiktiver) Partner vorhanden ist, weil es sich um Erinnerungen an vergangene Erlebnisse (Cienie: Choreodaktyl) oder um Reflexionen zum Thema "Liebe" im allgemeinen handelt (Posag i dziew- 
czyna: teilweise kollektiv: Nie, jam wcale nie kochall, oder weil der Partner unerreichbar fern ist (R 9):

Isoliert steht das zwischen 'Liebes' - und 'Natur'-Lyrik oszillierende " $R$ 22", das keine Partnerin, sondern die wellen apostrophiert (Ib), die das lyrische Subjekt an die Augen der einstigen Geliebten erinnern. Neben der rhetorischen Wirkung des fiktiven $\mathrm{Zwlegesprächs} \mathrm{w1rd} \mathrm{durch} \mathrm{die} \mathrm{anaphorisch} \mathrm{gereih-}$ ten auffalligen Apostrophen das schon graphisch angedeutete Element des Wellenschlags auch akustisch hervorgehoben:

A kto te oczy widzial - zapomniec nie moze!

- fale - skad wy macie taki blask zielony. Jak ten, co lśnil w jej oczach - zielonych jak morze?

o fale - skad wy macie tych iskier miliony. Jakbyście w sobie zlota rozpryskaly zorze?

- fale - skad wy macie te ognie promienne, Którymi sie iskrzyly jej oczy plomienne?

A kto te oczy widzial - zapomniec nie moze! (R 22, vv. 1-8) lund wer diese Augen gesehen hat - kann nicht vergessen!

- Wellen - woher habt ihr solch einen grunen Glanz.

we der, der in ihren augen - grun wie das Meer - funkelte?

o wellen - woher habt ihr die Millionen dieser Funken,

Als ob ihr einen goldenen Morgenstern in euch zersplittert hat tet?

o Wellen - woher habt ihr diese strahlenden feuer.

In denen ihre flammenden augen funkelten?

und wer diese Augen gesehen hat - kann nicht vergessen!]

\subsubsection{Besondere Gestal tungen der 'Naturlyrik'}

Neben der Mehrzahl erzählender (IIIa) oder beschreibender (IIIb), also 'mittelbarer' 'Naturgedichte' (D) finden sich auch einige Gestaltungen des Typs Ia, die sich dadurch abheben, daß sie ganz persönliche - geistige Erlebnisse und Reflexionen des Ichs bel der Betrachtung von Naturgegebenheiten $x p l i z i t$ zum Aus druck bringen (EZ 3, 6; Sw 6, 7, 9; DP 15; mit Schlußwendung an den Partner: $R$ 18; kollektiv: Wiosenna pieśn), teilwelse ergänzt durch allgemein formulierte Schlußfolgerungen (Ia+IIId: Nad stawem: $R$ 64-4).

In einıgen fällen leitet auch eine 'mittelbare' Gestaltung (IIIa oder IIIb) scheinbar ohne Einschaltung des lyrischen Ichs in den verallgemeinernden Schluß (IIId) über (Zachód slońca: Na roli: mit uberraschendem Sprung von 'Naturlyrik' 2 u gesell- 
schaftlicher Problematik im Sonett "W lesie III" bzw. von Naturbeschreibung 24 poetologischer Pointe in "Topola", wobei diese - graphisch abgesetzte - Pointe zudem teilweise als 'Appell' gestaltet ist).

Isoliert steht eine appellative" Konstruktion (II) mit ihrer Aufforderung zum Naturerlebnis (DP 14). Diese Gestaltungsweise entspricht der hervorgehobenen stellung, die das Gedicht in Gruppe D elnnimmt: Es faßt bilanzartig lim Rahmen des retrospektiven zyklus "Deuteronomion czyli Powtórzenze"; vgl. dazu unten Abschnitt 5.5.) die Gesamtheit von LANGES 'naturlyrischem" Schaffen zusammen:

Teraz, znuzony duchu, porzuć miejskie rynki. Uchodź! Oko się lzawi pośród ludzkich gwarów. Lekarka jest ukojność pól i leśnych czarów. W zieleni tam czekaja ciebie odpoczynki.

Tam otocza cie kolem snów lesnych boginki I motyle, co z kwietnych sacza miód nektarów Tam milczeniem bezkreśnym szemrze cichy parów. A śród pól juz cl plasem śpiewaja dozynki.

Tam waz, jak sosny pachna, jak sie chmury gonia, Jak trzody marza senne, jak skowronki dzwonia: Niech jak we śnie - trosk prózny duch ściaga marzenia!

zatrać myśl, pamięć, wszystko. Rozplyń się w zywioly Dzieckıem bądz, a ku tobie zejda archanioly. Spiewajac kolysanke raju odpocznienia.

[Jetzt, ermüdeter Geist, verlasse die städischen Marktplatze. Entweiche! Das Auge tränt inmitten des Menschenlärms. Arztin ist die besäntigende Kraft der felder und Waldzauber. Im $G$ rü dort erwartet dich Erholung.

Dort werden dich die feen von waldträumen umgeben Und Schmetterlinge, die Honig aus Blütennektaren schlürfen Dort raunt in grenzenlosem schweigen die stille schlucht, Und auf den Feldern singt schon das Erntedankfest im Tanze.

Dort gib acht, wie die Kiefern duften, wie sich die Wolken jagen, wie schlafrige Herden träumen, wie Lerchen klingeln: Moge wie im Schlafe der sorgenfreie Geist Traume einfangent Verliere Gedanken, Erinnerung, alles. Zerfliebe in die Elemente Sei wie ein Kind, und zu dir werden Erzengel herabsteigen, und das Wiegenlied des Ruheparadieses singen.]

\subsection{Zusammenfassung}

Wie ich zu zelgen versucht habe, läßt sich durch eine Verbindung der Kriterien 'Themenbereich' und 'Monologtyp' ein sinnvolles erstes Einteilungsprinzip für größere Werkkomplexe gewinnen. LANGES Gedichte gliedern sich demnach in folgende füf haupt- 
gruppen: unmittelbare Bekenntnislyrik philosophisch-reflexiven Gehalts (Ia/A), kollektiv gestaltete unmittelbare Bekenntnislyrik politisch-sozialer Thematik (Iak/B), an die Geliebte gerichtete Bekenntnislyrik (IC/C), narrativ gestaltete polltisch+soziale Lyrik (IIIa/B) sowle verallgemeinernd-abstrakte philosophisch-reflexive Lyrik (IIId/A). Diese fünf Gruppen erfassen ca. die Hälfte aller Gedichte.

Dazu treten sechs weitere, doch kleinere Gruppen mit 'Standardgestaltungen : rhetorisch apostrophierende philosophischreflexive Bekenntinislyrik (Ib/A), appellatıve politisch-soziale Lyrik (II/B), narrative philosophisch-reflexive Lyrik (IIIa/A). narrative Naturlyrik (IIIa/D), verallgemeinernde politisch-soziale Lyrik (IIId/B) und verallgemeinernde Llebeslyrik (IIId/C).

In die angefühten elf Gruppen lassen sich insgesamt etwa zwel Drlttel von LANGES Gedichten elnordnen. Der Rest vertellt sich auf elne Vielzahl von stark individualisierten Gestaltungen, die of auch Kombinationen von mehreren verschiedenen Mono-logtypen darstellen (z.B.: Ia+IIId/A). Dieses Drittel von LANGES; Gedichten hebt sich aufgrund der seltenen und of komplizierten Konstruktionen vor dem Hintergrund der 'Standardgestaltungen' ab. 1st gleichsam in dieser Hinsicht stärker 'markiert'. Insbesondere in diesen Fällen können den Monologgestaltungen neben ihren "Grundfunktionen" wichtige, von Fall zu Fall sehr unterschledliche Bedeutungen zukommen.

Bei den 'Standardgestaltungen' hingegen werden melst nur die sehr allgemelnen "Grundfunktionen" wirksam. Dlese ergeben sich in den melsten Fallen quasi automatisch aus dem jeweiligen Monologtyp und lassen sich kurz folgendermaßen charakterisieren:

Die 'unmittelbaren' Monologgestaltungen (I) unterstreichen den persönlichen Bekenntnischarakter elner explizit subjektiv gefaßten Aussage. Dabei werden durch die Gestaltungs:ypen Ib und Ic 'scheinbare' bzw. 'reale' Kommunikationssituationen elngeführt, die gewönnlich dazu dienen, die Aussage lebendiger und eindringlicher zu gestalten.

Dem stellen sich die "mittelbaren" Monologtypen (III) entgegen, die der Aussage ein $s$ : he $1 \mathrm{n}$ ba $r$ unpersonlich objektives Geprage verleihen und das lyrische Ich quasi zu verbergen suchem. Elne Zwischenstellung nehmen 'appellative' Konstruktionen (II) mit ihrer Elnwlrkungsabsicht sowle 'kollektıve' Gestaltun- 
gen (Iak: mit Einschränkungen auch IIIdk) ein, die dem Zugehörigkeitsgefül des lyrischen Ichs zu bestimmten Gruppen Ausdruck verleihen.

Hervorzuheben ist unter diesen - auch allgemeiner gültigen Feststellungen die wichtige Rolle, die einem vielseitig verwendeten 'Du' in LANGES Lyrik zugewiesen wird. Es konstituiert nicht nur die Gestaltungstypen Ib und IC, sondern verleiht in seiner oszillierenden Unbestimmtheit auch den verallgemeinerndunpersönlichen Aussagen (IIId und IIldk) eIn spezifisches Gepräge. 


\section{Versbau}

Fragen der Versifikation leinschließlich Reimgestaltung und strophik) besitzen für LANGE einen hohen stellenwert, wie etwa seine formalen Experimente beweisen, die als solche tellweise sogar durch Titel und vorangestelltes metrisches Schema gekennzeichnet sind.

So schreibt er ein stichisches Gedicht, dessen Verszeilen aus einem 'Trochäus und einem Daktylus zusammengesetzt sind (Choreodaktyl), eln anderes, in dem er die alkäische Strophenform - etwas modifiziert - zugrunde legt (Strofa alcejska)“. schließlich ein Sonett ( $R$ 45), dessen Verszeilen aus einem einzigen Kretikus bestehen.'

Welterhin verfaßt er ein bekanntes Poem (Rym), in dem er ein wahres Feuerwerk ungewöhnlicher, of exotischer Reime abbrennt. Oder aber er fürt ein qanzes Sonett ( $R$ 24) mit zwel Reimpartnern, die füf "Ballady pijackle" (44 bzw. 29 Zellen!) mit jeweils drei Reimen durch. Schließlich gestaltet er kunstvolle Rondeaux (R 2, 13, 44), Sestinen (Ksiegi proroków), Pantuns (Samotność: R 23), usw.

Trotz alledem erscheint es nicht gerechtfertigt, daß J. KOS, der einen Teil des angefühten Materials zusammengestellt hat (1920:314-320), etwa den "Choreodaktyl", die "Strofa alcejska" und das Sonet "R 45" als humorvolle Spielereien bzw. Kuriositaten abtut (ebd.:318-320).

Gegen diese Auffassung wandte sich indirekt schon W. BOROWY (1934:210 f.): LANGE sel es niemals nur auf den kunstvollen Klang angekommen: selbst diese formal orientlerten Gedichte wiesen eine Sinnebene auf, die $1 \mathrm{~m}$ Falle des "Choreodaktyl" sogar bewußt hinter der ungewöhnlichen äußeren form versteckt worden sei.

- Beide Gedichte weisen der polnischen Prosodie völlig fremde daktylische Klauseln auf.

s Die andere mögliche Interpretation, es handle sich um zweifüßige katalektische Trochaen, erscheint angesichts der konsequenten Oxytonle der Klausel unwahrscheinlich. Doch auch eine solche Deutung nahme der Versgestaltung nichts von ihrer Ungewönlichkeit.

- Die Formbezeichnung als Iitel darf in di e s e m Zusammenhang nicht uberbewertet werden. Auch in anderen, eindeutig vom "Inhalt" bestimmten Gedichten verwendet LANGE ähnliche Titel. etwa die Gattungsbezeichnungen "Sonet". "Villanella", etc. 
Mir scheint, daß man noch weiter gehen muß: Auch bei diesen auffalligen Formexperimenten besteht ein unlösbarer zusammenhang zwischen der "äußeren" Gestaltung des Wortmaterials und dem 'inneren' Gehalt.

So ist der Inhalt der "Strofa alcejska" nicht nur die Geschichte des sturms, des leidens und des aus ihnen hervorgehenden lieds, wie BOROWY schreibt (1934:210), sondern diese Beschreibung des dichterischen Schaffensprozesses lebt geradezu von ihrer Anknüpfung an die Antike, deren wichtigstes Element - neben der liberwiegend griechischen Begriffswelt: Helzkon. Apo110, Stesichoros, usw. - eben die Odenform par excellence. die alkäische strophe ist. Das Gedicht wird so letztlich zu einer bewußt in die abendlandische Kulturtradition gestellten Ode an den Dichter und seine Dichtkunst.' 'Form' und 'Inhalt' ergänzen sich gegenseitig.

Vielleicht wollte der von schamhaftigkeit ("wstydliwość") geprägte LANGE hinter der Maske seines "Choreodaktyl" tatsächlich seine Liebessehnsucht verstecken, wie BOROWY meint 11934: 211). Zunächst jedoch lebt dieses Gedicht von der Melodie, von der die Erinnerung an das Liebeserlebnis durchdrungen wird und bestimmt ist ("Díwieki muzyki, / Cudnej muzyki" [Klänge der Musik, / Der wunderbaren Musik]; vv. 11 f.). Und diese Melodie spiegelt sich eben in dem beschwingten und zugleich zarten Versrhythmus des "Choreodaktyl" $(\dot{x} \times / \dot{x} \times x)$.

Ahnlich verbindet sich der dynamische stakkatorhythmus des Sonetts " $R$ 45" mit dem Bild des Marsches in die ersehnte $2 u-$ kunft: "Idziem, driac, / w jutra sny!" ([wir schreiten bebend / In die Träume des Morgen!]; vv. 13 f.l.'

Aus dem Gesagten wird deutlich, daß LANGE nicht nur der formalen Gestaltung seiner Werke große Aufmerksamkeit schenkt. sondern diese auch $z u$ einem bedeutenden Funktionselement in seiner Lyrik macht.

Das Ziel dieses Kapitels ist es nun, LANGES Versgestaltungen und deren konkrete Funktionen im Textaufbau zu charakterisieren.

'Ähnlıch scheint K. WYKA die "Strofa alcejska" zu begreifen (1977:182, Anm. 87).

- Eine rein formale Spıelerei hatte LANGE uberdies kaum in seine "Rozmyślania". eine Sammlung ernster Reflexionslyrik, aufgenommen, deren Bedeutung der Autor uberdies durch den bibiliophilen Druck unterstreichen läßt. 
Da eine erschöpfende Untersuchung des Gegenstandes den Rahmen dieser Arbeit sprengen würde, lege ich dabei den Schwerpunkt - exemplarısch - auf den metrischen Berezch im engeren sinne und berücksichtige Rhythmik, Reim und strophik nur insoweit. als diese zur Interpretation der Metrik notwendig sind.

Die Gliederung des Materials erfolgt nach dem relativen Stellenwert, der dem Versbau innerhalb des Textganzen zukommt, d.h., welches Maß an Aufmerksamkeit die Versgestaltung von vorneherein auf sich und damit auch auf ihre konkrete Funktion im Text lenkt. Dieses Maß bestımmt sich in erster Linie vor dem Hintergrund der historischen Epoche, des Gesamtwerks des Schrlftstellers, des Bandes und des zyklus, in die das Gedicht integriert ist, etc. Ich muß mich bei dieser 'Gewichtung' aus praktischen Gründen allerdings auf die - wohl wichtigsten Kontexte von Epoche und Gesamtwerk beschränken.

\subsection{Stark 'marklerte' Versgestaltungen}

Die im vorhergehenden Abschnitt angefürten Ausnahmeerschelnungen gewagter versifikatorıscher Experimente dürfen nicht darüber hinwegtäuschen, daß LANGE fast alle seine Gedichte nach den Prinzipien der traditionellen polnischen syllabik und syllabotonik leinschließlich des polnischen Hexameters und Pentameters) gestaltet hat, wobei wiederum die allermeisten von diesen den beiden 'Standardmaßen' $7 p+6 p$ ' und $5 p+6 p$ sowie - in etwas geringerem Maße - einigen acht-bzw. zehnsilbigen Versmaßen folgen.

Ähnlich ist die überwiegende Mehrzahl der jungpolnischen Lyriker der traditionellen Versifikation verpflichtet, wobei auch sie die genannten Versmaße bevorzugen (vgl. KOPCZYNSKA/MAYENOWA 1956:409, 332 f.: KOPCZYNSKA/MAYENOWA 1957:201): daraus folgt. daß sich die meisten Gedichte LANGES in ihrem Versbau kaum vom

- Zur Bezeichnung der numerischen Versmaße verwende ich Kurzformeln, die nach den folgenden Prinzipien gebaut sind: Die arabische ziffer bezelchnet die Silbenzahl. "pp" proparoxytonische. "p" paroxytonische und " $O$ " oxytonische Klausel bei syllabischen. "t" trochälsche. "j" jambische, "d" daktylısche, "am" amphibrachische und "ana" anapastische Gestaltung bei syllabotonischen Versmaßen. Das Pluszeichen $("+")$ steht für die Zäsur ("średniówka"). 
Epochenhintergrund abheben, also gewissermaßen schwach 'markiert' sind.

Beachtung verdienen an dieser stelle - neben den schon erwähnten Experimenten - lediglich LANGES vereinzelte Versuche, zusammen mit einer kleinen Zahl von Kollegen wirklich neue Wege zu gehen. Beteiligt ist er zum einen an der Einburgerung des "vers libre" der französischen Symbolisten in Polen, zum anderen an der 'Modernisierung' des polnischen Hexameters." Diese wenigen Versgestaltungen, die sich naturgemäß auch vor seinem Gesamtschaffen deutlich abheben, lassen sich somit als stark 'markiert' und als besonders wichtige Elemente im jeweiligen Textzusammenhang bezeichnen.

\subsection{1. "Vers libres"}

Die ersten 'freien Verse' LANGES mußten zu ihrer Entstehungszeit (bis 1903 bzw. 1906)" in Polen als hochaktuelle Neuerungen gelten und schon in dieser Hinsicht die Aufmerksamkeit auf sich lenken. Für unsere Fragestellung wesentlicher ist aber die künstlerisch überzeugende funktionale Verwertung dieser neuen Gestaltungsmöglichkeit.

Die vier in den zyklus "Rozmyślania" eingegangenen Realisierungen des "vers libre" ( $R 26,36,48,49)$ haben - neben ihrem existentiell-philosophischen Gehalt - ein charakteristisches Kompositionsprinzip gemeinsam: Alle vier beziehen ihre poetische Wirkung aus dem Element der $v$ eränderung, des äußeren Wechsels oder auch des innerlichen Schwankens, und verbinden sich so mit ihrer extrem wechselvoll und kontrastiv gestalteten Rhythmik zu einer sinnhaften Einheit.

Am deutlichsten wird dies am Bild des sich ewig wandelnden

10 Ähnliche Versuche unternahmen im Bereich des freien Verses $^{\circ}$. wenn auch oft - wie LANGE - nur in Einzelfällen. TETMAJER, KASPROWICZ, WYSPIANSKI, LEMANSKI, WROCZYNSKI, ORKAN, MIRANDOLA, M. WOLSKA, M. KOMORNICKA, MICINSKI, die Brüder BRZOZOWSKI, SZANDLEROWSKI, LESZCZYNSKI, B. OSTROWSKA Und MAKUSZYNSKI, wie eine Durchsicht entsprechender Anthologien ergibt (ŻELENSKI 1947; HERTZ 1965; JASTRUN'1967). Den modernisierten Hexameter verwendeten zu dieser zeit neben LANGE etWa TETMAJER, BRONISKAWSKA, JEDLICZ und STAFF (vgl. KOPCZYNSKA) MAYENOWA 1957:3351.

12 Erstveröffentlichung von "R 48" und "R 49" in: Chimera 6, 1903:31-33, von "R 26" und " $R$ 36" spatestens 1m Lyrikband "Rozmyśsania" (1906). 
und doch immer gleichen proteus ( $R 48)$, in dem LANGES monistische Weltsicht'2 zum Ausdruck kommt. Das Gedicht lebt von der relhenden Aufzählung der ganz unterschiedlichen Gestalten, die der - wohlgemerkt am ewig wechselvollen Busen der wellen ("Na wiekuiście zmiennym Yonie fal": v. 1, varılert v. 27) lebende Proteus nacheinander annimmt. Im ersten Teil des Gedichts übernimmt diese Reihung grammatikalisch gleicher Formen (vv. 7-15 und 20-26: Instrumental Singular; vv. 16-18: Nominativ Singular) sogar die Funktion des hier fehlenden Reimes, der erst im zweiten Teil die Geschlossenheit der wechselnden Rhythmen gewährleistet:

Otom jest zmija, otom hipogryfem.

Otom bialoskrzydla mewa.

I naraz staje sie syrena -

I harpia jestem, i gorgona.

I eumenida!... (vv. 7-11)

lod bin ich elne Viper, da ein Hippogryph,

Da eine weisgeflugelte Möwe,

Und gleich werde ich zu einer sirene -

Und eine Harpyie bin ich, und elne Gorgone,

Und eine Eumenide!...]

In "R 26" befreit sich das lyrische Ich nach und nach von allen (proteischen) Äußerlichkeiten, fördert das eigentliche Wesen des ewig reinen (... Menschentums ("czystego <...> czlowieczeństwa": v. 8) zutage, so daß sich die von diesen fesseln befreite seele / In eine Linie, einem raumlosen, reinen punkt verwandelt ("Dusza $z$ tych pet wyrwana, / w linie sie zmienia, w punkt bezprzestrzenny, czysty": vv. 12 f.l, der das Geheimnis der ewigen Ureinheit ("tajemnica wszechjedni wieczystej": v. 15) erfahren kann.

Auch hier ist also das Motiv der Veränderung, Verwandlung das entscheidende Formprinzip. Interessant ist dabei die Tatsache, daß die ähnliche Themen behandelnden Gedichte " $R$ 27" und "R 29" konventionell syllabisch", gebaut sind (5p+6p bzw. 7p+6p). Doch steht in diesen beiden Varianten eben die Negation des The-

12 "Wszystkie $\langle\ldots>$ zjawiska sa przemianami jednej sily - podścieliska wszechrzeczy, sily nieznanej i niepoznawainej" ([Alle <...> Erscheinungen sind Wandlungsprozesse einer Kraft - der Grundlage des Alls, einer unbekannten und unerkennbaren Kraft]; A. LANGE: Studia 1 wrazenza. Warszawa 1900:7, zitiert nach szYMANSKA 1979:20).

13 In "R 27" sind die beiden letzten der sechs strophen etwas modifizlert. Vgl. dazu unten Abschnitt 3.4.1.! 
mas im Zentrum: Die Befreiung vom irdischen Ich ist nur ein quälender, unerfullbarer Traum; die Verwandlung findet in wirklichkeit nicht statt, wie es im Gegensatz dazu "R 26 " suggeriert und durch seine rhythmische Gestalt unterstreicht.

Das dritte angeführte Gedicht in 'freien Versen' (R 49 ) ist ebenfalls Ausdruck einer (räumlichen) Veränderung - das lyrische Ich überschreitet die selbstgebaute Brücke ins märchenhafte Morgen ("w jutro bajeczne"; v. 3) -, letztlich einer inneren wandlung. Doch rückt hier, und dieses Element verbindet sich am stärksten mit der rhythmischen Gestaltung, das innere Schwanken des Subjekts vor dem Gang über die Brücke in den Vordergrund: Soll es die irdischen Leiden und Leidenschaften (vv. 5-7), die Freuden der Jugend (v. 14) wirklich aufgeben und vergessen?

In "R 36" schließlich beruht das 'Schwanken' darauf, daß das lyrische Subjekt den erwünchten Zustand, der dieses Leben ablösen soll, gedanklich nicht fassen kann, so daß der Ausdruck begrifflich zwischen den verschiedenen Varianten von rod und Leben oszillieren muß. Nach einer ersten, sofort wieder in Frage gestellten ( $v v .22-25$ ) provisorischen Fassung ( vv. 20 f.) wird schließlich eine im Rahmen des Möglichen zufriedenstellende Synthese der vorgebrachten Gedanken gegeben (vv. 28-33), die durch nun ausschließlich verwendete von der Tradition sanktionierte Versmaße (vv. 27-31:7p+6p; vv. $32 \mathrm{f} .:(4+4) t)$ eine gewisse Endgültigkeit der Formulierung erhält.

In seinem späteren zyklus "strofy na dzisiaj" (im Band "Trzeci dzien'") greift LANGE noch einmal' "auf die Technik des 'freien Verses" zurück. Das Gedicht "Blyskawice" ist eine im Jahre 1917 verfaßte (und 1922 um eine Schlußstrophe erweiterte) Rückschau auf die polnische Geschichte von 1791 bis in die Gegenwart. Das leitmotiv der hoffnungsvollen Blitze, die immer wieder das geschichtliche Dunkel plötzlich erhellen's, und ihr

1. Das zweite Gedicht dieses zyklus' in 'freien Versen" "Cesarz wilhelm", ist lediglich eine freie übersetzung des "Guillaume II" von E. VERHAEREN unter ubernahme von dessen Verstechnik (vgl. E. VERHAEREN: Les Ailes rouges de la Guerre. Poèmes. Paris 19:6:83-88), für unsere Fragestellung also nicht aussagekräftig.

is Ausdrücklich als Blitze bezeichnet sind die Verfassung vom 3. Mai 1791 ( I, vv. 1 f.), der Aufstand von 1863 (X, vv. 1 f.) und der japanische Sieg bei Tsuschima (XIII, vv. 3 f.). 
und doch immer gleichen proteus ( $R$ 48), in dem LANGES monistische Weltsicht'z zum Ausdruck kommt. Das Gedicht lebt von der reihenden Aufzählung der ganz unterschiedlichen Gestalten, die der - wohlgemerkt am ewig wechselvollen busen der wellen ("Na wiekuiście zmiennym Xonie fal": v. 1, varizert v. 27) lebende Proteus nacheinander annimmt. Im ersten Teil des Gedichts übernimmt diese Reihung grammatikalisch gleicher formen (vv. 7-15 und 20-26: Instrumental Singular: vv. 16-18: Nominativ Singular) sogar die Funktion des hier fehlenden Reimes, der erst im zweiten Teil die Geschlossenheit der wechselnden Rhythmen gewahrleistet:

Otom jest zmija, otom hipogryfem.

otom bialoskrzydla mewa.

I naraz staje sie syrena -

I harpia jestem, i gorgona.

I eumenida!... ( $v v .7-11)$

[Da bin lch elne Viper, da ein Hippogryph,

Da eine weikgeflügelte Möwe,

Und gleich werde ich zu einer sirene -

Und eine Harpyie bin ich, und eine Gorgone,

Und eine Eumenide!... J

In "R 26" befreit sich das lyrische Ich nach und nach von allen (proteischen) Äußerlichkeiten, fördert das eigentliche Wesen des ewig reinen <...> Menschentums ("czystego <...> czlowieczeństwa": v. B) zutage, so daß sich die von diesen Fesseln befreite seele / In eine Linie, einem raumlosen, reinen punkt verwandelt ("Dusza z tych pet wyrwana, / w linie sie zmienia, w punkt bezprzestrzenny, czysty"; vv. 12 f.l, der das Gehesmnis der ewigen Ureinheit ("tajemnica wszechjedni wieczystej"; v. 15) erfahren kann.

Auch hier ist also das Motiv der Veränderung, Verwandiung das entscheidende Formprinzip. Interessant ist dabei die Tatsache, daß die ähnliche Themen behandelnden Gedichte " $R$ 27" und "R 29" konventionell syllabisch"' gebaut sind (5p+6p bzw. 7p+6p). Doch steht in diesen beiden Varianten eben die Negation des The-

12 "Wszystkie $\langle\ldots\rangle$ zjawiska sa przemianami jednej sily - podścieliska wszechrzeczy, sily nieznanej i niepoznawalnej" ([Alle $\langle\ldots\rangle$ Erscheinungen sind Wandlungsprozesse elner Kraft - der Grundlage des Alls, einer unbekannten und unerkennbaren Kraft]: A. LANGE: Studia i wrazenia. Warszawa 1900:7, zitiert nach SzYMANSKA $1979: 20)$.

"In "R $27 "$ sind die beiden letzten der sechs Strophen etwas modifizzert. Vgl. dazu unten Abschnitt 3.4.1.! 
mas im Zentrum: Die Befreiung vom irdischen $I c h$ ist nur ein quälender, unerfüllbarer Traum; die Verwandlung findet in wirklichkeit nicht statt, wie es im Gegensatz dazu "R 26" suggeriert und durch seine rhythmische Gestalt unterstreicht.

Das dritte angefürte Gedicht in 'freien Versen' ( $R 49$ ) ist ebenfalls Ausdruck einer (räumlichen) Veränderung - das lyrische Ich überschreitet die selbstgebaute Brücke ins märchenhafte Morgen (" w jutro bajeczne"; v. 3) -, letztlich einer inneren wandlung. Doch rückt hier, und dieses Element verbindet sich am stärksten mit der rhythmischen Gestaltung, das innere Schwanken des subjekts vor dem Gang über die Brücke in den Vordergrund: Soll es die irdischen Leiden und Leidenschaften ( $v v$. 5-7), die Freuden der Jugend (v. 14) wirklich aufgeben und vergessen?

In "R 36" schließlich beruht das 'Schwanken' darauf, daß das lyrische Subjekt den erwünschten zustand, der dieses Leben ablösen soll, gedanklich nicht fassen kann, so daß der Ausdruck begrifflich zwischen den verschiedenen Varianten von rod und Leben oszillieren muß. Nach einer ersten, sofort wieder in Frage gestellten ( $v v .22-25$ ) provisorischen Fassung ( $v v .20$ f.) wird schließlich eine im Rahmen des Möglichen zufriedenstellende Synthese der vorgebrachten Gedanken gegeben (vv. 28-33), die durch nun ausschließlich verwendete von der Tradition sanktionierte versmaße ( $v v .27-31: 7 p+6 p$; $v v .32$ f.: $(4+4) t$ ) eine gewisse Endgültigkeit der Formulierung erhält.

In seinem späteren zyklus "Strofy na dzisiaj" (im Band "Trzeci dzień") greift LANGE noch einmal" auf die Technik des 'freien Verses" zurück. Das Gedicht "Blyskawice" ist eine im Jahre 1917 verfaßte (und 1922 um eine Schlußstrophe erweiterte) Rückschau auf die polnische Geschichte von 1791 bis in die Gegenwart. Das Leitmotiv der hoffnungsvollen blitze, die immer wieder das geschichtliche Dunkel plötzlich erhellen's, und ihr

1" Das zweite Gedicht dieses zyklus' in "freien Versen". "Cesarz Wilhelm". Ist lediglich eine freie Ubersetzung des "Guillaume II" von E. VERHAEREN unter Ubernahme von dessen Verstechnik (vgl. E. VERHAEREN: Les Ailes rouges de la Guerre. Poèmes. Paris 1916:83-88), für unsere Fragestellung also nicht aussagekräftig.

is Ausdrücklich als Blitze bezeichnet sind die Verfassung vom 3. Mal 1791 (I, vv. 1 f.), der Aufstand von 1863 (X, vv. $1 \mathrm{f}$ ) ) und der japanische sieg bei Tsuschima (XIII, vv. 3 f.). 
Aufzucken im wechselvollen Verlauf der Geschlchte werden durch die Versgestaltung plastisch untermalt.

In der noch späteren "Romantycznośc" dient der "freie vers" des zweiten Gedichtteils zur Darstellung der technikgläubigen modernen Großstadtwelt, die der romantzschen Gessteshaltung und vorstellungswelt des - traditionell versifizlerten (vgl. unten Abschnitt 3.2.1.1 - ersten Teils gegenübergestellt wird. Erst die Vision einer zuküntigen Herrschaft des befreiten menschlichen Geistes gegen Ende des zweiten Tells vermag die Rhythmik wieder in glatte Bahnen $(14$ Zeilen lang: $5 p+6 p)$ zu lenken “. und die Ankündigung einer Zerstörung der 'Maschinenwelt' bringt schließlich die metrische Wiederanknüpfung an den ersten Tell (14 anapästısche Zehnsilber wie in den geradzahligen Verszeilen des ersten Teils), womit slch der kompositionelle 'Ring' schließt. Die formale Gestaltung unterstreicht somit deutlich die Intention des Autors.

Insgesamt betrachtet, wird der "vers libre" bel LANGE also nur in sehr begrenztem Umfang verwendet und erhalt in dresen Fallen elne ganz konkrete, klar definierbare gestalterische Funktion, die mit seinem wechselvollen, sehr anpassungsfähigen Rhythmus in Verbindung steht.

1. Mit diesem Abschnitt wird auch der im zweiten Teil durch Assonanzen ersetzte Reim wieder verwendet. Nur noch 2 Zeilen greifen $1 \mathrm{~m}$ folgenden auf die Assonanz zurück: Es sind dies diejenigen, die erklären, daß es sich bei den im zweiten Gedichtteil verwendeten unahnlichen, ungleichartigen, nicht zusammenfliebenden <... L Laten - / Gleichsam wie die tollen streiche schlecht dressierter pferde ("Díwieki <...> niebliźniacze, niejednakie, niesplywne - / Jak gdyby koni zle wytresowanych harce": vv. $114 \mathrm{f.l}$ eben um Assonanzen handelt, die heutzutage jeder Dichterling ("wierszokleta") verwende. - Diese negative Bewertung der Assonanzen zieht automatisch auch eine Abwertung der mit ihnen gekoppelten 'frelen Verse" nach sich, so daß die in diesem Abschnitt als negativ geschilderte Technikwelt durch die verwendeten formalen Mittel nicht nur von der Alternativkonzeption abgehoben, sondern durch diese auch explizit a bgewerte $t$ wird. Gerade weil diese Ablehnung der Technikgläubigkeit der modernen Großstadtwelt einerseits und der formalen Tendenzen der Gegenwartskunst andererseits mitelnander gekoppelt sind, kann man im ganzen Gedicht uberdies elnen gezielten Angriff auf das avantgardistische Kunstverständnis der zwanziger Jahre (miasto, masa, maszyna; T. PEIPER) sehen. Vgl. dazu auch: PROKOP 1968:427. Eine weiter gehende Deutung des Gedichts im Rahmen von LANGES Evolutionstheorie unternimmt J. PORADECKI $(1979: 20)$. 


\subsubsection{Der 'modernisierte' Hexameter}

Neben dem tonischen und dem freien Vers wurde von den Dichtern der "Mloda Polska" auch eine 'modernisierte' Form des - inzwischen stark syllabotonisierten - von MICKIEWICZ geschaffenen 'klassischen' Hexameters in die polnische Literatur eingeführt (KOPCZYNSKA/MAYENOWA 1957:335). Ein in der Auflockerung der Formmerkmale sehr weitgehendes und zugleich frühes', Beispiel dieses Hexametertyps findet sich bei LANGE in einem der zahlreichen "Rozmyślania" zur Todesproblematik (R 33 ).

Die poetische Funktion des 'modernisierten' Hexameters in diesem Gedicht wird deutlich vor dem Hintergrund der allgemeinen Hexameterverwendung bei LANGE:

In einer ersten Gruppe dient der ( $r$ e im los verwendete) griechische epische Vers zur stilisierung von Texten, deren mythologischer, philosophisch gedeuteter stoff (Akteon) bzw. poetologische Problematik (Apollo i Muzy: Kuk i arfa) eng mit der antiken Kulturwelt verbunden sind.

Loser ist dieser Zusammenhang bei einigen ge re im te n Hexametern bzw. elegischen Distichen: "Iliada i Odyseja" verwendet antikes Kulturgut als dichterischen Vergleich zur Darstellung aktueller (politischer) Probleme. "Cyfra i slowo" schließ$13 \mathrm{ch}$ erweitert die dichterisch-prophetische Komponente der intuitiven Erkenntnis ("slowo"), die in gewohnter Manier antikisierend dargestellt wird ("na Helikonach", "Homery"), um das rationale, logische Denken der Wissenschaft ("cyfra"), wobei sich beide Elemente zur Welterkenntnis ergänzen."

Dieser Gruppe des ge lockerten Antikebezugs ist auch das fragliche Gedicht "R 33" zuzurechnen, dessen 'modernisierter'. gereimter und strophisch gebauter Hexameter sich noch weiter vom antiken Vorbild entfernt, als es schon die beiden zuletzt angefürten Beispiele tun. Worin ist nun die Funktion des versmaßes in diesem inhaltlich so unantiken Gedicht zu sehen, dessen Gedankengang am Bild des Delinquenten entwickelt wird, der aus

"Erstveröffentllchung in: Chimera 6, 1903:39. Nicht zufällig wird dieses Gedicht von J. KOS (1920:319) vollständig zitiert und eingehender analysiert.

1. Diese dualistische Formulierung kommt auch in der distichischen Fassung des Textes zum Ausdruck. 
den venezianischen Bleikammern tritt und dem nun vor der Hinrichtung alles Irdische in den leuchtendsten Farben erscheint?

w każej chwili zywota jesteś w przededniu mogily. Jako wifeczysty więzien, co kosy czeka smiertelnej: Czuwaj! Przygotowany badz - i wszystkie sily Zbieraj, byśs stanal wobec niej - nieskazitelny.

Jestés jako skazaniec, co $z$ olowianych podziemi Wchodzi na marmurowy Ponte dei Sospiri. Gdzie cle kat zatrzymuje, bys spojrzeniami ostatniemi Morze szerokie pozegnal - i marmury - i niebios szafiry.

I oglada skazaniec, jakie to skarby zatraca -

I co mu niegdy's sie zdalo liche i obojętne.

Teraz ma tajemnicze kolory odswiętne

I marzeniem, wspomnienlem, tesknota sie w oczach wyzlaca.

Tak my ciagle wchodzimy na jakiś most skazańców

I opuszczamy cudowne jakies weneckie pobrzeza -

I plyniem w nicośc jutra do tych krańców.

Gdzie cala przeszlość w zlote sońca się rozszerza. ( $\left(\begin{array}{ll}R & 33\end{array}\right)$

[In jedem Augenblick des Lebens bist du am Vorabend des Grabes. wie ein ewiger Gefangener, der auf die rodessense wartet:

sel wachsam! sei vorbereitet - und alle Kräte

sammle, auf dab du ihm makellos entgegentreten kannst.

Du bist wie ein Delinguent, der aus den Bleikammern

Auf den marmornen ponte dei sospiritritt,

Wo dich der Henker anhalt, damit du mit letzten Blicken

Vom weiten Meer abschied nimmst, und vom Marmor, und vom saphir [des Himmels.

Und es betrachtet der Delinquent, welche schäze er verliert und was ihm einst elend und gleichgültig schien,

Besitzt jetzt geheimnisvolle festragsfarben

Und vergoldet sich in seinem Auge als rraum, Erinnerung, sehnsucht

so treten wir ständig auf irgendeine Delinquentenbrücke

Und verlassen irgendwelche wunderbaren venezianischen Gestade Und flieben in das Nichts des Morgen zu den Grenzen, Wo sich die ganze vergangenheit zu goldenen sonnen erweitert.]

Die Funktion dieses 'verfremdeten' Hexameters besteht $z u-$ nächst darin, einen im Text verborgenen Bezug zur antiken Kultur diskret zu unterstreichen: Es ist die griechische Hadesvorstellung, die in der dritten strophe paraphrasiert und am Schluß des Gedichts noch einmal aufgenommen wird, die Vorstellung eines bedauernswerten Schicksals der Toten, denen das irdische Leben trotz all seiner Mühen zu einer ersehnten, gleichsam paradieslschen ' Vorstellung wird."

"Das dem selben Zyklus zugehörige Gedicht "R 21 " welst im ubrigen die gleiche Verbindung von Venedig und Hadesvorstellung (styx, charon) auf. 
Ganz im Gegensatz dazu steht die christliche Todessicht, auf die in Strophe 1 angespielt wird. Besonders die Verse 3 und 4 erinnern an die biblischen Gleichnisse vom "Warten auf das Kommen Christi" (Matth 24, 42-44; Mar 13, 33-37; Luk 12, 35-40). Das Schlußwort dieser Strophe ("nieskazitelny") gewinnt in diesem Zusammenhang religiös-moralische Bedeutung. ${ }^{\circ}$

Insgesamt betrachtet, wird so in der ersten strophe eine Erwartung geweckt, die der weitere Verlauf des Gedichts nicht bestätigt: Die angedeutete christliche Aufforderung zur Wachsamkeit und zur moralischen Lebensweise in der Hoffnung auf eine dadurch $2 u$ erlangende Belohnung im Tode wird nicht ausgefüht, sondern - in der durch das Reimschema (umfassender statt kreuzreim) vom Rest abgehobenen dritten strophe - durch die antikheidnische Diesseitsbezogenheit ersetzt, wodurch der Hexameter seine zweite, jetzt auf das Gesamtgedicht bezogene Funktion erhält.

In diesem licht nun gewinnen die zunächst christlich erscheinenden Imperative der Verse 3 und 4 eine neue Bedeutung: Man muß sich stets des drohenden Todes bewußt sein, der uns ins Nichts stürzt (vgl. v. 15), und infolgedessen das irdische Leben ständig in seiner Schönheit $z u$ erleben versuchen. Diese Lebenshaltung ist die wirkliche Makellosigkeit, mit der man dem Tod ins Auge blicken soll (v. 4).

Der zuletzt eingehender interpretierte Text führt exemplarisch die Bedeutung vor Augen, die dem Gestaltungselement 'Versbau' bei LANGE zukommen kann.

\subsection{Schwächer 'marklerte' Versgestaltungen}

Die in den beiden vorhergehenden Abschnitten analysierten Gedichte heben sich durch ihre versifikatorischen Neuerungen deutlich vom Epochenhintergrund wie auch vom Gesamtwerk LANGES

20 Bestätigt wird diese Interpretation der strophen 1 und 3 durch das spätere, aber ebenfalls den "Rozmyślania" zugehörige Gedicht "R 63", dessen 1. Abschnitt auf "R 33" bezug nimmt. Hier wird gleichfalls zunächst die Bibel paraphrasiert ("zlodziej nieoczekiwany" [unerwarteter Dieb]; vgl. Matth 24, 43; Luk 12, 39) und anschließend der Hades eingefüht, diesmal konkret durch Verweis auf den 11. Gesang der Odyssee (vgl. dort besonders vv. 475 f., 489-491,619). 
ab. Aus der Perspektıve dieses Ges am $t$ werks betrachtet, gewinnen zusätzlich zu diesen fällen auch einige durchaus nach den Prinziplen der traditionellen Versifikation gebaute Gedichte elne besondere stellung, da sie einen bei LANGE selten realisierten Versbau aufweisen, der zudem sehr spezifische Gestaltungsfunktzorien $2 u$ übernehmen hat.

\subsubsection{Syllabotonische Versmaße}

Insbesondere gilt dies für die bei LANGE stark differenzierten syllabotonischen Gestaltungen:

Ein gutes Beispiel für bewußte Anknüpfung an bekannte Traditionen ist der erste Teil der schon erwahnten "Romantycznośc" (vgl. oben Abschnitt 3.1.1.), der wechselweise anapästische Zwölf- und Zehnsilber aufweist. Je eine Reimperiode der unstrophischen Verse LANGES entspricht so genau der typischen Balladenstrophe von MICKIEWICZ ("strofa mlckiewiczowska"; vgl. KOPCZYNSKA/MAYENOWA 1957:267). Dabei werden lediglich deren (weiblich binnengereimte) hyperkatalektische Zäsur und Klausel in den Languersen durch oxytonese (mit mannlichem Reim) ersetzt. wodurch der anapästische Rhythmus hervorgehoben wird.

Der Versbau stellt so einerseits eine formale Beziehung zur Gattung der romantischen Ballade her, die von LANGE mit der "Romantycznośc" insgesamt imitiert wird, andererseits - und vor allem - einen Bezug zur romantischen Geisteshaltung, der in die Gesamtaussage des Gedichts zusätzliche und verdeutlichende Aspekte einbringt.

Eine gänzlich andere Funktion des Versbaus läßt sich deutlich an einer amphibrachischen Gestaltung zeigen: In den "Skowronki" dient das durch syntax und Gedankenstriche stark hervorgehobene, vollkommen diäresierte Versmaß (9am) zur Veranschaulichung des flinken flugs der Lerchen, dessen beschwingter Rhythmus sich schließlich auch ihrem frühlingkündenden Gesang mitteilt:

I dzwoniac - świergocac - szczebioczac,

Po niebie szerokim lataja

I skrzydlem nerwowo trzepoczac

Spiewaja - spiewaja - spiewaja! (vv. 29-32)

[und klingelnd - trillernd - zwitschernd,

fliegen sie am weiten Himmel dahin

Und mit dem flügel nervös flatternd

singen sie - singen sie - singen siel] 
Vor allem die Dynamik der Bewegung unterstreichen die in "Sw 5" dominierenden Jamben:" das Boot schießt auf den See hinaus:

Hej, wiosla w dlonie!

Na srebrne tonie Skierujmy lódź!

$w$ ciszy wieczora

Kódź plynie skora...

Na glab jeziora

Ster lódki zwróć. (vv. 1-7)

[Hej, die Ruder in die Hände!

Auf die silbernen tiefen

Lenken wir das Boot!

In der stille des abends

Schwimmt das Boot schnell dahin...

Auf die tiefe des sees

Lenke das steuer des Boots.]

Im Anfangsgedicht des gleichen zyklus korrespondiert die jambische Gestaltung mit dem mehrfach beschworenen Wellenschlag

des Sees:

A fala myje brzegu stok

I drzewom pieśni śpıewa.

I nęci - nęci w glab a w mrok,

Az $w$ glab sie chyla drzewa.

$\langle\ldots\rangle$

Badź pozdrowiona, świętych wód,

Srebrzystych wód równino!

Skąd boskich pieśni rozgrzmial cud, Co w nieśmiertelność plyna.

$z$ fal, kolysanych w spiewny ruch, Piéśn idzie tajemnicza:

w powietrzu święty plynie duch. Duch święty Mickiewicza! (Sw 1, vv. 13-16, 25-32)

[und die Welle spult die uferböschung

Und singt den Bäumen lieder,

Und lockt - lockt in die tiefe und in die Finsternis,

Bis sich die bäume in die Tiefe neigen.

$\langle\ldots\rangle$

Sei gegrüBt, der heiligen wasser,

Der silbernen Wasser Fläche!

Von der das wunder göttlicher lieder erklang,

Die in die Unsterblichkeit flieben.

2 Unabhängig von der starken Jambisierung verleihen schon die kurzen Verszeilen $(5 p, 5 p, 40,5 p, 5 p, 5 p, 40)$ dem Gedicht eine charakteristische Dynamik, wie sich an der syllabisch fast gleichgebauten "Pochwala kycia" zeigt (die "katalektischen" zeilen sind meist um eine weitere silbe zu 30 verkürzt). In deren "Langzeilen" herrscht jedoch der Daktylus vor, der das Motto "Ev० ë Vit a" durch das ganze Gedicht rhythmisch fortträgt und ihm eine nicht weniger dynamische, wenn auch anders geartete Struktur als dem Parallelfall "Sw 5 " verleint. 
Von den wellen, die in singende Bewegung gewiegt sind, Geht ein gehelmnisvolles lied aus:

In der luft fliebt ein helliger Geist, Der heilige Geist Mickiewicz'l]

Die "Abstrahierung" der zunächst äußerlich motivierten jambischen Dynamik, die sich in den beiden letzten strophen des Gedichts andeutet (MICKIEWICZ. Werk wird mit den wellen des Sees in Beziehung gesetzt), ist in "Sw 6" zum grundlegenden Konstruktionsprinzip geworden: Zunächst wird das Rufen über den See (Refrain "Hej, hej!") und die hundertfache Echowlrkung beschrieben, anscnließend wird damit die wirkung des mächtigen, donnergleichen liedes von MICKIEWICZ assozilert, das vom Switez aus in die welt ging:

Z Swltezi srebrnych fal, z pluzyńskich clemnych puszcz Stokrotnym echem gra i zywi pier's miliona Poteznej pleśni grom, plomienny Boga kuszcz. Nicugaszony znicz na przyszlych dni plemiona. Hej. hej! (vv. 16-20)

lvon des Switez silbernen wellen, aus den dunklen wlidnissen von LPIuzyny

Splelt in hundertfachem Echo und nahrt die Brust von Millionen Des gewaltigen liedes Donner, der flammende Busch Gottes, Das unauslöshliche Ewige feuer fur die Geschlechter der komHej, hej!

[menden Tage.]

Abgeschlossen erscheint dieser 'AbstrahierungsprozeB' in dem ebenfalls aus (teilweise hyperkatalektischen) sechsfüßigen Jamben mit mannlicher zäsur nach dem 3. Fuß gebauten Gedicht "Pog 7". Hier wird ein mächtiges Losungswort gefordert, das dze Geschlechter aus dem schlaf weckt ("co budzi z snu plemiona": v. 23). In allen drei zuletzt angefuhrten Gedichten wird also. wie leicht zu sehen ist, die wirkung des machtvollen wortes durch dynamische Jamben suggeriert.

Neben den bisher angefuhrten "dynamischen" Jamben gibt es aber auch konträre Gestaltungen: Im Gedicht "Przebacz" wird der ungewöhnliche, durch weibliche zäsur und klausel rhythmisch schon stark verfremdete jambische Dreizehnsilber durch prosaisierende Zeilenzergliederung nach syntaktischen Gesichtspunkten sowie durch antimetrische Betonungen vollends entstellt. In dieser Form kann der Jambus nun $z u$ einem adäquaten Gestaltungsmittel für ein Gedicht werden, in dem ein reumuitiges lyrisches Ich der Geliebten zu Füßen sinkt:

o. przebacz mi ty. wymarzona, ukochana, 
żem do cię mówil

tak zuchwale, tak bezboznie!

O. widze, zés ty siostra bogıń!

Na kolana.

Jak przed oltarzem. dziś przed toba padam trwoznie! (vv. 1-8)

[O, verzein mir du,

Erträumte, Geliebte,

DaB ich zu dir sprach

so frech, so ruchlos!

0 , ich sehe, daB du eine Schwester von Göttinnen bist!

Auf die Knie,

wie vor einem Altar,

falle ich heute angstroll vor dir!]

Die Versgestalt verbindet sich so mit dem verunsicherten, wenig selbstbewußten Auftreten des Sprechers.

Neben literarischer Anspielung und rhythmisierend-lautmalerischer Gestaltung dienen die syllabotonischen Versmaße bei LANGE schließlich auch $z$ u liedhaftem und volkstümlich-einfachem Ausdruck: insbesondere gilt dies für trochäische und trochäischamphibrachische Formen.

Mehrere solcher Beispiele finden sich in den "Rozmyślania": In "R 52-1" wird durch die völlig regelmäßigen dreifüßigen Trochäen die Einfachheit des Dialogs mit dem einsamen Blatt hervorgehoben (vgl, oben Abschnitt 2.3 .1$.$) , in den aus verschieden$ langen trochäischen Zeilen bestehenden " $R$ " und " $R$ " 4 " wird eine melancholische bzw. versonnene Liedhaftigkeit der Texte unterstrichen.

Dabei benutzt "R 4 " die auch sonst der volkstümlichen Stilisierung dienende Strophenform: $(4+4) t, 5 t,(4+4) t, 5 t$ (vgl. MAYENOWA 1964:160 f.) in geringer Modifikation: Einmal wird der strophische Charakter und damit die Herkunft des Versbaus durch die Graphik etwas verwischt, zum anderen durch zusätzlichen Binnenreim an der Zäsur der je dritten Zeile einer Reimperiode die Lautstruktur eindringlicher gestaltet. Das Ergebnis ist eine stark lyrisierte Klage des bei der Lebensrückschau sein Scheitern feststellenden Subjekts.

Die aus trochäischen Acht-, Sieben- und Fünfsilbern gebauten, etwas unregelmäßigen Strophen von " $R$ 34" entsprechen dem versonnen-liedhaften Inhalt: Der Verliebte gibt 'ihr' gegenüber seinem Gefühl Ausdruck, daß er 'sie' schon aus einer vorirdischen Vergangenheit kenne, und daß 'sie' ihn auf geheimnisvolle Weise an eine solche Präexistenz (ihrer beider Seelen) erinnere: 
Ták mi cós sie przypomina -

Jakis inny swiat - nie ten!

(I te oczy, niby sen -

I te wlosy, niby len - )

Promienista gdzies dolina.

Innych bytow ukraina. Zapomniany dzlwny sen!... (vv. 35-41)

[So komat mir etwas in Erinnerung -

Irgendeine andere welt - nicht diese!

(Und aiese Augen. Wle ein Traum -

und diese Hade, wie flachs -)

$E$ in strahlendes $T a l$ irgendwo,

$E$ in Grenzgef 11 de anderer Existenzen,

Ean vergessener seltsamer Trauml...]

Volkstumliche Einfachheit verleiht der siebensilbige Versrhythmus $(4 t+3 \mathrm{am})$ dem Gedicht "Pog 2": unprätentiös kommt so die Klage der ohne Hoffnungen und Träume aufgewachsenen, in gleichgültige Resignation verfallenen - nach dem Januaraufstand von 1863 geborenen - Generation LANGES zum Ausdruck. Zugleich unterstreicht der in sich differenzierte Rhythmus den Kontrast $z$ wlschen elner gewönlich hof fnungsfrohen Jugend und dieser desillusionierten Generation, was zu Beglnn auch syntaktisch deutlich gemacht wird:

Myśmy rajów $\langle+>$ nie śnili,

Mysmy wiosny $<+>$ nie znali: (vv. 1 f.)

[wir haben von Paradiesen nicht getraumt,

Wir haben den fruhling nicht gekannt;]

Die volkstümliche Stilisierung des Gedichts "Topola" schlieB$11 \mathrm{ch}$ beruht (neben den durchgehenden vierfüßigen Trochäen) vor allem auf dem mit dem Titel identischen dreisilbigen Refrain. der den ersten - blldhaften - Teil des Ganzen charakterisiert und an das typische dreisilbige Schlußglied des Volksliedverses gemahnt (vgl. KOPCZYNSKA/MAYENOWA 1956:107 f.). Zugleich unterbricht der rhythmisch abgesetzte Refrain (Amphibrachys) den trochäischen 'Fluß' jewells nach zwei Versen, so daß sich diese geschlossenen Distichen rhythmisch leicht mit der hochaufgeschossenen pappel des Blldes verbinden lassen:

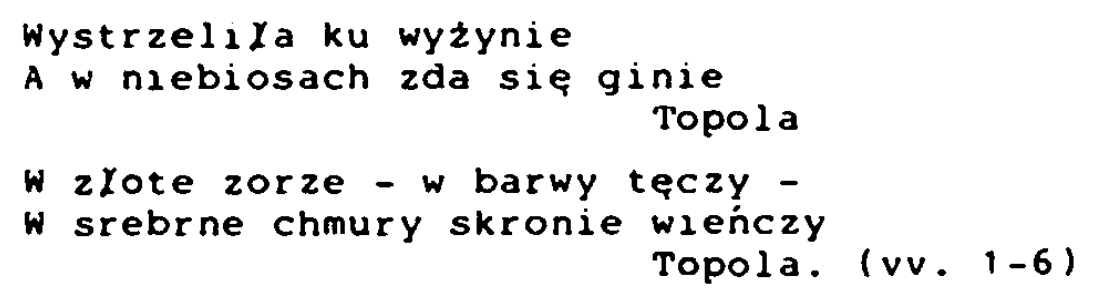


les schiebt in die Hohe

und scheint in den Himmeln zu verschwinden

Die Pappel.

Mit goldenen Morgenröten - mit Regenbogenfarben -

Mit silbernen Wolken bekränzt die Schläfen

Die pappel.]

Aus diesem Grunde weisen die beiden - auch graphisch abgehobenen - Schlußstrophen, die das Bild der pappel auf den Dichter übertragen, keinen Refrain auf und sind vierzeilig gestaltet; die Trochäen fließen also vollkommen gleichmäßig dahin:

Baqú, poeto, jak topola -

Kochaj tęcze i granity.

Jednym skrzydyem leć w blękity.

Drugim ziemskie odczuj pola! (vv. 43-46)

[Sei, Dichter, wie eine pappel -

Liebe Regenbogen und Granit,

Mit dem einen flügel fliege in den Himmel,

Mit dem anderen erfühle die Erdenfelder!]

\subsubsection{Syllablsche Versmaße}

Volkstümiche bzw. liedhafte stilisierung findet sich auch bei rein syllabisch gebauten Versen:

So verleiht das dreisilbige, wie in "Topola" graphisch abgesetzte Schlußglied dem Dreizehnsilber $(5 p+5 p /+3 p)$ "Chcialbym..." einen lyrisch-liedhaften Charakter (vgl. zu ähnlichen Gestaltungen: KOPCZYNSKA/MAYENOWA 1956:412 f.l:

Chcialbym być świezym porannym tchnieniem wietrzyka.

Co w twoje piersi wiosny pragnieniem Przenika.

Chcialbym być slońcem, co cię ogrzewa

W szat bieli:

Chcialbym być fala, co cie oblewa

W kapieli. (vv. 1-8)

[Ich wollte gerne der frlsche Morgenhauch

Eines Lüftchens sein,

Das deine Brüste mit frühlingsverlangen

Durchdringt.

Ich wollte gerne die sonne sein, die dich wärmt

In der Weibe der Kleider;

Ich wollte gerne die welle sein, die dich umspült Im Bade.]

Von den, wie der Untertitel schon andeutet, scherzohaften "Pieśni o pocalunkach" bezieht das zweite seine Liedhaftigkeit aus dem volkstümlich anmutenden Versbau (durchgehend sechssilbige Zeilen ohne zäsur, die wechselweise reimlos und gereimt 
sınd), während das erste darüber hinaus durch vollkommen identıschen Vers - und Strophenbau möglicherweise an TKEMBECKIS "Anakreontyka" anknüpft (vgl. KOPCZYNSKA/MAYENOWA 1956:136 f.) und auf diese weise den Scherzocharakter betont. In beiden Gedichten wird das liedhafte Element auch an der starken, aber nicht durchgehaltenen Rhythmssierung (Trochäen bzw. Daktylen) deutlich.

Ähnlich wie in "R 52-1" eln Blatt, wird in "R 52-2" eine verelnzelte wolke zum volkstümlich anmutenden Bild für den einsamen Menschen, wobei die Einfachheit des Bildes unterstrichen wird durch kurze, syllabisch nicht ganz konstante Verse (Verflechtung eines Siebensilbers, der einmal zum Dreizehnsilber erweitert ist, mit kürzeren, füf-oder sechssilbigen, am Schluß dreisilbigen Versenl.

Einfachheit der Gestaltung dominiert aber auch im explizit reflexiven " $R$ 64". Beweist der erste Tell mit seiner Verflechtung acht- und funfsilbiger Verse und der stellenweisen (daktylischen) Rhythmisierung noch einen gewissen formalen Anspruch. so beschränken sich der zweite und dritte Teil auf stichische Achtsilber, das wohl einfachste - und besonders im Mittelalter populäre - Versmaß der polnischen Dichtung, dessen sich - sofern nicht syllabotonisch oder tonisch gestaltet - zu Ende des 19. Jahrhunderts kaum noch jemand bediente (KOPCZYNSKA/MAYENOWA $1956: 211,2361$.

In diesem bewußt kunstlosen, zumal in seiner Unstrophigkeit fast prosaisierend anmutenden Rahmen werden die Probleme von Tod und Präexistenz abgehandelt, wodurch die verse fast archaische Diktion gewinnen. Zudem ruft der zweite Teil mit seiner Apostrophe des personifizierten Todes - vor diesem formalen Hintergrund - den mittelalterlichen Dialog Meister Pollkarps mit dem Tode in Erinnerung:

Smierci, dość $w$ swoim oblędzie Patrzalem w twe oczodoly Co ma być, to niechaj będzie, Gdy sie obróce w popioly. ( $R$ 64-2, vv. 1-4)

lrod, genug habe ich in meiner sinnesverwirrung In delne Augenhöhlen geblickt -

Was sein soll, das möge geschehen, Wenn lch zu staub zerfallen sein werde.]

Neben den angefürten Aufgaben bewußt einfacher Gestaltung bzw. Iiterarischen Bezugnehmens werden auch dem syllabischen 
Vers von LANGE rhythmisierend-lautmalende Funktionen zugewiesen:

Die "Kolysanka" erhält durch ihren über vier Zeilen hin wiederholten symmetrisch zweiteiligen Zehnsilber $(5 p+5 p)$ mit eindeutig syllabotonischen bzw. tonisch-syllabischen Tendenzen (vgl. dazu KOPCZYNSKA/MAYENOWA 1956:274) einen wiegenden Rhythmus, der jeweils in der füften (Schluß-)zeile durch oxytonische Acht-bzw. Viersilber scharf durchbrochen wird, ganz entsprechend der Thematik: Es handelt sich um ein wiegenlied, das die personifizierte Not ihrem kleinen Opfer singt:

Spij, moje dziecie! Sen daje cisze,

Sen troski zycia z duszy wypęza:

Lecz ja do innych snów cie kolysze -

Ja twa piastunka, matka twa - Neqdza,

Ja czuwam wiecznie nad twym snem. (I, vv. 1-5)

[schlafe, mein Kindl Der schlaf gibt Ruhe,

Der schlaf verjagt die sorgen des lebens aus der seele:

Aber ich wiege dich in einen anderen Schlat -

Ich, deine Amme, deine Mutter - die Not,

Ich wache ewig über deinen schlaf.]

Die Wirkung wird $1 \mathrm{~m}$ weiteren Verlauf des Gedichts dadurch gesteigert, daß der (etwa in der ersten strophe dominierende) daktylische Rhythmus der Zehnsilber an charakteristischen stellen durchbrochen wird und so den inneren widerspruch eines wiegenlieds der Not sinnfällig macht.

Im ersten Teil der "Nowa pieśn" wird durch den Versbau der ubergang von freudiger Erwartung, die sich in den dynamisch kurzen, männlich binnengereimten Gliedern der je ersten Verszeile $(40+40)$ ausdrückt, zur schließlichen Enttäuschung gesshildert: Länger wirkende, da zäsurlose Verse, die zunächst noch mit männlichem Reim an die erste Zeile anknüpfen (80), werden schließ 1 lch von paroxytonisch verklingenden ( $8 p)$ abgelöst:

Gdzie byl ten dreszcz? gdzie ten lez deszcz,

Co wrózyl nam natchniony wieszcz.

że tryśnie nam w dzień zmartwychwstania?

Gdzie byl ów hymn - co dźwiekiem swym

w radość mial przybrać grzmiacy rym. Że wolność $z$ mgiel się wylania? ( $I$, vv. 1-6)

(wo war dieses Beben? wo dieser Tränenregen,

Von dem uns der inspirierte seher prophezeit hatte,

$D a B$ er am Auferstehungstag hervorschieben werde?

wo war jener Hymnus, den mit seinem Klang

Der donnernde Reim in Freude kleiden sollte, Weil sich die freiheit den Finsternissen entreibt?] 
Eine deutliche Korrespondenz mit dem Inhalt weist der lersbau duch in " $R$ 38" auf. Die Interdependenz von unbewubtem ("nieswiadomośc") und Bewußtsein kommt in der regelmäßıgen Verflechtung von traditionell gebauten Drelzehnsılbern $(7 p+6 p)$ und unregelmảigen kürzeren Versen zum Ausdruck. Dabei sind diese in ihrer 'Normalform' Achtsilber ( $v v .2,10)$ und verkürzen sich zu einem Füfsilber (v. 6) bzw. zu Dreisilbern (vv. 4, 8, 12 ) jeweils am strophenende. Diese verkürzten Verse suggerieren im Gesamtzusammenhang den Eindruck von Unabgeschlossenheit, geheimnisvoller Ungreifbarkeit, der durch die jewells folgenden orel pünktchen noch gesteigert wird. Mit der deutlich abgegrenzten bewußten Sphare wird somit ein nicht klar faßbares unbewubtes verflochten, ein schatten unseres exgenen wesens (v. 2), in dessen Schatten wlederum unser ganzes Leben dahinfliebt (vv. 5 f.):

$z$ naml 1 ponad naml 1 w nas wciqz sie wlecze Cien naszej wlasnej istoty:

Nieśwladomość, co dusze osnuwa czlowiecze w swe sploty...

hiszystko w nas jest jej dzielem. Cale nasze zycie Plynie w jej cieniu...

Sny nasze, mary nasze ona przędzie skrycie w milczeniu...

Ona drwi z naszych myśli, bo wie, ze te mysill Nie w naszej rodza sie glowie:

Bo jakie badí sa rzeczy, ona je nam kreśli w swym slowie...

[Mit uns und über uns und in uns schleppt sich Ein schatten unseres eigenen Wesens:

Das unbewubte, das die menschlichen seelen In seine Geflechte einspinnt...

Alles in uns ist sein Werk. Unser ganzes Leben Fliebt in seinem schatcen dahin...

Unsere Schlaf-und wachträume spinnt es im verborgenen In schweigen...

Es macht sich uber unsere Gedanken lustig, denn es weik, daß liese Gedanken

Nicht in unserem Kopf geboren werden:

Denn welche Dinge es auch immer sind, es zeichnet sie uns In seinem wort...]

\subsection{Schwach 'markierte' Versgestaltungen}

Bei den bisher angeführten Gedichten wurde die versifikatorische Seite schon allein durch die relativ seltene Verwendung der jeweiligen Versgestaltungen bei LANGE hervorgehoben, zumal diese im allgemeinen - und dies gilt nicht nur fur LANGES Neuerungen 
und Experimente - auch vor dem Epochenhintergrund mehr oder weniger stark 'markiert' sind. In diesen Fällen kann die Versifikation leicht individuell gestaltende Funktionen für das Einzelwerk ubernehmen. Hinzu kommt die Anpassungsfähigkeit dieser oft komplizierteren strophischen Kombinationen.

Die einfacher gebauten und häufıger gebrauchten Zehnsilber $(4 p+6 p ; 5 p+5 p)$ und vierfüßigen Jamben bzw. Trochäen, vor allem aber die 'Standardmaße' $(7 p+6 p ; 5 p+6 p)$ vermögen die Aufmerksamkeit nur noch in geringem Maße auf sich zu lenken.

\subsubsection{Häufiger gebrauchte Versmaße}

Aber auch bei den relativ häufigen Zehnsilbern und Vierfüßern lassen sich einige - schwächer ausgeprägte und meist überindividuelle - Funktionstendenzen feststellen, die im wesentlichen den drei bisher unterschiedenen Grundtypen entsprechen:

So macht LANGE etwa in zwei politisch-sozialen Paraphrasen der bekannten Totenamtssequenz des Thomas von Celano (Pog 11; Dies illa) seine literarische Anspielung durch übernahme von Versmaß $(8 t)$ und Strophenform vollends deutlich (vgl. unten $A b-$ schnitt 5.3.). Ähnliches gilt für die vierfüßigen Trochäen in "ZSL 3", das an die Schlußszenen (Akt III, Szenen 34-37) von WYSPIANSKIS "Wesele" anknüpft.

Mit dem Versmaß $4 p+6 p$ wird einmal die Anspielung auf das Volkslied "Kiedy będzie slońce i pogoda" (vgl. PRZYBOS 1957: 221 ) in "ZSL 12" unterstrichen, dann auch ein Bezug innerhalb des eigenen Werks hervorgehoben: "DP 16" ubernimmt das Versmaß der paraphrasierten "Powieśc o Waligórze i Wyrwidębie".

'Lautmalend' -rhythmisierende wirkung charakterisiert den Zehnsilber $5 p+5 p$ (vgl. aber seine abweichende Funktion in "Kolysanka"!), vor allem in Verbindung mit seiner oxytonischen Varlante $(5 p+40)$ : Rasende zerstörungs- und Vernichtungswut wird so in den Gedichten "Pieśn Hunnów" und "DP 17" unterstrichen, der Wechsel von zerstörung und wiederaufbau in " $R$ 47" und "ZSL 1 ":

2 wichrów poświstem, $z$ piorunów grzmotem, We krwi strumiensach i ogniu Xun, Wilczym rozpędem, krogulczym lotem, Na lekkim koniu w świat pedzi hun! (Pieśn Hunnów, vv. 1-4) 
[Mit dem pfeifen der stürme, mit dem Dröhnen der Donner In strömen von Blut und im feuerschein von Bränden.

Im Wolfesdrang, im sperbertlug.

Jagt der Hunne auf leichtem ROB in die welt!]

Die Dynamisierung der Aussage ist eine Hauptfunktion vor allem des - ganz oder tellweise - oxytonischen vierfüßıgen Jambus. analog $z u$ den schor erwähnten selteneren kurzen oder langen Varianten.

Deutlich zeigt sich dies an der lakonischen schärfe und Prägnanz, die det (nur teilweise hyperkatalektische) vierfüßige Jambus der kritischen selbstbefragung des Dichters verleiht, die den zyklus "Deuteronomion czyli Powtórzenie" einleitet (DP Pr.). insbesondere aber den sechs anaphorisch mit "Czyli" eingeleiteten Fragen, die sich genau in den Rahmen je einer Versieile fügen.

Weniger von strenger Disziplin gepragt ist entsprechend seiner Thematik das Gedicht "Upojenie" ([Rausch]: DP 13 ) aus demseliben zyklus, was unter anderem in den hier vewendeten, zum Tell starken (vv. $6 \mathrm{f}$. ) Enjambements zum Ausdruck kommt, doch ist auch hier die jambische Dynamik fiur die vom feurigen, perlenden wein hervorgerufenen rauschhaften Träume rhythmusbestimmend, verstärkt durch den ausschließlich männlichen Reim und weitere auffällige Einsilber im Innern der verszeilen.

Schwungvoll gestalten sich insbesondere die Terzette, die eine einzige Intonationsperlode bilden; erst nach vierfacher Antikadenz erfolgt die Lösung in einer halben und schließlich volien Kadenz:

Nimf niewldzialnych lekki tan.

Stolice pelne bialych wiez -

zlotem szumiacy zyzny lan -

Moc - ponad nędze ludzkich rzesz:

Da ci ognisty wina dzban.

Da cl perlisty winakierz! (vv. 9-14)

lDen leichten Tanz unsichtbarer Nymphen, Hauptstadte voll weiber Turme -

Im Gold rauschende fruchtbare Flur -

Eine Gewalt - hoher als die Erbärmichkeit der Menschenhaufen: kann dir der feurige weinkrug geben. kann dir der perlende Weinstock geben!]

Ahnlich dynamische Gestaltungstendenzen weisen die späten Gedichte "ZSL 11 " und "Inwokacja" auf, die ebentalls in vierfüBlgen Jamben verfaßt sind. 
Dagegen ruft der 'sanfte' hyperkatalektische jambische Vierfüßer mit fast ausnahmslos weiblicher Zäsur nach der füften Silbe meist lyrische Liedhaftigkeit hervor. Dies gilt für den naturlyrischen zyklus "Echa zimowe" (EZ) ebenso wie für die melancholisch-stimmungshaften bzw. reflexiven " $R$ 46" und " $R 25$ ". womit sich LANGE vollkommen im Rahmen der "jungpolnischen" Verwendungsweise dieses Versmaßes bewegt (vgl. KOPCZYNSKA/MAYENOWA 1957:229).

Eine ganz ähnliche Funktion übernimmt bei LANGE der rhythmisch vergleichbare (meist akatalektische) vierfüßige Trochäus: Er gestaltet liedhaft-lyrisch geprägte Naturschilderungen ( Na roli; Zachód slońca; Nad stawem), aber auch Scherzi (Scherzo: MXynareczka) und Reflexionen ( $8,20,31$; DP 21: Sw 7).

Eine wenıger lyrisch, als dynamisch geprägte Liedhaftigkeit - oft Ergebnis eines katalektischen Gebrauchs des Trochäus zeichnet dagegen mehrere Gedichte politisch-geschichtsphilosophischen Charakters aus (DP 22; Chrabaszcze; ZSL 2, 5, 8, 9 ; Nieboska komedia).

\subsection{2. 'Standardversmaße'}

Haben sich für die Versmaße 'mittlerer Häufigkeit' (vgl. Abschnitt 3.3.1.) noch charakteristische Funktionsprinzipien feststellen lassen, so muß bei den beiden kaum 'markierten' 'Standardversen', die weit über die Hälfte aller LANGEschen Gedichte formen, eine solche Interpretation versagen.22 Doch auch bei der Verwendung dieser scheinbaren Allerweltsverse beweist LANGE sein Können auf formalem Gebiet.

Es ist gerade die 'Unauffäligkeit' dieser beiden Versmaße. die seinen besten Gedichten ihre scheinbar kunstlose, unaufdringliche überzeugungskraft verleiht. Zum anderen ermöglichen

22 Lediglich literarische Bezugnahmen lassen sich auch hier feststellen: So ahmt LANGE etwa in Gedichten, die auf DANTE anspielen (Boska komedia; Vita Nova), den italienischen Endecasillabo mit dem polnischen Elfsilber $(5 p+6 p)$ nach oder er führt in "Fragment [1]" wörtliche Zitate aus dem "Sonet V" des M. SĘPSZARZYNSKI (1973:11) an und übernimmt mit diesen auch das versmaß $(5 p+6 p)$ für das Gesamtgedicht. "DP 18. Wenedzi" und "DP 19. Atylla" richten sich im Versmaß nach den jeweils angesprochenen LANGEschen Tragödien $(5 p+6 p$ bzw. $7 p+6 p ; v g l$. unten Abschnitt $5.5 . ! 1$. 
gerade diese beiden, im Vergleich zu den bisher analysierten durch relatıv wenige vorgegebene Konstanten eingeengten versmaße eine kunstvolle Gestaltung der Gedichte durch zusätzliche subtile Rhythmisierungseffekte. (Dies zu zeigen, wird das Hauptanliegen des Abschnitts 3.4.2. sein.)

Insgesamt betrachtet lassen sich nur sehr allgemelne Unterschlede für die Wirkungsweise der beiden Versmaße bei LANGE angeben, die direkt mit ihrer Gestalt zusammenhangen: Der kürzere Elfsilber ist bei gleicher Zahl der rhythmischen Konstanten (paroxytonische Zäsur und Klausel) von Natur aus stärker rhythmisiert und bei gleicher Zahl der Reimsilben stärker lautlich organisiert als der längere Dreizehnsilber. Daraus ergibt sich die auch für LANGE gültige Folgerung, daß der Elfsilber graziler und zugleich dynamischer wirkt als der etwas wuchtige, manchmal fust bombastische und statische Dreizehnsilber. Zudem verführt letzterer durch seinen Umfang zu wortreichtum und mangelnder Prazision.

Diese Tendenzen kommen bei LANGE verschiedentlich zum Tragen und lassen $1 \mathrm{~m}$ a $1 \mathrm{lg}$ e me 1 ne $\mathrm{n}$ die elfsilbig gestalteten Gedichte als den bleibenderen Bestandteil in seinem Werk erschelnen."

Beide Versmaße werden vorzugsweise im "philosophisch-reflexi$v^{\circ}$ Bereich (A) verwendet. Daruber hinaus gestaltet der Dreizehnsilber vor allem 'politisch-sozlale' Themen (B), der grazilere Elfsilber aber bezeichnenderweise einen Teil der 'Liebeslyrik' (C).

\subsection{Die innere Gestaltung des einzelnen Gedichts}

Nachdem ich in den vorhergehenden Abschnitten versucht habe, im größeren Zusammenhang darzustellen, welche grundsätzlichen Versgestaltungen LANGE für welche Art der Darstellung in seinen Gedichten wählt, soll an dieser stelle die Frage untersucht werden, wie das - aus thematischen Grüden im weitesten sinne einmal gewählte Versschema im Einzelgedicht realisiert wird.

2) So ist es sicher kein zufall, daß J. Z. JAKUBOWSKI in seinem 1960 erschienenen Auswahlband (PW) von den 17 elfsilbigen "Rozmyślanıa" 13, von den 29 dreizehnsilbigen aber nur 12 abgedruckt hat (PW:105-154). 
so daß es im inneren Zusammenhang des einzelnen Gedichts zusätzlich bedeutungsstiftend wirksam werden kann. Nach der 'Grobabstzmmung' der Wahl des Versschemas steht jetzt die 'Feineinstellung' der metrischen und insbesondere rhythmischen Variation des Versmaßes zur Diskussion.

Die im folgenden analysierten Gestaltungselemente lassen sich letztlich auf ein einziges prinzip zurückfüren, das Moment der enttäuschten Erwartung. Dieses beruht darauf, daß in den traditionellen Verssystemen mit ihrer regelmäßigen (numerischen) Rhythmik im Gegensatz zu den modernen (nichtnumerischen) 'freien Versen' nur Abweichungen von der Norm expressiv verwertet werden können (vgl. CHRZĄSTOWSKA/WYSKOUCH 1974:132). Unter 'Norm' verstehe ich hier die neutrale, im Idealfall 'unmarkierte $e^{\cdot}$ Realisierung des jeweiligen Versmaßes, vollständige Beachtung der vorgegebenen Konstanten, aber auch nur dieser.

Selbstverständlich könnte theoretisch auch eine solche Gestaltung Bedeutung für den Gesamttext gewinnen, doch ware diese aufs engste mit dem Versmaß selbst verbunden: es würde quasi nur dessen - mehr oder weniger - charakteristische Diktion voll zur Geltung gebracht, und dementsprechend unspezifisch müßte die 'Bedeutung' einer 'unmarkierten' Versgestaltung bleiben, zumal sie sich nur auf das Gedicht in seiner Gesamtheit beziehen könnte.

Eigenständige Bedeutung erlangt hingegen nur eine irgendwie 'markierte' Realisierung, und dies immer nur für bestimmte Texttelse, die dann allerdings auf den Gesamtkontext zurükwirken.

\subsubsection{Metrische Besonderheiten}

Zunächst sollen in dieser Hinsicht die deutlicher ins Auge fallenden met $\mathrm{r}$ is $\mathrm{ch}$ e Abweichungen vom Normalschema untersucht werden, die LANGE einige Male als Gestaltungsmittel von Gedichtanfängen und -schlüssen, aber auch innerhalb der Texte verwendet. Es sind dies also Fälle, in denen die vorgegebenen Konstanten nicht vollständig beachtet werden.

So weisen die Anfangszeilen der Gedichte "R 54" und "Cienie" eine metrische Verkürzung auf $(5 p+6 p$ statt $7 p+6 p)$, was auch graphisch durch Einrückung und vorangesetzte drei Püktchen 
deutlich gemacht wird. Das Versmaß stabilisiert sich damit im Bewußtsein des Rezipienten erst im Verlauf der nächsten zeilen.

Dieser gleichsam zögernde, zurückhaltende Beginn korrespondiert mit der Eigentülichkeit dieser langen Gedichte, daß sie ihre Themat $1 k$ erst allmählich entwickeln, also einer längeren 'Expositzon' bedürfen:

...Nie moge bladzic po miescie bezkarnie. Mam takie dziwne miejsca, czarami zaklete. Co wiecznie budza we mnie pamiatek męczarnie. Na nowo moje rany krwawlac niezamkniete. Mam takj: nieme okna w martwych kamienicach, Takie clemne aleje w ciemnych parków gluszy. Takie zimne kamienie na pustych ulicach. Gdzie kryja sle umarle czastki mojej duszy. I nieraz - kiedy bladze - w ranki czy wieczory Nagle - niby spod ziemi rośnie me wspomnienie, Co wnet w rzeczywistości barwi sie pozory:

Ach, tu jej cleń pozostal - i mój cién - dwa cienie!

(crenie, vv. 1-12)

l ...Ich kann nicht ungestraft in der stadt umherschwelfen, Ich besitze solche seltsamen platze, mit zaubern verwunschen, Die ewig in mir qualen der Erinnerungen wecken, und aufs neue meine unverheilten wunden zum bluten bringen. Ich besitze solche stummen fenster in toten Hausern. Solche finsteren Alleen in der Einsamkeit finsterer Parks. Solche kalten steine in kalten straben. wo sich tote Teilchen meiner seele verbergen. Und manchmal - wenn ich umherschweife - am Morgen oder Abend Wächst plötzlich - gleichsam aus der Erde - meine Erinnerung Die sich sogleich in Wirklichkeitsschein färbt: [hervor, Ach, hier lst ihr schatten geblieben - und mein schatten [zwei Schatten!]

Erst an dieser stelle $(v, 12)$ erscheint die eigentliche Thematik des Gedichts, die dann über weitere 80 zeilen ausgefürt wird. Diese Art der Gestaltung steht bezeichnenderweise in deutlichem Gegensatz zu der für LANGE typischen zupackenden Konstruktion des Gedichtanfangs. So findet sich in den "Rozmyślania" kaum ein Gedicht, das seine Thematik nicht gleich zu Beginn in nuce formuliert, etwa: "Nic tak nie boli jako śmierćmarzenia" ([Nichts schmerzt so wie der Tod eines Traums]; R 15, v. 1). Dieser thematische Vorwurf wird dann gewöhnlich ausgebaut, varliert, in Frage gestellt, bis schließlich in einem Schlußteil eine Quintessenz - ähnlich prägnant - formuliert wird.

Diese wiederum ist häufiger durch metrische verkürzungen hervorgehoben, wodurch gleichzeitig das ganze Gedicht einen deutlichen Abschluß erhält. So endet das soeben angesprochene "R 15 " mit folgender summierenden Begründung der Anfangsthese: 


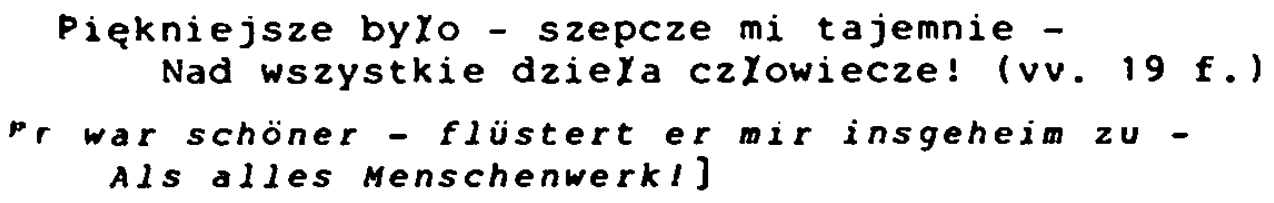

Nicht graphisch durch Einrückung, wie in diesem Fall, sondern lurch fehlende Reimbindung ist die metrisch verkürzte Schlußrointe in "DP 15" zusätzlich hervorgehoben:

A nad te krzyki - widma - szumy - kolysanki

Ducha pomnę, co krazy tam wieczyście zywy -

Litewskiej pieśni wieszczy duch... (vv. 12-14)

[Und mehr als an diese Rufe - diese Gespenster - dieses Rauschen [ diese wiegenlieder

Erinnere ich mich an den Geist, der dort ewig lebendig kreist An den Sehergeist des litauischen Lieds...]

Gleiches gilt für den stark verkürzten rhetorischen Schluß, der das Zentralwort im vierten Gedicht des "Przekleństwa"-zyklus, den pathetischen Imperativ "Przeklinajcie!...", auf den sich alles Vorhergehende bezieht, hervorhebt und das Gedicht wirkungsvoll schließt (vgl. Oben Abschnitt 2.2.2.).

In "R 29" steht eine - ebenfalls ungereimte - rhetorısche Apostrophe am Ende, die das in die vier Silben "Przeklęte Ja!..." ([Verfluchtes Ichl...]; v. 19) kondensierte Zentralmotiv des längeren Gedichts wirkungsvoll wiederholt und so den zweiten Teil des Werks ( $v v, 17-32$ ) zugleich als 'Ring' gestaltet.

Der verkürzte und ungereimte, gleichsam abbrechende Schluß von " $R$ 4" veranschaulicht zunächst ein inhaltliches Element (Unwissenheit), mit dem das Gedicht ausklingt. Dann hebt er aber auch den ganzen graphisch abgesetzten Schlußteil (vv. 31-33) hervor, dessen Bild sich nicht nur auf den direkt verglichenen vorhergehenden Teil (vv. 27-30) bezieht, sondern (durch Wortubernahmen und analoge Bildkonstruktion; vgl. die Verse $4 \mathrm{f}$. 9, 20) ebenso an die drei anderen Kompositionsabschnitte anknüpft, also eine zentrale kompositionelle Funktion im Gesamtaufbau des Gedichts erhält.

In "R 6" wird neben der Schlußpointe ( $v v .27$ f.) auch der Abschluß einer Reihe von Fragen im Gedichtinnern durch metrische Verkürzung hervorgehoben (v, 12). Zugleich verdeutlichen diese auffallig gestalteten Stelien im Zusammenwirken die beiden grundlegenden Kompositionsabschnitte des Gedichts: Leben als unverstandliches Chaos vs. Lösung des Rätsels durch den Tod, diesen Sinn des Lebens ("sens zycia"; v. 25). 
Die Gliederung des Textes kann schließlich auch durch einen - vom metrischen Grundschema unabhängigen - Refrain erfolgen. wie in "R 6?" deutlich wird. Das "Kto tam?" [Wer ist da?], das zudem als Titel exponiert ist, grenzt die drei 'Akte' des quasidramatisch aufgebauten Gedichts voneinander ab. (Am Rande sei vermerkt, daß LANGE in Vers 7 auf eine zäsur verzichtet, um die In den drei kurzen - asyndetisch gefügten - gleichgebauten Sätzen zum Ausdruck kommende Hast und Atemlosigkelt zu unterstreichen.)

Schließs zch dient metrische Abweichung im Textinnern zur Hervorhebung zentraler Aussagen, wie in "Mickiewicz" die zweifache Anknüpfung an ein als Motto vorangestelltes 2itat (III. v. 12: IV, v. 31: vgl. MICKIEWICZ 1948:163).

Sehr viel weiter, als in den bisher untersuchten fallen, geht die metrische Differenzierung in " $R$ 27": Nach vier regulären strophen $(5 p+6 p)$ verschiebt sich die Zäsur in den Versen 17-19 und nimmt oxytonische Gestalt an $(40+7 p)$, ab Vers 20 verkürzen sich die Zeilen allmählich (mit Ausnahme von Vers 21 !)

bis hin zu einem achtsilbigen schlußdistichon (vv. $23 \mathrm{f}$.):

Wciaz roje, zem sie oderwal od ziemi.

żem ponad ludzkie ulecralem cieśnie:

$\langle\ldots\rangle$

A przeciez ciagle zycie na mnie wola, I nieraz widze jakies sny dziecięce. Co mi śpiewaja jak cytry aniola I wyciagaja do mnie bıale ręce.

Lub wycie warg spienionych kurczem slysze,

I chóry lkań rozpaczy spazmatycznych.

I zgliszczów jęk, co mi rozdziera cisze

Lodowców moich krystalicznych.

Te cytr spiewania i ten rozgwar dziki

Dręczą ma zamyśloną dusze -

I we mnie budza okrzyki.

I na zlemie wracać muszę! (vv. I f., 13-24)

[Standig wahne ich, daB ich mich von der Erde losgerissen habe, DaB ich uber menschliche Engen emporgeflogen bin;

$\langle\ldots\rangle$

Und doch ruft das Leben standig nach mir,

Und manchmal sehe lch irgendwelche Kinderträume.

Die mir wie Engelszithern singen

Und weibe Hande nach mir austrecken.

oder lch hore das Heulen von im Krampf schaumbedeckten Lippen, Und chöre von spasmatischem Verzwelf lungsschluchzen.

Und das Klagegestöhn von Brandstatten was mir die Ruhe Meiner Kristallgletscher zerreibt. 
Dieses singen der zithern und dieser wilde Lärm

Quälen meine in Gedanken versunkene seele -

Und wecken in mir Schreie,

Und ich muB auf die Erde zurückkehren!]

Die Funktion dieser Gestaltung geht über die bisher vor allem konstatierte pointierende wirkung weit hinaus: Der anfängliche Traum, sich von der irdischen Wirklichkeit zu lösen, wird konventionell gestaltet. Ebenso das Locken dieser Wirklichkeit durch kindliche Glücksträume. Sobald aber die schlimmen Seiten des Daseins in das Bewußtsein des lyrischen Subjekts dringen, beginnt die schrittweise Auflösung des Metrums, um schließlich mit der Rückkehr aus dem Traum auf die Erde gänzlich zu zerflattern. Zugleich lllustriert das Metrum die wachsende Dynamik des Geschehens.

Noch stärker zum "vers libre" tendiert das schon zitierte "R 30" (vgl. oben Abschnitt 2.2.3.), das von vorneherein kein ganz festes Versmaß einführt. Die ersten 7 Verse oszillieren um den Dreizehnsilber $(7 p+6 p)^{2}$ und verbinden sich mit der scheinbaren - Möglichkeit einer Lösung des Lebensrätsels aus der neuen Perspektive, die der Tod briıgen soll (vgl. auch das schon erwähnte "R 6"!). Dann jedoch durchläuft der Vers verschiedene Transformationen ( $v v \cdot 8-11: 7 p+4 p$ bzw. 9p+4p), denen die Einsicht in die Vergeblichkeit dieser Hoffnung entspricht. Die Schlußzeile knüpt dann im kompositionellen 'Ring' metrisch $(7 p+6 p)$ und lnhaltlich an den Beginn an.

3.4.2. Rhythmische Besonderheiten

Ähnlich sparsam und effektiv wie Abweichungen vom metrischen Schema macht sich LANGE Elemente der $r$ hy $\mathrm{h}$ mischen Realisierung des vorgegebenen Versmaßes für die Gesamtaussage nutzbar. Hier handelt es sich zunächst um streckenweise Einführung zusätzlicher Konstanten, dann aber auch um Effekte, die sich aus einer - gleichsam sekundären - Durchbrechung solcher Konstanten durch abweichende Stellen oder andere zusätzliche Konstanten ergeben.

24 Eindeutig ist diesem Versmaß nur v. 2 zuzurechnen, während vv. 1, 3-5, 7 eine oxytonische bzw. proparoxytonische Zäsur (allerdings ebenfalls nach der 7 . Silbe: $70+6 p ; 7 p p+6 p)$ aufweisen, die sich jedoch teilweise (vv. 1, 4, 7) auch weiblich realisieren ließe. In $v .6$ schließlich ist das 1 . Versglied um 2 silben erweitert $(9 p+6 p)$. 
Im folgenden beschränke ich mich auf Beispiele aus dem Bereich des Dreizehnsilbers $(7 p+6 p)$, da dieser - wie erwähnt von Natur aus schwach rhythmisiert ist und sich deshalb rhythmisierende Eingriffe deutlicher abheben und uberzeugender darzustellen sind, als bei anderen versgestaltungen und auch dem zweiten 'Standardmaß' $(5 p+6 p)$.

Den elnfachsten Fall stellt eine streckenweise Rhythmislerung dar, die die betreffenden stellen vom ungegliederten Kontext abhebt:

In "R 9" wird das Gedicht durch eine anapästische Zeile abgeschlossen, wodurch der summierende Schluß hervorgehoben und zugleich der rhythmisierte Ablauf der gewüschten Handlung (drel Verben gleicher Struktur!) unterstrichen wird:

Obym wodzinie śmierci przeniknal te ciemnie

I ulecial, pozdrowil, pozegnal ja cieniem. (vv. 23 f.)

[DaB zch doch in der rodesstunde diese finsternisse durchdringen und als schaten wegfliegen, sie gruben, mich von ihr verab[schieden könnte.]

In "R 10" wird das Erklingen eines idyllischen Lieds (v. 4) durch alternierenden, das gerührte Lächeln unter Tränen ( durch anapästischen Rhythmus veranschaulicht.

Der Kontrast von langem Schweigen und plötzlichem Erdonnern des Prophetenworts wird in " $R$ " 3 " durch Gegenüberstellung von alternierendem und anapästischem Rhythmus deutlich gemacht:

Niechaj wiec dyugo warga twoja milczy niema,

Nim zahuczy plomienna gromami Jehowy. ( vv. 7 f.)

lMöge also lange deine lippe stumm schweigen, Bevor sie flammend mit Jehovas Donnern zu dröhnen beginnt.]

Diese quası 'lautmalenden' Wirkungen stehen in engem Zusammenhang mit dem schon aufgezeigten Gebrauch von syllabotonischen. aber auch bestimmten syllabischen versmaßen. Öfter besitzen solche Gestaltungen jedoch strukturierende Bedeutung:

Die letzte Strophe von " $R$ 37" ist von den drei vorhergehenden durch vollkommen durchgeformten alternierenden Versrhythmus abgehoben, so daß der hier gestalteten verallgemeinernden Schlußfolgerung (kollektives subjekt) aus dem persönlichen, bildhaft dargestellten Erleben und Fühlen (persönliches Subjekt) zusätzliches Eigengewicht verliehen wird.

Strukturierung durch Gegenüberstellung verschiedener zusätzlicher Konstanten wird in "R 32" errescht: Die (konstatierenden 
und dann neutral fragenden) Verse 1-6 sind durch alternierenden Rhythmus geprägt, der mit Beginn der nun folgenden schlimmen Befürchtungen von zwei anapästischen Zeilen (vv. 7 f.) abgelöst wird und schließlich in verschiedenartige Gestaltungen ubergeht. Im großen Block der alternierenden Verse wiederum sind einige Stellen durch Abweichung rhetorisch hervorgehoben: die personifizierende Apostrophe an den rod zu Beginn sowie die reimverbundenen amphibrachischen zweiten Teile der Verse 2 und 3 , die im ersten Fall den Schluß einer die verse 1 und 2 beherrschenden dreigliedrigen Klimax, im zweiten Fall das in den Versen 3 und 4 ausgeführte Bild enthalten:

Smierci, jam cie we wszystkie przyozdobll wdzieki. We wszystkie kwiaty marzeń i wszystkie nadzieje... Czy znajde w twym królestwie czarowna Eeje. Gdzie Cyrce niewidzialna leczy duchów jęki?...

Czy znajde zapomniense to i ukojenie. Którego tak potrzeba duchom umęczonym? Moze tam, za tym progiem istnienia zamglonym Nie ma nic? Moze śmierć - to najwyzsze zludzenie -

I klamstwo niepojete - mrok i sen kamienny,

I próznia - i zaprzeczeń wieczysta bezlicość -

I zgnilizna bezduszna - i nicość - i nicość...

Smierci, a jam cie przybral w zloty plaszcz bezcenny!

[rod, ich habe dich mit allen Reizen geschmückt, Mit allen Traumblüten und allen Hoffnungen... Werde $1 \mathrm{ch}$ in deinem Reich ein zauberhaftes Aiaia tinden, wo eine unsichtbare Karke der Geister Klagegestöhn heltt?

Werde ich das vergessen und die linderung finden. Die den müden Geistern so nötig ist? vielleicht ist dort, hinter dieser verschwomenen schwelle des Nichts? Vielleicht ist der Tod - die höchste Täuschung -

Und eine unbegreifliche Luge - Finsternis und bleierner schlaf, und Leere - und ewige Gesichtslosigkeit von Negationen und seelenlose Faulnis - und Nichts - und Nichts!... Tod, und ich habe dich in einen goldenen, unschatzbar wert[vollen Mantel gekleidet.]

Ein eindrucksvolles Belsplel für die Hervorhebung von wichtigen Teilen bietet das Sonett " $R$ 24", das fast vollständig jambisch gestaltet ist. Dieser Verscharakter wird durch die teilweise um eine Silbe verkürzten, oxytonischen Zellen mit männlichem Reim unterstrichen. Daß es sich hierbei nicht um syllabotonik handelt, wird allein durch vers 3 deutlich gemacht, der abweichend gestaltet ist und durch diese Besonderheit den emotional am stärksten geladenen, die vorhergehende Aussage konkretısierenden Teil hervorhebt: 
Źem niósl zbyt nieostroźnie swoje serce w świat, Przetom dzis ukarany... żem go nie kryl ślepy. Ale zem je wystawial na ludzkie oszczepy.

Rozbilo mi je zycie, jak pszenice grad. (vv. 1-4)

[Weil ich mein Herz zu unvorsichtig in die welt getragen habe, Deshalb bin ich heute bestraft... Weil ich es nicht verborgen

lhabe, ich Blinder,

Sondern weil lch es den Speeren der Menschen ausgesetzt habe. Hat es mir das Leben zerschlagen. wie den weizen der Hagel.]

Die übrigen 'hypermetrischen' oder (zu Versbeginn) 'antimetrischen Betonungen des Gedichtes, die einer syllabotonischen Interpretation nicht im Wege stünden, heben vor dem jambischen Hintergrund ebenfalls einige stellen rhetorisch hervor (vgl. die Verse $2,8,11,121$.

\subsection{Zusammenfassung}

Obwohl sich LANGE bei seiner Versgestaltung fast ausschlleßlich an traditionellen syllabischen und syllabotonischen Mustern orientlert, er also wie die meisten seiner Generationskollegen nur sporadisch an zukunftsweisenden versifikatorıschen Neuerungen betelligt ist, stellt er doch, wie lch zu zeigen versucht habe, gerade auf dem Gebiet der Versgestaltung seine Fähigkeiten unter Beweis. Er vermag den einzelnen Gedichten durch entsprechende Wahl seiner versifikatorischen Mittel ein individuelles Aussehen zu verleihen, ja in vielen fällen den Versbau zu einem entscheidenden Element der Gesamtaussage zu machen.

Dies gilt für seltene, also an sich schon stärker 'markierte' Gestaltungen ähnllch wie für weniger ungewöhnliche oder gerade$z u$ 'standardisierte' Versmaße $(7 p+6 p ; 5 p+6 p)$. Allerdings lassen sıch für die in weit über der Hälfte seiner Gedichte verwendeten 'Standardmaße' - abgesehen von einer sporadischen Gestaltung literarischer Bezüge - nur sehr allgemeine Wirkungstendenzen im konkreten Textganzen feststellen; vor allem zeichnet sie beide eine bewußte 'Unauffälligkeit' aus, die bewirkt, daß insbesondere in LANGES reflexiv geprägter Lyrik die Aufmerksamkeit auf die im Vordergrund stehende 'Aussage' konzentriert wird und kein Eindruck einer 'Spielerei' entstehen kann.

Die stärker 'markierten' Versgestaltungen hingegen übernehmen - wie ausfürlich belegt wurde - genauer abgrenzbare Funktionen: Sie knüpfen literarische Bezüge, werden zu Lautmalerei und Dyna- 
misierung verwendet, verleihen der Aussage liedhaften oder volkstümlich einfachen Charakter.

Spezifische Realisationen der vorgegebenen Versschemata verdeutlichen schließlich vor allem kompositionelle strukturen und Gewichtungen innerhalb der Einzeltexte.

Die 'Wahl' des Versmaßes hängt demnach von 'inhaltlichen'. seine konkrete Realisation vor allem von 'kompositionellen' Gesichtspunkten ab. 
Ein besonders wichtiges Element von LANGES poetischer Sprache ist die Verwendung vieler 'Schlüsselwörter', das heißt, von wörtern (und sich daran anschließenden Wortfeldern), die in seinen lyrischen Texten eine höhere relative Häufigkeit aufweisen, als sie es in der allgemeinen Schriftsprache tun. Auf diese Weise sind sie vom 'normalen' Sprachmaterial sezner Texte mehr oder weniger deutlich abgehoben und gewinnen besonderes Gewicht (vgl. SKAWINSKI 1976:408).2"

Es handelt sich dabel einmal um Ausdrücke, die in den Texten nicht nur relativ, sondern auch absolut gesehen sehr häufig auftreten. wa die Substantzve 'duch'. 'dusza', 'serce', 'zycie'. 'byt', 'smzerć', 'lza', 'sen' (in der Bedeutung [traum]), 'cisza'. 'kwlat', 'zorza', 'slońce', 'mrok', 'otchlań', 'glab'. 'bóg'. 'niebo', 'fala', 'pleśn'; die Adjektıve 'wlecznv' I'wleczysty'), 'tajemniczy', 'zloty'; die Verben 'bladzic' und 'plynaćc'.

Dazu kommen - absolut betrachtet - etwas wenıger häufige wör ter, die aber in der standardsprache eine relativ niedrigere Frequenz aufwelsen, wie die Substantive 'cien'. 'widmo'. 'nieskończonośc'. 'blękit', 'dal', 'kres', 'aniol', 'mogila', 'grób'. 'tajemnzca'. 'toń', 'rozpacz', 'marzenie', 'mara', 'czar', 'róza'. 'wicher', 'grom', 'chmura', 'gwlazda'. 'tecza', 'promień'. 'noc'. 'mgla'; die Adjektıve 'daleki'. 'nieznany'. 'clchy'. 'czysty'. 'czarny', 'bialy'. 'promienny'.

2s Mangels statistischer Hilfsmittel muß ich mich bei der Erarbeitung dieser Wortgruppen - nach dem Vorbild K. WYKAS 11969: $216 \mathrm{f.l}$ - auf den gesunden Menschenverstand und eine gewisse Dosis Gefühl verlassen. - Ich setze LANGES Wortschatz bewußt in Bezug zur allgemeinen Schriftsprache seiner zeit, und nicht etwa zur Sprache der Lyrik seiner Epoche (zumal diese erst detailliert erforscht werden müßte), um neben seinen individuellen zügen auch die für die Lyriker seiner Generation spezifischen Sprach- und Denkstrukturen, sowelt sie in seinem Werk zum Ausdruck kommen, erfassen zu können, zumal die Untersuchung von LANGES Dichtungssprache in dieser Arbeit eben auch ein Beitrag zur Erforschung 'jungpolnischer" Poetik sein soll. Der Begriff "Schlüsselwort" wird von mir also in einem sehr weiten sinne gebraucht, um ein möglichst abgerundetes Bild des von LANGE verwendeten Wortmater als zu gewinnen. 
Schließlich sind noch wörter anzuführen, die zwar auch bei LANGE nur einige Male auftreten, in der allgemeinen Schriftsprache aber - relativ gesehen - außerordentlich selten sind, wie die Substantive 'bezmiar', 'calun', 'kir', 'żal', 'swit'. 'planeta'. 'cud'. 'kolysanka'; die Adjektive 'cmentarny' und 'ponury'.

In den meisten dieser Fälle wird die 'Schlüssel'-stellung der einzelnen wörter dadurch zusätzlich deutlich, daß sie sich untereinander $2 u$ eng zusammengehörigen stilistischen feldern verbinden oder solche zusammen mit anderen, zunächst weniger hervorstechenden wörtern bilden.

Die Erstellung und Interpretation solcher Wortfelder wird im Zentrum dieses Kapitels stehen, eröfnen sie doch wichtige Einblicke in die Mechanismen der poetischen semantik (SKAWINSKI 1976:408; vgl. auch WYKA 1969:229), die in LANGES Gedichten wirksam werden. Neben bestimmten ubergreifenden Motiv- und Themenkomplexen können auf diese Weise vor allem durchgehende Vorstellungs-, Wertungs- und Stimmungsgehalte der Lyrik sichtbar gemacht werden (WYKA 1969:216). Wohlgemerkt kann es sich bei einer solchen Interpretation der Schlüsselwörter nicht um die Konstituierung eines rationalen Denkgebäudes handeln, die zudem schon ausfürlich und auf der angemesseneren Materialbasis vor allem den theoretischen Schriften des Autors - geleistet wurde (SZYMANSKA 1979). Es soll hingegen die in der Lyrik als solcher begründete " $p$ e $t$ is che we $1 t^{\prime}$ erschlossen werden, ein System von Bildern und Begriffen, die ständig als konstitutive Elemente in verschiedene thematische Zusammenhänge eingehen und diese wesentlich prägen. Dem schon erstellten philosophischen Denkmodell (SZYMANSKA 1979) kann hierbei lediglich eine Hilfsfunktion zukommen: Es vermag die geistesgeschichtliche Einordnung und inhaltiche Interpretation einiger Begriffe zu erleichtern.

Neben der semantisch-strukturellen Deutung, die vor allem die Funktion der herausgearbeiteten wortfelder innerhalb der Einzeltexte und schließlich im Rahmen des lyrischen Gesamtwerks aufzuzeigen hat, ist mlt Hilfe der Schlüsselwörter, zumal diese bel LANGE so zahlreich sind, auch eine stilistische Tellcharakterisierung seznes dichterischen wortschatzes mög$11 \mathrm{ch}$. 
4.1. Philosophisch und religiös geprägte Grundbegr iffe

Zunächst ist elne Reihe von - meist abstrakten oder zumindest immaterielien - Schlüsselwörtern samt 'stilistischen Feldern' anzuführen, die allgemeingultige Grundbegriffe philosophisch, teilweise auch religiös geprägter Reflexion bezeichnen. Sie dienen zur Umschreibung der für LANGES Gedankengebäude zentralen Kategorie der Transzendenz oder des Absoluten, das den Kern des Weltganzen bildet (vgl. die Abschnitte 4.1.2.-4.1.5.) und sich im geistigen Bereich des Menschen manifestiert (vgl. Abschnitt 4.1.1.).

\subsubsection{Die geistige Sphäre im Menschen}

Zu den Schliusselwörtern mit dem absolut höchsten Vorkommen zählen bei LANGE die substantive 'duch' [Geist] und 'dusza' [seele], mit Abstrichen auch 'serce' [Herz]. So erscheinen die beiden ersten z.B. in fast der Hälfe aller Gedichte des "Rozmyślania"-zyklus mindestens einmal, oft zwei-, dreimal und noch häufiger. 'serce' immerhin in fast einem Viertel dieser Gedichte mindestens einmal.

Die drei Substantive bezeichnen zunächst die geistigen Elemente des Menschen im Gegensatz zum Körper: "Cialem zyje w tym czasie, na tutejszym globie, / Ale duch zamieszkuje odmienne regiony" ([Mit dem Körper lebe ich in dieser zeit, auf dem hiesigen Globus, / Aber der Geist bewohnt andere Regionen]; $R 39$. vv. 3 f.); "Dusze swą, cialo <...> Ofiarowalem Tobie" ([Meine Seele, meinen Körper <... Habe ich Dir geopfert]; DP Epi.. vV. 1 f.). Dabei ist 'serce' zusätzlich als sitz der Gefühle im Gegensatz zum kalten Verstand eingegrenzt: "Dzisiaj nasze serce/ Tak mózglem przesiąknięte, ze juz być nie umie / Sercem. Samo sie mózgiem stalo." ([Heute ist unser Herz/ so von Gehirn durchtränkt, daB es kein/Herz mehr sein kann. Es ist selbst zu Gehirn geworden.]; Nie. jam wcale nie kochal, vv. 8-10); "Serce - jest to najwiekszy skarb ludzkiego ducha, / wiekszy nad wiedze, rozum, geniusz." ([Das Herz - ist der gröbte schatz. des menschlichen Geistes, , Ein gröberer als wissen, verstand, Genie.]: Impromptu, vv. $13 \mathrm{f}$. ). 
Wie M. PODRAZA-KWIATKOWSKA gezeigt hat (1975:161-166), ist die besondere Popularität des Begriffs 'dusza' in der jungpolnischen Dichtungssprache neben der traditionellen, religlös und (idealistisch-)philosophisch geprägten Dualismus-Konzeption vor allem auf neue Aspekte der Psychologie ('Unbewußtes' und 'Unterbewußtes ${ }^{\circ}$ ) und Parapsychologie (angebliche Materialisationen des 'Astralleibs' der Seele) zurückzuführen, die mit den überkommenen Vorstellungen eine symbiose eingehen. Auf diese Weise wird die 'Seele' $z u$ einem wichtigen Erkenntniselement: Das $\varepsilon r-$ gründen ihres Geheimnisses würde zugleich ein Ergrunden des Geheimnzsses des seins bedeuten (ebd.:165).

Diese neuen Einflüsse verbinden sich auch bei LANGE mit der traditionellen Fassung $z u$ einem verschwommenen 'Seelen'-Begriff. So erscheint psychologisches Gedankengut ( $R$ 38; zitiert in Abschnitt 3.2.2.): spiritistische Elemente weist "R 9" auf (der 'Astralleib" wird als schatten bezeichnet; v. 15).2" Und auch be 1 LANGE führt der Erkenntnisprozeß über die 'Seele' zu den Urgründen des Seins: "Dusza z tych pęt wyrwana / w linie sie zmienia, w punkt bezprzestrzenny, czysty, / Przez który zda sie przelamana - / Drga tajemnica wszechjedni wieczystej" (lDie seele, von diesen fesseln losgerissen, / Verwandelt sich in eine Linie, in einen raumlosen, reinen punkt. / Von diesem scheint es - durchbrochen, / Bebt das Geheimnis der ewigen AllEinheit]; R 26, vv. 12-15; vgl. oben Abschnitt 2.1.1.).

Bezeichnenderweise macht LANGE den Begriff 'seele' nicht, wie PODRAZA-KWIATKOWSKA (1975:162) für die jungpolnischen Dichter allgemein konstatıert, zu einem Quasi-Gesprächspartner in Dialogkonstruktionen und Apostrophen, der dem lyrischen Ich die zwischenmenschlichen Beziehungen ersetzt. LANGES 'dusza' ist reines objekt der (meist streng rationalen) Reflexion, ja sie dient oft (wie noch ausgeprägter: 'duch') gerade zur objektivierung von selbstbetrachtungen, die gleichsam auf ein anderes Wesen projiziert werden (vgl. ebd.).

2. Vg1. MACHALSKI 1937:42. Dagegen vermag ich seiner Interpretation (ebd.:48) des von mir als Beisplel für den Bereich des "Unbewußten" angeführten Gedichts "R 38" (vgl. oben Abschnitt 3.2.2.) nicht zu folgen. Er sieht in ihm die Beschreibung der Wirkungswelse des indischen Begriffs 'Maja'. der den Illusionscharakter der materiellen Wirklichkeit bezeichnet. Vgl. dazu auch unten Abschnitt 4.2.2.! 
In ganz ähnlichen Sinnzusammenhängen wie 'dusza' verwendet LANGE den noch vieldeutigeren Begriff 'duch', so daß eine Abgrenzung $z$ wischen beiden im Bedeutungsbereich gelstage Schicht des Menschen" kaum durchzuführen ist. So werden beide Ausdrücke 2.B. in den Kontexten "ulatać" ([wegfliegen]; vgl. R 3,v. 11 vs. R 9, v. 4: außerdem "wzlatac" [auffliegen] in $R$ 5, v. 4) und "rwać sie" ([sehnlichst nach etwas verlangen]; vgl. R 18 , v. 2 vs. R $36, v .3$ ) verwendet, beide weisen tiefen auf ("tonie": R 41, v. 22 vs. "glabie": R 57, v. 27) und werden als krank bezeichnet ("chory": $R 26, v .4$ vs. $R 51, v, 19$ und $R 55, v, 8$ ).

Der Begriff 'duch' nimmt in LANGES philosophischer Konzeption einen wichtigen Platz ein: Das wahrhafte Seln ist geistiger Natur, und auf ein geistiges Absolutum hin entwickeln sich Natur und Geschichte (SZYMANSKA 1979:21, 28). Alles Materielle hat Anteil am Geistigen: "Tak to duch rozlany jest wszedzie. Nie ma ducha bez materii, jak nie ma materii bez ducha" ([so ist also der Geist uberall vergossen. Es gibt keinen Geist ohne Materie, wie es keine Materie ohne Geist gibt]: A. LANGE: Studia z wrazenia. Warszawa 1900:4: zitiert nach SzYMANSKA 1979:221. Dieses allgemeingullıge geistige Element im Materiellen ist bei LANGE stärker mit dem Gebrauch von 'duch' als von 'dusza' verbunden, 'duch' wirkt insgesamt unpersönlicher und abstrakter. als das konkret und gestalthaft dargestellte. Oft substantiell vorgestellte 'dusza' (vgl. auch PODRAzA-KWIATKOWSKA 1975:161 f.). Zwar wird auch 'duch' oft personifiziert (vgl. die entsprechenden schon angefuhrten Beispiele), doch handelt es sich hierbel um einen reinen Tropos, zumal 'duch' in diesen fällen mit der Gesamtperson praktisch identisch ist."'

2'Am Rande sei vermerkt, daß LANGE den Begriff 'duch' - gleichsam in Personalisierung der gelstigen Seite des Seins - auch im sinne von geistiges wesen" bls hin zu 'Gespenst" verwendet: "duchem bezcielesnym" ([ein körperloser Geist]; R 48, v. 14), meist im Plural gebraucht: "zamogilne duchy" ([jenseitige Geister]: R 51, v. 7): "Chcesz <... plynać / do krain czystych, / do wniebowziętych / duchów świętych" ([Du willst <... zu reinen Gefilden flieben, / zu himmlischen,/heiligen Geistern]: $R$ 36, vv. 14 bis 19) und weiter: "Czy sa w blekicie / przestrzenie, / gdzie duchy-cienie / zyja takim zywotem?" ([Gibt es im Himmelsgefilde) Räume, wo Geister-schatten, ein solches [eben leben?]: R 36 . vv. 22-25). Das letzte Beisplel verweist zudem darauf, daß im gleichen Sinne teilweise auch 'cień' [schatten] gebraucht wiró (vgl. etwa auch: R 55, v. 8: R 63-1, v. 10: DP 16, v. 5), ähnlich wie die mehrfach verwendeten Substantive 'wldmo' und 'upiór' 
Insgesamt betrachtet, verweisen die drei Schlüsselwörter 'duch'. 'dusza' und 'serce' bei LANGE auf eine im Gefolge der philosophischen Gesamtkonzeption bewußt hervorgehobene geistige Sphäre im Menschen (und darüber hinaus), der so eine zentrale Position in seinen Reflexionen zugewiesen wird. Dieser Bereich wird zwar einige Male direkt thematisiert (vgl, R 23, 38, 57). ist aber vor allem aufgrund der ständigen Verwendung der genannten Schlüsselwörter durchgehend präsent. Die poetische Wirkungskraft der wörter selbst ist hingegen durch ihre häufige, of unmotiviert anmutende Verwendung stark eingeschränkt, so daß diese dem heutigen Leser oft als unnötiger Ballast erscheinen.

\subsubsection{Kategorien des 'Absoluten'}

Ein ähnlicher semantischer 'Verwaschungsprozeß" läßt sich für das Wortfeld 'Ewigkeit'. 'Unendlichkeit'. 'Unermeßlichkeit' feststellen: Ihrer philosophischen Herkunft nach vollkommen berechtigt in der Lyrik des 'Jungen Polen' (unaufhörlicher Entwicklungsgang des Weltganzen, ewiges absolutum, etc.; vgl. SzYMANSKA 1979:35-37), verlieren die wörter 'wieczność [Ewigkeit], 'nieskończonośc' [Unendlichkeit], 'bezmiar' [Unermebljchkeit] und insbesondere ihre verschiedenen, von LANGE besonders zahlreich verwendeten adjektivischen Abkömmlinge ('wieczny'. 'wieczysty', 'wiekuisty', 'nieskończony', dazu 'na wieki'; außerdem: 'nieustanny'. 'bezustanny' [unaufhörlich]; 'bezgraniczny', bezkreśny' [grenzenlos]; 'bezbrzezny' [uferlos]; 'niewymierny' [unermeBlich]) durch ständige Verbindung mit den verschiedensten Aussagebereichen einen Teil ihrer Ausdruckskraft: "Pod rozczarowań cmentarzyskiem smutniem, / Co twarz mi w wieczna przyodzialy bladosć" ([Unter dem traurigen Friedhof von Enttäuschungen, / Die mir das cesicht in ewige Bleichheit gekleidet haben]; R 16, vv. 5 f.l: "W pamieci mojej wieczyście stać bedzie / Ten dziwny świat" ([In meiner Erinnerung wird / Diese seltsame Welt ewig bestehen]; R 54, v. I f.).

(samt zugehörigen Adjektiven 'widmowy' und 'upiorny'). Der im jungpolnischen Verständnis der Begriffe 'duch' und 'dusza' angelegte übergang von der Immanenz zur Transzendenz wird hier explizit vollzogen. 
Dies darf Jedoch nicht darüber hinwegtäuschen, daß bei LANGE meist elne präzise Verwendung und Rezeption dieser Begriffe auch in scheinbar "harmlosen" Kontexten - intendiert ist: "Fala mi śpiewa - fala szelésci - / W bezmiary ducha rozszerza" ([Die Welle singt mir - die welle rauscht - / In die Grenzenlosigkeiten <mystisches Erleben!> erweitert sie den Geist]; Sw 9, vv. 15 f.).

Dafur spricht auch die explizite Thematisierung des Begriffsbereichs 'Ewlgkeit" in "R 20" ("wszystko - wieczne" lalles ist ewig): v. 20) und "R 48" ("Bo Proteusz, bóg wyklety, / Choć wiecznie inny, jest wiecznie ten sam" [Denn proteus, der ausgestokene Gott, ( Obwohl immer ein anderer, ist immer derselbe]; vv. $41 \mathrm{f}$.$) unter ausgiebiger Verwendung des entsprechenden Wort-$ schatzes.

\subsection{3. 'Raum' und 'Ferne'}

Die explzzit metaphysischen Formeln 'Ewigkeit'. 'Unendlichkelt'. 'Unermeßlichkeit ' werden durch die in dieser Hinsicht nicht festgelegten Begriffsfelder 'Raum' und 'Ferne' ergänzt. Erst der jeweilige Kontext verleint den Begriffen 'przestrzen'. 'przestwor' (auch adjektivisch: 'przestworny'), 'przestworze' [Raum] bzw. [raumlich], 'roztocz' [weite Flache], 'kraina' und auch 'ukralna' [Land, Gebiet], 'region'. 'strona' [Gebiet] sowie 'dal', 'oddal'. 'oddalenie' [Ferne], 'daleki'. 'dalny' [fern] in vielen Fallen eindeutig transzendenten charakter: "bezgraniczne przestworza" ([grenzenlose Raume]: R 50, V. 50): "Tajemnych krain bytu misterni pajacy" (CDie meisterhaften spinnen der geheimen Gefilde des seins]; R 9, V. 5): "Innych bytów ukraina" ([Das Gefilde anderer seinsweisen]; R 34, v. 40); "Musze plynąc w dal - / W te krainy niepojemne" ( [I ch muB in die Ferne flieben - I In diese unverstandlichen Gefllde]; $R 49$. vv. 9 f.l: "Przychodze do was z daleka, / Przychodze $z$ nzeznanych stron" (lich komme zu euch von ferne, I Ich komme aus unbekannten Gegenden]: $R$ 64-3, vv. $1 \mathrm{f}$. und $55 \mathrm{f} .1$; "Drogie oczy <...> Gdzie wy? Jakie was kryja mgly, jakie oddale? / Jakie nieskończoności zlote i ogromne?" (lteure Augen <... > wo seid lhr? Welche Nebel, welche Fernen verbergen euch? / Welche goldenen und gewaltigen Unendlichkeiten?]; R 63-3, vv. 17-20). 
Da LANGE diese Begriffe auch im üblichen Sinne verwendet. entsteht eine interessante Spannung in weniger eindeutigen Kontexten. Es bleibt hier - scheinbar - dem Interpreten überlassen, ob er dem Text eine metaphysische Ausdeutung geben will: "Gdziekolwlek jesteś, chcialbyś odejść w dal" ([Wo auch immer du bist, würdest du gerne in die ferne fortgehen]; R 1, v. 5); "Idź za tym klonów zielonym sklepieniem, / W ściezek dalekie wpatrzon perspektywy - / A wstaniesz olśnion swoim objawieniem" ([Geh diesem grünen ahorngewölbe nach, / Versunken in den Anblick der fernen perspektiven der pfade - / Und du wirst auferstehen, erleuchtet von deiner offenbarungl; R 64-4, vv. 18-20).

4.1.4. 'Ende', 'Grenze', 'Ufer'

Auf ähnliche Weise erhalten die Schlüsselwörter 'kres'. 'kraniec' [Ende, Grenze], 'rubiez' [Grenze] sowie 'brzeg' [ufer], 'pobrzeze'. 'wybrzeze' [Küstenland] kontextuell metaphysische Bedeutung oder bezelchnen den Grenzbereich von Immanenz und Transzendenz: "ostatecznych siegajacy kresów <... J Jakby wyszedlszy poza kres przestworów" ([die äuBersten Grenzen erreichend <... Gleichsam das Ende der Räume überschrjtten habend]; R 27, vv. 6 und 10); "Jak dobrze by oglądać świat z innego brzegu" ([wie gut wäre es, die welt vom anderen Ufer aus zu betrachten]; $R$ 54, v. 80); "Tak my ciagle <... opuszczamy cudowne jakieś weneckie pobrzeza - / I plyniem w nıcość jutra do tych krańców, / Gdzie cala przeszlośc w zlote slońca sle rozszerza" ( dig $\langle. . .>$ irgendwelche wunderbaren venezianischen Gestade - / und flzeBen in das Nichts des Morgen zu den Grenzen, / Wo sich dze ganze Vergangenheit zu goldenen sonnen erweitert]; $R 33$, vv. 13-16; vgl. oben Abschnitt 3.1.2.); "Wybiegam poza kres jego rubiezy // W dalekie jutro..." ([Ich laufe über das Ende seiner <d.h. des unreinen spiegels des äuBerlichen flusses> Grenzen hinaus // In das ferne Morgen]; R 14, vv. $6 \mathrm{f.l}$.

Vor diesem Hintergrund gewinnen - nach dem gleichen Muster wle im Begriffsbereich 'Raum'/'Ferne' - scheinbar einfache Aussagen eine zusätzliche Deutungsdimension: die Rolle als Schlüsselwörter unterstreicht die (teilweise) doppelte semantisierung der entsprechenden Begriffe: "Az-ci tajemna sila mie uniesie / Na kres nieznany - i tam spotkam ciebie!" (lEine geheimnisvolle 
Kraft wird mich forttragen / An eine unbekannte Grenze - und dort werde zch dich treffen]; R 18, vV. 23 f.). Ganz ähnlich unbestimmt bleiben "daleka kraina" ([fernes Land]; v. 8) in "R 9" und "oddalenie" sowie "przestworna cisza" [fferne] bzw. [stille des Raums]; VV. $18 \mathrm{f}$. ) In "R $17 "$ " wo ebenfalls Kontakt mit der Geliebten aufgenommen wird. Der weg führt in beiden Fàlen scheinbar ganz irdisch über Berge und flüsse ("góry i rzeki"; R 9, V. 17; R 17, v. 3). Erst eine Einbeziehung von "R 12 " brächte die völlıge Gewißheit, daß die Geliebte tot ist. und die doppeldeutigen Ausdricke sich auf das Jenselts beziehen.

\subsubsection{Begriffe aus dem religiösen Bereich}

Elne weltere Gruppe von Wortfeldern konkretisiert die Sphäre des Transzendenten durch Anknipfung an - vorwiegend christliche - Glaubensbegriffe: 'zaślaty' [Jenseits], 'zaświtowy'. 'zagrobowy'. 'zamogilny' [jenseitzg]: 'nieziemski' [unirdisch], 'nadziemski' [überirdisch] und 'nadziemianie' [die Uberirdischen]: 'niebo' [Himme1]. 'niebieski'. 'nlebiański'. 'podniebny'. 'wniebowziety' [himmlisch]; 'świety' [heilig], dazu 'święośc'; 'nleśmiertelny' [unsterblich], dazu 'nieśmiertelność'; 'bóg' [Gott]. 'boski' [göttlich]. 'bozy' [göttlich, cottes...], 'bóstwo' [cottheit], 'bogini' [Göttin]; 'aniol' [Engel], 'archaniol' [Erzengel]. dazu 'anielski' und 'archanielski'.

Trotz der differenzierten und reichlich verwendeten Begriffe aus dem religiösen Bereich oibt es bei LANGE keine Gedichte, die diese Sphäre als solche thematisieren: sogar die "Ksiegl proroków" und die entsprechenden Teile des "Logos"-zyklus sind eher philosophischer denn religiöser Natur. Allenfalls wird sporadisch das eigene. sich wandelnde Verhältnis zur Religion dargestellt (vgl. Prz 8; R 61), eine persönliche Reflexion in einen religiösen Rahmen eingebettet (vgl. R 12: DP Epi.) oder mit einer Anrufung Gottes abgeschlossen ( $R$ 60; Bezsenna noc).

Dagegen verwendet LANGE die angefihrten Begriffe aus der relıgiösen Sphäre sehr häufig dazu, metaphysische - seltener explizit religiöse - Bezüge innerhalb verschiedenster Themenbereiche herzustellen. Als Beispiel dafür möge die Verwendung des stark 'markierten' Begriffs 'Engel' bzw. 'Erzengel' dienen:

Der religiöse Rahmen wird in dem schon erwähnten "R 12 " $u$.a. mit Hilfe dieses Begriffs geschaffen: "O Lillo moja, jeśli tam 
u Boga / Pomiedzy srebrne wstapilaś anioly" (lo meine Lilla. wenn du dort bei Gott/In die Schar der silbernen Engel gekommen bist]: vv. 1 f.l: der Tod wird als Engel positiv gezelchnet: "Jak aniol bialoskrzydly śmierć mi sie uśmiecha" ([w1e ein weibgeflügelter Engel lachelt mir der Tod zu]; R 10, V. 2; ebenso: DP 21, v. 5), wobei aber diese Wertung durch Entgegensetzung des Begriffs 'Hölle' auch in Frage gestellt werden kann: "Glos to piekiel czy aniola?" ([Ist das die stimme der Höllen oder eines Engels?]; R 8, v. 3). Ebenfalls dem metaphysischen Bereich im weitesten Sinne gehören die unbekannten stimmen an, die mit einem Lied der Engel verglichen werden ("niewladome glosy <...> jako pieśn aniolów": R 39, vv. 9 f.). Mehrfach endet das Naturerlebnis mit einem Einbrechen der transzendenten Sphäre, das durch Engelsgeflister ("Szeptem aniolów": R 18, v. 17) oder das Herabsteigen von Erzengeln (DP 14, v. 13) angedeutet wird und im ersteren Fall tatsächlich in ein konkretes mystisches Erleben übergeht.

Doch dienen Engel (R 50, v. 55; Prz 1, v. 8; Sonet [1], v. 7). Engelszithern ("cytry aniola": R 27, v. 15) oder ein götllcher Engelschor ("chór aniolów boskich"; W imionniku R. D. $v$. 12) auch $z u$ verschiedenen dichterischen vergleichen bei ganz 'irdischen' Reflexionen, Belehrungen oder Träumen, als volkstümliches Requisit im scherzohaften Liebeslied (Pieśni o pocalunkach 2, v. 23), zur Anspielung auf biblische Ereignisse ( $R$ 50, v. 11: Prz 3, v. 9) oder zur Allegorisierung des reinen Revolutionsgedankens, der sich grausamer Werkzeuge bedienen muß: "Blaly aniol z krwawym mieczem" ([Ein weiber Engel mit blutigem Schwert]: Pog 11, v. 181.

In den meisten Fällen ruft die Verwendung des Begriffs 'Engel' mehr oder weniger deutliche Assoziationen mit dem religiösen oder metaphysischen Bereich hervor, wodurch die jeweiligen Kontexte entsprechend 'gefärbt' werden. Analoges gilt für die ubrigen Begriffe, die der religiösen Sphäre entstammen.

Als besonders deutliches Beispiel für diesen Mechanismus kann der zyklus "Na Switezi" dienen: Die ständige Verwendung der Begriffe 'święty', 'boski', 'bozy', 'bóg'. 'bóstwo', 'niebieski'. 'nlesmiertelnośc', u.a. - auch in bezug auf Naturgegebenheiten (wasser, Wellen und die stllle werden als heilig bezelchnet) macht den See zum 'Heiligtum' des Dichters MICKIEWICZ, der 
selbst in metaphysische Spharen erhoben wird: "W powietrzu swięty pyynie duch, / Duch świety Mickiewicza" ([ In der luft fliebt der heillge Geist, / Der heilige Geist Mickiewlcz']; Sw 1. vv. 31 f.l: "Bo tu jest Czestochowa, tu jest święta Meka / Pieśniarzy" ([Denn hler ist das rschenstochau, hler lst das heilige Mekka / Der sanger]; Sw 2, vv. 1 f.); "tworzysz $z$ tychze iródel, z których Bóg korzysta" ([du <Mickiewicz) schaffst aus den gleichen quellen heraus, die cott benutzt]; Sw 2, v. 22). Vor diesem Hintergrund wird schlleblich unklar, we $r$ eigentlich in folgender strophe als cott bezeichnet wird: zielony bór - odwieczny bór.

Szumiacych drzew szeregi. Swiatyni Boga zywy mur Jezzoru wieńczy brzegi. (Sw 1, vv. 9-12)

lDer grune wald-der ewlge wald, Reihen rauschender Baume,

Die lebendige Mauer von Gottes Heiligtum Bekranzt dem see die ufer.]

\subsection{Zentralbegr Iffe der persönlichen Reflexion}

Den eigentlichen Kern von LANGES 'poetischer Welt', soweit sich diese im Wortschatz manifestiert, bilden die in diesem Abschnitt zusammengestellten 'stilistischen Felder', da vor allem diese das gedankliche Ringen des Dichters mit den ihn bedrängenden Problemen zum Ausdruck bringen. Die hier zu behandelnde Lexik ist im allgemeinen konkreter und bildhafter als die in Abschnitt 4.1. dargestellte und weist eine stärkere emotionale färbung in belden Richtungen auf. Die Stimmungslage der einzelnen Gedichte hängt wesentlich von der Verwendung $d i$ es e $r$ Schlüsselwörter ab.

4.2.1. 'Tod' vs. 'Leben'

Eine herausragende stellung kommt dem Wortfeld 'Tod' aufgrund seiner Frequenz und begrifflichen Differenzierung zu. Die abstrakten Substantive 'śmıerć', 'zgon' [Tod], auch 'nirwana' (mlt oszillierender Bedeutung), sowie die zugehörigen Verben 'umierać'. 'konać' [sterben] (dazu 'konanıe'), 'wymierać' [aussterben], 'zamierać' [absterben] und Adjektive 'śmiertelny' [Todes...], 'nirwani' [Nirwana...], 'umarly', 'zmar $y_{y}$ ' [tot], 'zamarly' [abgestorben] verbinden sich zu einer Gruppe mit den 
konkreten, oft bildhaft gebrauchten wörtern 'trup' [Leiche] (dazu adjektivisch 'trupi'), 'zwloki', 'prochy', 'pyly', 'popioly' [sterbliche Uberreste]; 'pogrzeb' [Begräbnis] (dazu 'pogrzebowy'), 'trumna' oder 'truna' [sarg], 'wieko' [sargdecke1], 'calun', 'kir', 'krepa' [Sargtuch; Trauerflor] (dazu auch 'calunowy'), 'grób'. 'mogila' [Grab] (auch 'grobowy'. 'mogilny'). 'grobowiec' [Gruft]; 'cmentarz' [friedhof] (dazu 'cmentarny'), 'cmentarzysko' [groBer friedhof; Gräberstäte], schließlich auch 'krzyz cmentarny' [Friedhofskreuz].

Die Todesproblematik als $\mathrm{T}$ he $\mathrm{m}$ a nimmt insbesondere in LANGES wrchtigstem Zyklus, den "Rozmyślania", einen bedeutenden Platz ein, wie schon $w$. BOROWY festgestelllt hat (1934: 197-200; vgl. auch WYKA 1977:103). Unmittelbar in diesen Bereich gehören zumindest: $R 2,8,21,32,36,63,64-2$ (außerdem: DP 21), im weiteren sinne auch: $R$ 1, 5, 6, 10, 11, 30, 33, 35, 54 .

Daruber hinaus erscheinen Begriffe dieses 'stilistischen Felds' in vielen anderen Gedichten mit abweichender Thematik und bringen so die verschiedensten Bereiche in Verbindung mit dem Tod, teils durch Einführung wirklicher Todesmotive: "Natura kocha swoja pieśn cmentarna" ([Die Natur liebt ihr friedhofslied]; R 44, v. 9); "Klamstwem śmierć, co pod ziemia prochy ludzkie grzebie" ( [Eine lüge ist der Tod, der unter der Erde die menschlichen Uberreste begräbt]; R 53, v. 4), teils durch reine Metaphorisierung:

Nic tak nie boli jako śmierć marzenia,

W grób skladasz serca najdrozsze Sezamy.

Które nam zycie calunem ocienia,

I juz nie mamy ich - i nic nie mamy! (R 15, vv. 1-4)

[Nichts schmerzt so wie der Tod eines Traums, Ins Grab legst du die teuersten Sesame des Herzens, Die uns das Leben mit einem <oder: wie ein> Leichentuch be[schattet. Und wir haben sie nicht mehr - und wir haben nichts mehr!]

w najcmentarniejsze dni zywota. Gdy caly blękit mrocza chmury: Gdy piewce glucha ire martwota, że milszya mu i grób ponury: ( 246 , vv. 1-4)

2" Ich verbessere das "milczy" der Originalausgabe zu "milszy". Schon A. TOM hat diese Korrektur erwogen (OZP I:180), aber nicht durchgeführt (vgl. OzP I:64). Obwohl man "R 55" ("Mnie cmentarze spiewaja" [Mir singen friedhöfe]; $v .10)$ als Argument für die Richtigkeit der Druckfassung ansehen könnte, entscheide ich mich 
[An den friedhofartigsten ragen des Lebens,

wenn den ganzen Himmel wolken verdustern;

Wenn am sänger dumpfe lähmung nagt,

So dab inm sogar das dustere Grab lieber ist:]

Insgesamt läßt sich feststellen, daß die bildhaft-konkrete Sphäre des Todes meist emotional negativ befrachtet ist loder allenfalls neutral bleibt; vgl. die zitierten Beispiele. Ausnahme z.B.: "Lecz kir mogily i calun śmiertelny / w logiczna calośc powiaźa ci zycie" [aber der trauerflor des crabs und das leichentuch / Werden dir das Leben in eine logische Ganzheit verknupfen]: R 6 , vv. 19 f.), die abstrakten Begriffe 'śmierć' und 'zgon' samt zugehörigen Verben und Adjektiven hingegen differenziert gebraucht werden, einmal positi $v$ :

Smierć jest to podróz nad wszystkie podróze,

Co nam ukwieci byt i rozdiamenci.

Gozie zycia czarne tocza sie kaluze ze wszystkich rzeczy. (R 2, vv. 6-9)

CDer Tod ist die herrlichste Reise,

Die uns die Existenz mit Blumen und Diamanten schmuckt,

In der des Lebens schwarze Pfützen Aus allen Dingen rinnen.].

ein anderes Mal $n$ egat i $v$ :

życie to caly sens zycia

I cala jego przejrzystość,

Bo wszystkim sa pulsów bicia,

A śmierć - to nierzeczywistość. (R 64-2, vv. 9-12)

[Das Leben ist der ganze sinn des tebens

Und seine ganze Klarheit,

Denn das schlagen der Pulse ist alles,

und der rod ist unwirklichkeit. ]2"

aus folgenden Gründen für die Konjektur: 1. Es ist unwahrscheinlich, daß im selben Kontext zwei wörter der gleichen Bildsphäre ('Friedhof') gegensätzliche Wertungen suggerieren sollen: "najcmentarniejsze" ist mit Sicherheit negativ gemeint, also muß es "grób" ebenfalls sein (anders als "cmentarz" im Kontext von "R 55"). Zudem wird "grób" ausdrücklich "ponury" genannt. 2 . In "DP 8. Nirwana" wird im gleichen Zusammenhang genau das gleiche Bild verwendet: "Sa chwile tak ponure $\langle\ldots$.$\rangle , że grób milszy nad$ turmy zyciowej Gehenne" ([Es gibt so düstere Augenblicke <...>, DaB das Grab lieber ist als das Gehenna des Lebensgefängnisses]: vv. 1 und 4 ).

2 "Einige weitere 'Todes'-Begriffe sind entweder deutlich positiv gefärbt: 'niepamięc' und 'zapomnienie' [Vergessen] (vgl.: "Do mnie, do mnie plyń tu w ciszę, / W srebrna cisze niepamieci..." [schwame hierher zu mir, zumir in die stille, / In die silberne stille des vergessens]; $R$, vv. $7 \mathrm{f}$. ) oder sie werden explizit negativ verstanden: 'nicośc'. 'nicestwo' [Nichts] sowie mit Einschrankungen 'niebyt' [Nichtsein] (vgl. 2.B. Vers 8 des im Abschnitt 3.4.2. 2itierten Gedichts "R 32"). 
Zugleich zeigen die letzten drei Textbeispiele, daß dem 'Tod' ein quasi umgekehrt proportionaler 'Lebens'-Begriff zugeordnet ist: Wird er positiv gesehen, so dieses negatıv, und umgekehrt. Auf diese Weise erhäl das an sich schwach 'markierte' Wortfeld 'Leben' bei LANGE ebenfalls eine Schlüsselfunktion. Dies gilt vor allem für die Substantive 'zycie' und das meist noch konkreter auf das irdis che Dasein bezogene 'zywot'. während 'byt' und 'istnienie' [Existenz] oft ubergreifend verstanden werden Ivgl. das soeben zitierte Beispiel aus " $R$ " sowie: "w śmierci rolm nowe zycia przemienienie, / jakis byt archanielski, czystszy, podobloczny" [im rode erträumen wir uns eine neue verklärung dos lebens, / elne erzengelhafte, reinere, erhabene Existenz]; R 36 , vv. 29 f.).

\subsection{2. 'Geheimnis' und 'Abgrund'}

Ebenso wie die Sphäre des 'Todes' durchzieht das 'Geheimnis' im weitesten Sinne LANGES Schaffen. Die abstrakten Substantive 'tajemnica', 'tajnik', 'tajń', 'tajnia' [Geheimnis], 'zagadka' [Rätse1] und die Adjektive 'tajemniczy' [geheimnisvol1], 'tajemny'. 'tajny' [geheim], 'utajony' [verborgen], sowie die bildhaften Ausdrücke 'zaslona' [schleier, Hülle] und 'rabek' (in ähnlichem Sinne gebraucht) sowie 'mgla' [Nebel, schleier] beziehen sich zunächst auf existentielle Fragen von Leben und Tod: "tajemnice bytu czytać Jal zdradziecka, / I poznawszy jej rabek zaplakal jak dziecko" ([er <der Mensch) machte sich daran, das tückische Geheimnis des seins zu entziffern, / und als er dessen schleier erkannt hatte - begann er wie ein Kind zu weinen]; Prz 6, vv. 12 f.): "Cel tajemniczy we mgle ci migota" ([Eln geheimnisvolles ziel flimmert dir im Nebel]; R 6, v. 4). Thematisiert ist dieser Problemberelch U.a. in "R 30": "Życie zagadka ci jest" usw. ([Das Leben ist dir ein Rätsel]; v. 1).

Darüber hinaus wird mit Hilfe dieser Begriffssphäre eine Verbindung des Realen mit dem Metaphysischen hergestellt: So dient im schon erwähnten "R 18" nicht nur die Anwesenheit von Engeln der Vorbereitung auf das mystische Erlebnis (vgl. oben Abschnitt 4.1.5.). es durchwehen den Zauberwald auch geheimnisvolle Lufthauche und alles ist voll seltsamen Geheimnisses ("Jakies powiewy przebiegaja tajne: $\langle. .$.$\rangle wszystko pelne dziwnej tajemnicy":$ 
vv. $10 \mathrm{f}$. ). Noch deutlicher wird dieses verfahren in "Sw 4" am übergang von Naturbeschreibung ("Czarna noc. Wience trzciny tworza wielkie sploty" [Schwarze Nacht. Die Schilfkränze bilden große Geflechte); v. 5) zum Vergleich ("Gęste, jakby tajemnic nieprzebyte ściany, / że strach kierować lódka w ten swiat niezbadany" [Dichte, gleichsam undurchdringliche wände von Geheimnissen. / So daB man Angst hat, das Boot in diese unerforschten Welten zu lenken]; vv. $6 \mathrm{f}$. ), der die explizit transzendente Formulierung am Schluß der strophe (v. 3) vorwegnimmt: "Gdzie, zda sie, zieje otchlań grobowej tęsknoty" [wo, wie es scheint. ein Abgrund von Grabessehnsucht gähnt]. Der Leser wird aus dieser 'schauerromantischen' Sphäre bezeichnenderweise dadurch wleder herausgefürt, daß die düstere Hulle schwarzer Wolken zerstiebt ("Pierzcha czarnych obloków ponura zaslona": v. 9).

Das soeben sukzessiv zitierte Quartett aus "Sw 4" (vv. 5-8) läßt zugleich erkennen, daß zum Bereich des Geheimnisses weitere Schlüsselwortfelder gehören: Eine ganze Reihe von morphologisch gleichgebauten Adjektiven drückt das Undurchdringliche ("nieprzebyte") und Unerforschte, Unergrüdliche ("niezbadane") aus: 'nieznany'. 'nieznajomy', 'niewiadomy' [unbekannt] (auch substantiviert: 'niewiadoma' [die unbekannte]): 'nieokresiny' und 'niewyraźny' [unbestimmt, undeutlich]; 'niewidzialny' und 'niedojrzany' [unsichtbar] (dazu 'niewidzialnośc'): 'niedotykalny' [unberührbar], 'bezcielesny' [körperlos]; 'niedostepny' [unzugänglich]: 'niepojety'. 'niepojemny'. 'nleuchwytny' [unverständlich, unfabbar]; auch: 'nieświadomy', 'pozaświadomy'. 'bezwiedny' [unbewuBt] (dazu 'nieświadomośc').

Der Bereich des 'Unbewußten' in der menschlichen Psyche wird in mehreren Gedichten thematisiert ( $R 37,38,57)$. Die 'nieświadomość nimmt hier eine auch philosophisch untermauerte Mittlerfunktion zwischen Mensch und absolutum ein." 0

Doch fält auch den anderen, weniger festgelegten wörtern dieser Gruppe eine solche Verbindungsfunktion zu, etwa den Adjektiven 'niewiadomy' und 'nieznany': "jest we mnie jakas melodia odświetna, / co plynie we mnie z owej dalekiej otchlani. // $z$ tej otchlani mi plyna niewiadome glosy, <... Glos mój jest

SO Zur Rolle des 'Unterbewußten' in LANGES philosophischer Gesamtkonzeption vgl. SZYMANSKA 1979:67-73. 
glosem owych nieznanych kywiolow" (les ist in mir elne feierliche Melodie, / Die in mir aus jenem fernen Abgrund heraus fliebt. // Aus diesem Abgrund flieben mir unbekannte stimmen, <...> Meine stimme ist die stimme jener unbekannten Elemente]:

R 39, vv. 7-9 und 12: vgl. oben Abschnitt 2.2.1.1.

Die letzten Textbeispiele verweisen zudem deutlich auf die Sphäre der 'Abgründe', in denen die 'Geheimnisse' oft angesiedelt sind. Es sind dies die Begriffe 'otchlan'. 'odmęt'. 'przepaść. 'bezdeń [Abgrund], sowie die von ihnen abgeleiteten Adjektive 'otchlanny' (dazu 'otchlanność') und 'bezdenny'; außerdem 'glab'. 'glębia'. 'glębina'. 'toń' [Tiefe]. Zumeist werden die angeführten wörter in diesem übertragenen sinne verwendet. Weitere Beispiele: "díwięki z nieznanych toni mego ducha" ([Klänge aus den unbekannten Tiefen meines Geistes]; $R$ 41, V. 22): "Dusza 〈...>, spragniona otchlannych i bezdennych rzeczy" ( Die seele $\langle\ldots\rangle$, begierig auf abgrundige und bodenlose Dinge ]: DP 2, vv. 8 und 111 .

Ein gewlsses Spannungsfeld kann hingegen bei konkretem Gebrauch der Begriffe oder bei Gebrauch in zunächst anderem Sinne entstehen. So ist der ganze zyklus "Na Switezi" von den Ausdrücken 'gląb'. 'glębia'. 'glębina'. 'ton' durchsetzt, die sich auf natüliche weise mit dem beschriebenen see verbinden. Vor dem Hintergrund einiger transzendierender Verwendungen jedoch, wie etwa im oben zitierten Quartett aus "Sw 4", die die Naturschilderung mit dem 'geheimnisvoll-abgründigen' metaphysischen Bereich verknüpfen, gewinnen die genannten Vokabeln in den konkreten Kontexten potentielle Doppeldeutigkeit:

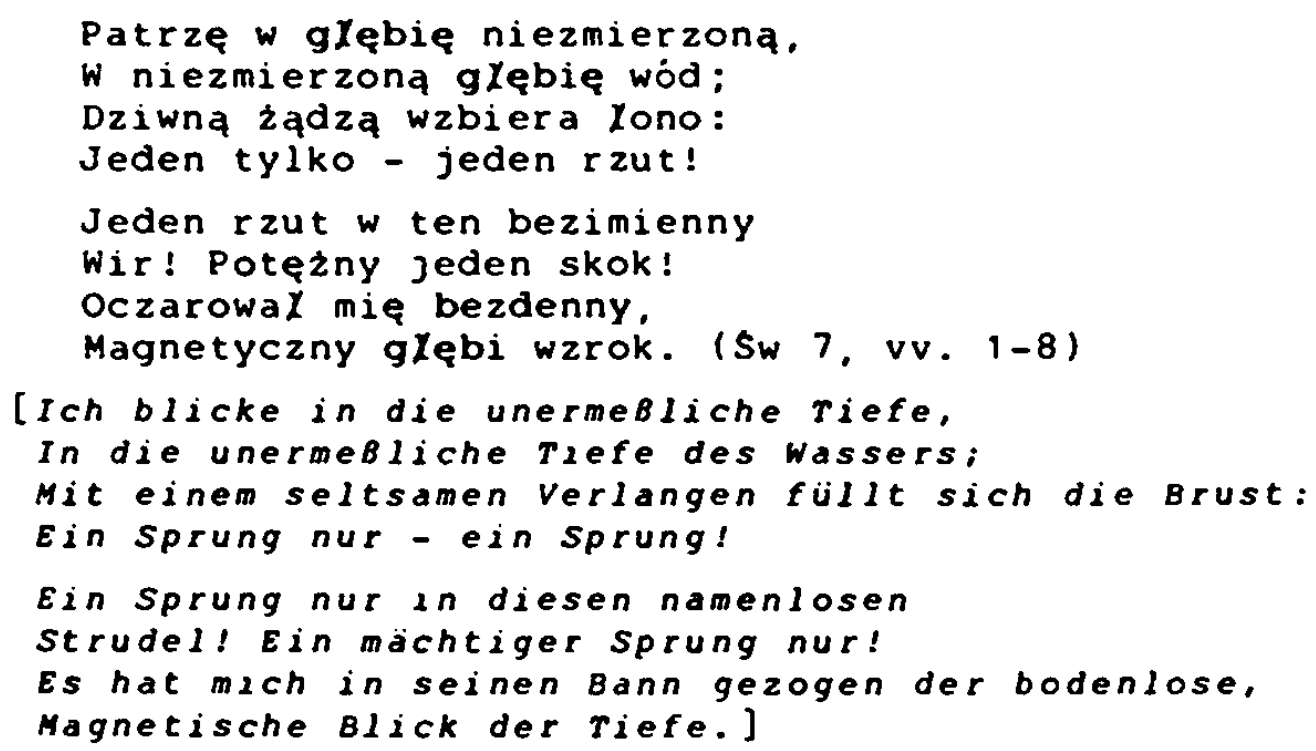




\subsection{3. 'Finsternis' und 'Chaos'}

Die transzendente Sphäre ist nicht nur hinter einem 'Schleier' von 'Gehelmnissen' und in 'Abgründen' verborgen, auch diverse 'Finsternisse' und das 'Chaos' des Lebens schieben sich zwischen den Menschen und das Wesen der Dinge: "Tutaj dzika wrzawa / Glos bozy, z niebios idacy, zaglusza... / Tu w mroku chaos jakiś sie porusza" ([Hier übertönt wilder Lärm/ Die aus den Himmeln kommende gottliche stimme... / Hier bewegt sich irgendein chaos in der Dunkelheit]; R 14, vv. 7-9); "gdzie ów tajń odźwierny, / Co myśl mu w ciemni dzlerzy niewolniczej" ([wo ist jener türhüter der Geheimnisse, / Der ihm <dem Menschen> den Geist in sklavenhafter finsternis hält]; SW, vV. 7 f.l: "Chaosem ciemnym bez rozumnejosi / zda ci sie twoja na ziemi robota" ([Ein dunkles chaos ohne vernüntige Achse/ Scheint dir deine irdische plakkerei]; R 6, vv. 1 f.).

Meist in dresem Sinne gebraucht sind die Substantive 'mrok' und 'omrocze' [Dämmerung, Dunkelheit] (samt zugehörigen Adjektiven 'mroczny', 'pomroczny' und dem Verbum 'mroczyć'), 'ciemność', 'ciemnia'. 'ciemnica' [Dunkelheit, finsternis] (dazu 'ciemny'. 'pociemnialy'; Im weiteren Sinne auch 'ponury'. 'posepny' [düster]), 'noc' [Nacht], sowie 'chaos' [Chaos] (auch 'chaotyczny'). 'bezlad' [Durcheinander], 'wir' [strudel, wirbel].

Geradezu thematisiert ist diese Art der 'Finsternis' in " $R$ 50": "W morzu ciemności duch mój toczy się bez końca <...> Cisza jest $t a m$, gdzie nie ma tego morza mroków <...> Ono jest wszędzie - wszędzie ono mie uciska - / Nierozwzązanych pytań węlem mie okala". usw. ([In einem Meer von finsternis fldebt mein Geist ohne Ende <...> Ruhe ist dort, wo dieses Meer von Dunkelheiten nicht ist $\langle. . .>E S$ ist überall - überall bedrängt es mich - / Umfänt mich mit einem knoten ungelöster fragen]: $R$ 50, vv. 1, 13,17 f.).

Der 'chaotische' Charakter des Lebens kommt ebenso in den Schlüsselwörtern 'umherirren' ('blądzić', dazu 'blędny' [umherirrend, auch fehlerhaft]. 'zblakany' [verirrt]) und 'Unruhe' ('niepokój') zum Ausdruck: "Lıściu mój zbląkany, <...> Czego szukasz blędnie / Na wsze strony świata? <... Prózno szukasz. blądzisz - - Nie ma bratnich lisci!" ([Mein verirrtes Blatt, 
<...> Was suchst du, / In alle Himmelsrichtungen irrend? $<\ldots .>$ Vergeblich suchst du, irrst du - - Es gibt keine Bruderblätter]: R 52-1, vv. 1, 5 f., 11 f.: vgl. oben Abschnitt 2.3.1.); "niepokoje, co w tych piersiach hucza" ([Unruhen, die in ihrer Brust dröhnen]; R 54, v. 46).

Direkt thematisiert ist das suchende 'Umherirren' $2 . B$. im Poem "Latajacy holender" und im daran anknüpfenden "DP 12 . Vaisseau-fantôme" (zitiert unten im Abschnitt 4.3.5.).

4.2.4. 'Leiden' und 'Schmerz', 'Tränen' und 'Trauer'

Das 'Chaos' des Lebens führt schließlich zu 'Leiden' und 'Schmerz': 'cierpienie' [Leiden], 'męka'. 'meczarnia'. 'udreka' [oual], 'męczeństwo' [Martyrium], dazu die Verben 'cıerpieć' [leiden] und 'męczyć' [guälen] sowie die Adjektive 'znękany' [bedrückt, geknickt], 'utrudzony' [abgeplagt], im weiteren Sinne auch 'zmęczony'. 'znuzony' [mude, ermattet]; 'ból'. 'boleśc' [schmerz], dazu 'bolesny' [schmerzlich], 'bolesciwy' [schmerzvol1] und 'boleć' [schmerz empfinden]:

"A gdy nadmiarem bólu serce umęczone / Odpocznienia juz zada i grobowe] ciszy" ([und wenn das durch ein Ubermas an schmerz geguälte Herz/ Schon nach Ausruhen und Grabesstille verlangt]; R 53, vV. 25 f.); "wszystkich atomów meczarnie" ([die oualen aller Atome]; SW 7, v. 3).

In mehreren Gedichten macht LANGE 'Leiden' und 'Schmerz' zum Thema seiner uberlegungen: $R$ 19,40,59,60. Insbesondere an "R 40" wird deutlich, daß das 'Leiden' - gemäß LANGES philosophischer Konzeption"1 - auch eine positive seite besitzt, daß es nämlich den Menschen auf den Weg der Erkenntnis führt: "cierpienie jest wielkie, cierpienie jest swiete: / Ono imie nadaje

"Den Zustand der Gespaltenheit, des 'Chaos', d.h. der Diskrepanz zwischen Natur und Geist, empfindet der Mensch - nach LANGE - als 'Leiden'. Dieses bewegt inn dazu, auf die (wieder-) Gewinnung der Harmonie zwischen Natur und Geist hinzuwirken (nach SZYMANSKA 1979:37). "Poznanie, będace wynikiem cierpienia, narusza bezwladnośc naturalna ducha, rozdwaja go i budzi w nim zadze powrotu do tej bezwladnosci" [Die Erkenntnis, Ergebnis des Leidens, zerstört die natürliche Trägheit des Geistes, entzweit ihn und weckt in ihm das Verlangen nach Rückkehr zu dieser Trägheit]: A. LANGE: Studia i wrazenia. Warszawa 1900:16: zitiert nach SZYMANSKA $1979: 25$. 
rzeczom bez imienia / I w duszy nam Sezamy odkrywa zaklęte" ( ldas Leiden ist grob, das Leiden ist heillg; / Es verleiht den Dingen ohne Namen elnen Namen/ Und öffnet uns in der seele Zauber-sesame ]: $R$ 40, vv. 2-4).

Doch im konkreten Seinszusammenhang führt das 'Leiden' vor allem zu 'Tränen' und 'Trauer': 'Iza' [Träne], 'lzawo' [mit Tränen In den Augen], 'Xzawić się' [tränen, weinen]: 'plakać' [weinen], 'placz' [weinen, Tranen], 'oplakany' [beweinenswert] sowie 'smutek' [Trauer, Wehmut], 'smutny' [traurig], 'smecic sie' [traurig sein]; 'zal', 'zaloba', 'zalośc' [trauer, Leid], 'zalić sie' [klagen], dazu auch: 'zalowac' [bedauern], sowie 'zalobny' [trauer...] und 'zalosny' [k1aglzch]:

"Kzy i ból czlowieczeństwa" ([ Tranen und schmerz der Menschheit]; R 53, V. 17): "Żal serce przenika" ([Trauer durchdringt das Herz]: R 5, V. 11): "duch ludzki <...>Plakal, jak gdyby przeczuwal z bojaźnia, / że na cierpienie wieczne jest skazany" (lder menschliche Geist <...) Weinte, als ob er angstvoll vorausfuhlte, / DaB er zu ewigem Leiden verurteilt ist]; SW 2, vv.

2 und $13 \mathrm{f.l}$.

\subsubsection{Weltere Folgen von 'Chaos' und 'Finsternis'}

Ebenfalls dieser spezifischen 'conditio humana' entspringen Enttäuschung ('rozczarowanie', dazu auch partizipial 'rozczarowany'), sorge ('troska'), Angst ('trwoga', 'lęk', 'bojaźn'; dazu 'trwozny' [angstvol1], 'strwozony' [verägstigt], 'trwozliwy' [ängstlich], sowie 'lękać sie' (sich fürchten]), Grauen ('groza'), schließlich Verzweiflung ('rozpacz'; dazu 'rozpaczny' [verzweifelt] und 'rozpaczac' [verzweifeln]):

Gdyby's poznala czarne otchlanie. Gdzie ludzkie mary jedna za druga Jak w grób padaja $w$ rozczarowanie. Rozbite zycia twarda maczugą? (z erotyków, vv. 9-12)

[wenn du die schwarzen Abgründe kennenlerntest, Wo die menschlichen Träume, einer nach dem andern, wie in ein Grab in die Enttäuschung fallen, zerschlagen von der harten Keule des Lebens?]

Weiterhin: "troski dziwne, którymi duch mój jest chory" ([die seltsamen sorgen, an denen meln Geist krankt]; R 26, v. 4): "Okręt mój opętany plynie w dzikim lęku" ([Mein besessenes schiff schwimmt in wilder Angst dahin]; DP 12, v. 6); "Sa chwile <...> 
tak pelne rozpaczy - i tak pelne grozy" ([Es gibt Augenblicke <... so voll verzweiflung und so voll Grauen]; DP 8, vv. 1 f.). Andererseits führt das 'Chaos' des menschlichen Daseins zu Resignation in Form von 'Gleichgültigkeit' ('obojętnośc', dazu 'obojetny' [glelchgültig] und 'zobojętnic' (gleichgultig machen]) und 'Einsamkeit' ('samotność', dazu 'samotny' [einsam], 'samotn.ik' [der Einsame] und 'samotnica' [die Einsame]):

"Serce obojętności pokrywa mi zbroja" ([Das Herz bedeckt mir dier Panzer der Gleichgültigkeit]; Sonet [1], v. 5): "Jestem, jak sosna samotna, schylona / Nad przepaściami, na górskiej przeleczy!" ([ Ich bin wie eine einsame Kiefer, / An einem GebirgspaB über Abgründe gebeugt]; BP 4, vv. 9 f.l.

Darüber hinaus wird die 'Elnsamkeit' des Menschen in mehreren Gedichten direkt thematisiert: Samotnośc: R 25, 31, 52: DP 1 .

\subsection{6. 'Sehnsucht' und 'Traum'}

Sehr viel öfter als Resignation erzeugen die Fährnisse des Lebens jedoch 'Sehnsucht' ('tęsknota', 'tęsknica'; dazu 'tęsknić' [sich sehnen] und 'tęskny'. 'stesskniony' [sehnsüchtig]) und vor allem '(Wunsch)träume' ('sen', 'śnienie'. 'marzenie'. 'mara'. '(u)rojenie': dazu 'senny' [rraum...]. 'śnić (sie)'. 'marzyć'. 'roić. (träumen]):

"I wiecznie mie tęsknota gryzla nieskończona..." ([und ewig nagte eine unendliche sehnsucht an mirl; $R 35, v$. 8); "Dusze ludzkie <...> Wzajem tęsknia ku sobie z oddali" ([D1e menschlichen seelen <... sehnen sich aus der ferne zueinander]; Samotnośc, vv. I und 6): "I w świecie wlasnych zyje mar" ([und ich lebe in der welt meiner eigenen rraume]: R 25, vv. $3 \mathrm{f} .1$; "Mniej nizeli śmierć - oto twe marzenie - / a wiecej nizilizycle..." ([wensger als der tod - das ist dein traum - / aber mehr als das Leben...J; R 36, vv. 20 f.l; "Oto bladza po ziemi senne planetniki <...> A kazdy inną mare ściga w zaobloczu <...> Harmonii snow poszukiwacze, samotniki" ([Da irren schlafwandler über die Erde <...> Und jeder verfolgt einen anderen rraum am Himmelszelt <... Sucher der Harmonie von Träumen, Einsame]: DP 1. vv. 1, 3, 51.

Doch muß oftmals das Scheitern von solchen 'Träumen' konstatiert werden: "Mylnie sądzısz, / Że się sen twój ziści" ([Fälsch- 
lich meinst du, / DaB sich dein Traum verwirklichen kann]; $R$ 52-1. vv. 9 f.): "Rozprysly mi się na szczety / Sny moje dumne" ([Es sind restlos zerstoben/ Meine stolzen Träume]; R 64-1. vv. 21 f.): "bezpowrotne mary" ([unwiederbringliche Träume]; R 5, V. 9).

Die Wichtigkeit des Traumbereichs in LANGES Lyrik unterstreichen darüber hinaus die vielen Gedichte, die ausdrücklich als wiedergabe von Träumen bezeichnet werden, wie $2.8 .: R 9,10,15$, 27, 29 (erster Teil), 42.32

\subsubsection{Inhalt der 'Sehnsüchte' und 'Träume'}

Gegenstand dieser 'Träume' und 'Sehnsüchte' ist meist 'Stille' ('cisza', dazu das Adjektiv 'crchy'), 'Ruhe' ('spokój', dazu 'spokojny'), 'Erholung' ('spoczynek', 'odpoczynek', 'odpocznienie') sowie 'Besänftigung' ('ukojenie', 'ukojność', dazu 'ukojony' (besänfigt]) durch eine 'Melodie' ('melodia'), ein 'Lied' ('pieśn', dazu 'pieśniowy' [liedhaft]; auch 'kolysanka' [wiegenlied] und 'rozspiewany' [zum singen gebracht]), durch einen 'Zauber' ('czar', dazu 'czarowny' 'czarodziejski' [zauber.... zauberhaft]. auch 'zaklęty' [verzaubert]) oder durch einen 'Reiz' ('urok'. 'wdziek'), die alle den Gequälten 'locken' ('nęcić):

"Do spokoju my dazym. Spokój jest w marmurach - / w marmury sie przemienic, w granit przelać ducha!" ( lzur Ruhe streben wir. Ruhe ist im Marmor - / sich in Marmor verwandeln, den Geist in Granit gieBen!]: R 54, vv. 69 f.): "Niegdys, gdy zycie we mnie huczalo kraterem, / Smierć nęcila mie wlaśnie jak bogini ciszy" ( [Einst, als das leben in mir wie ein krater dröhnte, / Lockte mich der Tod gerade als Gottin der stille]; R 63-2, vv. 5 f.); "Szla naprzód strofa burz - i antystrofa / Jęku i cierpień. W końcu zaśs epodon - / Spoczynek - cisza - slodka pieśń - / Pieśń. gdzie poeta streszcza swa dusze" ( [Es kam zuerst die strophe der stürme - und die Antistrophe / Von Gestöhn und leiden. schlieblich aber das Epodon - / Erholung - Ruhe - süBes Lied - / Ein Lied, in dem der Dichter seine seele zusammenfaBt]; Strofa alcejska, vv. 41-44); "Pieśn - jest najwyzsza królowa i pania

12 . Die beiden ersten der angefühten Gedichte werden bezeichnenderweise von LANGE im Auswahlband "Pocalunki" (1925) mit den Titeln "Marzenie" bzw. "Jeszcze marzenie" versehen. 
<...> upojenie, wiosna, blyskawica" ([Das lied ist die höchste Königin und Herrin (...> Rausch, Frühling, Blitz]; DP 9, vv. 5 und 8 ).

'Pieśn' steht in vielen Fällen, wie wohl auch im letzten Beispiel, für die 'Dichtkunst', deren zentrale Rolle in LANGES philosophischem System durch die offenbarende Macht des 'Wortes' ('slowo' als 'Logos") begründet wird: "duch proroczy <...>w wielki Dzwon uderza - wielkie mówi slowo - / w którym stulecia hucza - 1 w jedność tęczowa / Kacza przeszlość i przyszlośc globu. Nieśmiertelni!" ([der prophetische Geist <...> lautet die Grobe Glocke - spricht das Grobe Wort - I In dem Jahrhunderte dröhnen - und zu einer regenbogenfarbenen Einheit / die unsterblichen vergangenheit und zukunft des Globus verbinden]'s: DP 7. Logos, vv. 4 und 6-8). Thematisiert wird der Begriff 'Logos' u.a. auch in den Poemen "Pieśn o slowie" und "Cyfra i slowo" (vgl. zu diesem Themenkomplex SZYMANSKA 1979:108-115).

Ersehnens- und erträumenswert sind, nach LANGES Schlüsselwortstruktur, weiterhin 'Wunder' ('cud'. dazu adjektivisch 'cudny'. '(prze)cudowny' [wunderbar]). 'Auferstehung' ('zmartwychwstanie'. dazu verbal 'zmartwychwstac' [auferstehen]) sowie 'Reinheit' ('czystość, dazu '(prze)czysty' [rein], 'oczyścić sie' [sich reinigen] und 'oczyszczenie' [Reinigung]:

"I o jeden cud blagam Tajemnicze Moce, / Bym sie mógl raz urodzıć na świat ostatecznie / I umrzeć ostatecznie..." ( lund um das eine wunder flehe ich die geheimnisvollen Mächte an, / DaB ich einmal endgultig auf die Welt kommen/ und endgülig starben könnte...];R 35, vv. 13-15): "Do czystego idę czlowieczeństwa" ([Ich gehe dem reinen Menschentum entgegen]; R 26, V. 8): "Tam prawda w czystym jawi sie krysztale" ([Dort zeigt sich die wahrheit in reinem Krista11]; R 14, v. 15).

Und in explizit politischem sinne: "Straszliwa zadza cudów piersi nam rozdziera: / Widuje biale orly na chmurach czerwonych - / I krzykiem zmartwychwstania brzmi nam atmosfera" ([Ein schreckliches verlangen nach wundern zerreibt uns dze Brust: / Es sieht weibe Adler vor dem Hintergrund roter wolken <polnisches Staatswappen!> - I Und die Atmosphare hallt uns wider vom

"Die Interpretatıon des Punktes vor "Niesmiertelni" als rein intonatorisches Mittel der Hervorhebung stutzt sich auf den deutlicheren Parallelfall von DP $1, v .9$. 
Auferstehungsschrei]; Swemu pokoleniu, vv. 9-11): "Mów, czy godzina zbliza sie, kiedy poeta / Uderzy w struny lutni hymnem Parakleta / I zabrzmi pieśnia szczéscia - w zmartwychwstań weselu!" ([Sag, ob sich die stunde naht, in der der Dichter / Die Saiten der Leier zu schlagen beginnt mit dem Hymnus eines Paraklet / Und ein Glückslied anstimmt - in der freude der Auferstehungen!]: Mrckiewicz III, vv. 15-17).

Quasi für die Synthese all dieser 'Träume' und 'Sehnsüchte' stehen die Ausdrücke 'raj' [Paradies], 'Eden' (auch 'edeński'), 'królestwo boze' [Cotteskönigreich], 'Elizeje' [Elysien], 'Atlantyda' [Atlantis] (auch als 'wyspa' [Insel])":

"Atlantydy kochalem niegdy's promieniste, / Platońskie, 2 mgly wysnute, senne Oceanie" ([strahlende Atlantis-Inseln liebte ich exnst, / Platonische, aus Dunst gesponnene Traumozeanien]:: R 42, vv. 1 f.): "A spolecznośc, spragniona Edenów blękitu - / o jutrze promienistym marzy przecudownie" (lund die Gesellschaft.. im Verlangen nach der Himmelsblaue von Eden-Garten - / Traumt wunderbar vom strahlenden Morgen]: DP 3, vv. 12 f.).

Den Gegenpol zu dieser Begriffssphäre bildet die biblische Höllenvorstellung, selten auch die antike Unterwelt, jeweils bezogen auf die reale Lebenssituation: "za mych lat mlodzieńczych ziemia byla pieklem / I prózno duch o zlotych marzyl blyskawicach <...> A szatan juz na niego zastawial swe sidla - / Aześmy wiare w boze stracili królestwo" ( $i$ in meinen Jugendjahren war die Erde eine Hölle, / Und vergebens träume der Geist von goldenen Blitzen <... Und der Satan legte schon seine Netze nach ihm aus - Ja, wir verloren sogar den Glauben an das cotteskönigreich]; R 61, vv. $3 \mathrm{f}$. und $7 \mathrm{f}$.$) : "Bo jeśli zechcesz swoja$ dloń polozyc / Na strunach arfy piekielnych zywiolów: / Nie zdolasz ziemskiej Gehenny umorzyć, / Ani powstrzymać jej czarnych aniolów" ([Denn wenn du deine Hand / Auf die saiten der Harfe der Hollenelemente legen willst: / Gelingt es dir doch nicht, das irdische Gehenna zu vernichten/Und seinen schwarzen Engeln Einhalt zu gebieten]; List do redaktora, vv. 85-88); "bylem w przepaściach na samym dnie hada" ([ ICh war in Abgrunden auf dem tiefsten Grund des Hades]; $R 60, v .18$ ).

3 Vgl. hierzu die geschichtsphilosophische Deutung dieser Begriffe durch M. PODRAZA-KWIATKOWSKA (1969:86-88). 


\subsection{Bildhafte Naturelemente und Farbsymbol ik}

Wie die jungpolnzsche Dichtung allgemein, verwendet auch LANGE eine vielzahl poetischer Requisiten, die die Anschaung der sache selbst ersetzen (JASTRUN'1967:LXVI), vor allem aus dem Berelch der Natur. Sie dienen meist zur Metaphorisierung abstrakter Begriffe oder Gedankengänge. Nichtsdestoweniger fügen sie sich in die Gesamtstruktur von LANGES Begriffswelt nahtlos ein und verlangen unter diesem Aspekt die gebührende Aufmerksamkeit. Analoges gilt für die gesondert zu betrachtende Funktion einiger charakteristischer Farbgebungen, die Eigenwert gewinnen können.

\subsubsection{Blumen}

Die Begriffe 'kwiat' [Blume, Blüte] (dazu 'kwiecie' [Blüte], 'kwietny' [Blumen.... Blüten...] und 'ukwiecic' [mit Blumen schmucken]) und 'kwitnać [blühen] (dazu 'rozkwit' [Aufblühen, Blüte]) werden in den verschiedensten zusammenhängen als positive Metaphern verwendet: "kwiaty marzeń" ([die Bluten der Träume]; R 32, v. 2); "kwiat milości" ([die Blume der Liebe]; strofa alcejska, v. 11); "Niegdyś inaczej śmierć mi zagladala w oczy - / Byl to swiat pelny ciszy, bialy i spokojny, / Woniejacy kwiatami blekitnych roztoczy" ([Einst blickte mir der rod anders in die Augen - / Es war dies eine welt von stille, weib und ruhig, / Nach den Blumen himmelblauer flächen duftend]; R 63-2, vv. 1-3): "Tajemniczy milości duch nad nia zakwitnie" ([Der geheimnisvolle Geist der liebe wird über ihm <dem Grab> erblühen]; R 10, v. 16).

Von den konkreten Blumenarten wird die 'Rose' ('róza') bei weitem am häufigsten verwendet, und $z$ war zunächst ebenfalls als positi ve Metapher: "Smierć mie dzis jedna swym urokiem neci: / Bo ma uśmiechów najpiekniejsze róze" ([Allein der rod lockt mich heute mit seinem Reiz: / Denn er besitzt die schönsten Rosen des Lächelns]: R 2, vV. 2 f.); "ja jestem blisko / Najpiekniejszych róz wiosny, barwnych tęcz zywota" ([ich <der Tod> bın nahe/ Den schönsten Frühlingsrosen, den farbigen Regenbogen des Lebens]; $R$ 63-4, vv. $17 \mathrm{f}$.$) .$

Dem stellen sich die negat i v befrachteten 'schwarzen Rosen' entgegen: 
Czy nigdy, nigdy nie ustana burze?

więc rzeklem: kwiaty niech mam ku ozdobie!

Róze chowalem i zakwitly róze,

Lecz róze czarne, jak kiry na grobie. ( $R$ 7, vv. 14-16)

[werden die Ungewitter nie, nie enden?

Also sprach ich: Blumen möge ich haben zum Schmuck!

Ich zog Rosen und es erbluhten Rosen,

Aber schwarze Rosen, wie Trauerflor auf dem Grabe.]

Die 'schwarzen Rosen' verbinden sich also mit dem Tod in negativer Wertung. Vgl. auch: "Dokola tu róze czarne w trupim oprzedzie" ([Ringsumher schwarze Rosen in Leichengespinst]: R 64-1, vv. $31 \mathrm{f}$.$) .$

Der positiv empfundene Tod läßt folgerichtig die schwarzen 'Rosen' $z u$ roten werden, wie er ja auch im (oben angeführten) Textbeispiel aus "R 2 " von vorneherein mit rote $n$ 'Rosen' geschmückt ist :

Jak aniol bialoskrzydyy śmierć mi się uśmiecha:

w jej promienności róze kraśnieja mi czarne, (R 10, vv. 2 f.)

[wie ein weibgeflügelter Engel lächelt mir der Tod zu:

In seinem strahlenglanz werden mir schwarze Rosen zu roten,]

\subsubsection{Witterungsphänomene}

Konventionell werden die Begriffe 'orkan' [orkan], 'wicher' [sturmwind], 'burza' [sturm, Gewitter], 'grom' [Donner, Blitz], 'plorun' [Blitz] im Sinne der Unbilden des Lebens verwendet's. die zu 'Wolken' ('chmury') und 'Eis' ('lod', dazu 'lodowy' [Eis...]. 'lodowaty' [eisig] und 'lodowiec' [Gletscher]) führen :

"Orkany wyly i huczal grom... / Pioruny bily w cichy mój dom <...> O, slońce! chmury rozpędi i zniszcz" ([Orkane heulten und der Donner dröhnte... / Blitze schlugen in mein stilles Haus <...> O sonne! zerstreue und vernichte die wolken]; $R$ 47-1, vv. 1 f. und 4): "I mrok I lód po sercach rozpostartej zimy, / I te wieczne chmury - te okropne chmury" ([Und die finsternis und das $E$ is des über die Herzen ausgebreiteten winters, / Und diese ewigen wolken - diese schrecklichen wolken]: R 54, vv. 59 f.l; "w poświstach wichru, gromach niepogody, / Ku lodom pustyń dązę

's 'Grom' dient daneben auch als bildhaftes Aquivalent mächtiger Stimmgewalt: "Niech zabrzmi haslo to <... n niby grom" ([Möge dieses Losungswort erschallen $\langle. .$.$\rangle wie ein Donner];$ Pog 7, vv. 22 f.l. 
niedostepnych" ( Im Pfeifen der sturme, in den Donnern des Unwetters / strebe ich zu den Eismassen unzuginglicher wusteneien]: R 7, vv. $3 \mathrm{f} . l$; "Bo na świecie sa wichry, na świecie sa burze" ([Denn auf Erden sind stürme, auf Erden sind Unwetter]; W imionniku R. D., v. (13).

Einer interessanten Verbindung der Schlüsselwörter 'chmura' und 'lod' mit ' $\not 2 a$ ' und 'plakać' bedient sich "R 19 " auf der Bildebene: Die stumm ertragenen 'Schmerzen' werden zunächst mit elner ewigen Wolke ("wieczna chmura"; v. 3) verglichen, die dann in zwei verschiedene Richtungen aufgelöst wird. Das Kind verflüssigt' sie gleichsam $2 u$ 'Tränen' und entledigt sich so des Schmerzes (vv. 5-8), während sie sich beim Erwachsenen, der diese Möglichkeit nicht besitzt, in 'Eis' verwandelt:

Tym bardziej nieme usta, bardziej sucha

Zrenica, bardziej twarz jest lodowata! (vv. 11 f.)

[Umso stummer ist der Mund, trockener

Die Pupille, eisiger das Gesicht/]

4.3.3. 'Meer' und 'Wellen', 'Flleßen' oder 'Schwimmen'

Der flüssige Aggregatszustand des Wassers, wie er etwa im letzten Beispiel in ' $\chi z a$ ' und ' $p l a k a c$ ' zum Ausdruck kommt, liegt auch den Begriffen 'morze' [Meer] (auch 'ocean') und 'fala' [welle] zugrunde. An diese ihre Eigenschaft vor allem knüpft LANGE mit seinen of gebrauchten konventionellen Metaphern "morze krwi" ([ein Meer von Blut]; 2.B. SW 6, v. 7; Strofa alcejska, v. 3) bzw. "fale krwi" ([wogen von Blut]; 2.B. R 59, v. 12; DP 10, v. 5) an.

Die große Ausdehnung des Meers steht hingegen zunächst bei folgenden Metaphern (alle aus "R 50") im Vordergrund: "morze clemności" bzw. "mroków" ([Meer der Finsternis]; vv. 1 und 13), "morze przerazeń" ([Meer der schrecken]; v. 68).

Den für LANGES 'poetische Welt' wichtigsten Aspekt liefert jedoch die unergründliche Tiefe des Meeres, die sich - ähnlich wie das Wortfeld 'Abgrund' (vgl, oben Abschnitt 4.2.2.) - mit den verborgenen Geheimnissen der Transzendenz verbindet: " $O$, gdzie sa tego morza trytony - straznicy / Mrocznych fal - by mi glębia stanella otworem?" ( $[0$, wo sind die Tritonen dieses Meers - die wachter / Der düsteren wellen - auf daB sich mir die Tiefe auftue]: $R 50$, vv. $35 \mathrm{f}$.$) . Diese und ähnliche stellen$ 
in "R 50" (vgl. vv. 17-20, 29-32) machen deutlich, daß auch in den oben zitierten Beispielen aus diesem Gedicht der Aspekt der 'Abgründigkeit' mitschwingt. Direkt wird dies gegen Ende des Texts zum Ausdruck gebracht: "I tocze sie po morzu ciemnośc1 bezdennym..." ( [und ich treibe auf einem abgrundtiefen Meer dear Finsternis...]; v. 64 ).

Ein weiteres Beispiel für die 'Abgründigkeit' des Meeres fimdet sich in "R 14":

Pod tym zewnętrznym zycia fal potokiem Dostrzegam glębsze, niewidzialne fale:

Tam prawda w czystym jawi sie krysztale,

Tam rzeczywistość ujrzysz jasnym okiem,

A dzień dzisiejszy w tym morzu glębokiem -

Jako widziadlo rozwiewa sie w dale. (R 14, vv. 13-18)

[unter diesem auberen strom der Lebenswellen

Erblicke ich thefere, unsichtbare wellen:

Dort zeigt sich die Wahrheit in reinem Kristall,

Dort kannst du die Wirklichkeit mit klarem Auge erblicken,

Und der heutige rag zerstiebt in diesem tiefen Meer -

Wle ein rrugbild in die fernen.]

Schlleßlich wird dieser Aspekt des Schlüsselwortes 'Meer' auch in (bewußt) doppeldeutigem Zusammenhang gebraucht. In " $R$ 22" erinnert der Anblick der wellen das lyrische Ich an "ihre" Augen (vgl. oben Abschnitt 2.3.3.):

Ach, nie! To nie sa fale! Nie - to sa jej oczy -

Ale tam - ja widzialem niegdyś wielkie morze!

Byl to ocean dziwny - bezdenny - przeźroczy-

A w glębi swej kryl tajnie - nieskończenie boze -

I mial wichry szalone - i cisze zaklete -

I wielka przérroczystość - i zagadki śwlete. (vv. 9-14)

[Ach nein! Das sind keine Wellen! Nein - das sind ihre Augen Aber dort - habe ich einst ein grobes Meer gesehen!

Das war ein seltsamer - abgrüdiger - durchsichtiger ozean und in seiner riefe barg er unendlich göttliche Geheimnisse -

und er besab rasende sturme - und verzauberte stillen -

Und grobe Durchsichtigkeit - und heilige Rätsel.]

Zunächst gibt das 'Meer' in den Augen der Geliebten deren innerste Geheimnisse preis, dann aber auch - mittelbar - Wissen um die letzten Seinsgründe, an denen alles Materiejle durch das ihm innewohnende 'geistige' Element Anteil hat."

wre die letzten Textbeispiele zeigen, wird das Wort 'fala' in quası wörtlichem sinne, daneben aber auch metaphorisch zur

1 Zu dieser Konzeption vgl. SZYMANSKA 1979, besonders: 21-223. $28-29$. 
Bezeichnung der 'Wechselhaftigkeit' des Lebens gebraucht: "zycia fale" oder "fala". "życiowe fale" ([welle(n) des Lebens]: R 14, v. 13; R 4, v. 1: Posag i dziewczyna, v. 29): In ähnlichem Sinne: "Wiesz-li, na jakiej staniesz jutro fali <...>?" ([WeiBt du denn, auf welcher woge du dich morgen befinden wirst <...??]; $R$ 6, v. 7). Das Element des 'Wechselhaften' bzw. des 'ungeordneten Durcheinanderlaufens' begründet auch in den folgenden Beispielen den Gebrauch des Worts 'Welle': "Niech mie nieustajacych ulud pieści fala" ([Möge mich die Woge unaufhörlicher Täuschungen kosen]; R 40, v. 11); "Ach, hasla trzeba nam, co w jeden zleje prad / Rozpierzchlych naszych sil niekrysztalone fale" ([Ach, ein Losungswort brauchen wir, das in einen strom / Die unklaren wellen unserer zerstreuten Kräfte zusammengleBt]; Pog 7. vv. 5 f.l.

Daneben dient das Schlüsselwort 'Welle' als eine Art Pars pro toto für ein metaphorisch verstandenes 'Gewässer', das verschiedene 'Bereiche' bezeichnet: "Ani wiesz, jakam piekna jakiej świezej mocy / Nablera, kto sie w fali mej wykapać zdola" ([Du weiBt gar nicht, wie schön ich <der personifizierte Tod> bin - welche frische Macht / Gewinnt, wer in meiner Welle baden kann]: R 63-4, vv. $15 \mathrm{f}$.$) ; "I troski nas rzucaja w egoizmu fale"$ ([Und die sorgen werfen uns in die wellen des Egoismus]; Impromptu, v. 19): "I plyniesz, zawsze rozdarty na dwoje, / Bo plyniesz zawsze do nie swoich fal" ([und du schwimmst, immer entzweigerissen, / Denn du schwimmst immer zu fremden wellen]: R 1, vv. 7 f.l.

Charakteristisch ist die sanfte, dem Bereich 'Meer' und 'Wellen' zugehörige Bewegungsform des 'Dahinfließens' oder 'Schwimmens' ('plynac') im letzten Textbeispiel, wie auch in anderen Kontexten. Es ist zunächst, wie im eben angefürten $z i t a t$ aus "R 1 ", das 'Dahinfließen' auf dem Lebensweg: "Im dalej plyne w swiata gwar" ([Je weiter ich in den Lärm der welt fliebe]; $R$ 25, v. 1): "Kazde plynie po swej linii - / Ja po swojej - świat po swojej" ([Alles fliebt in seiner Rlchtung - / Ich in meiner die welt in ihrer]: $R 31$, vv. 5 f.l: "Inna droga plynać blogo, I Moja ściezka zla" ([Einen anderen Weg sollte man glückselig flieben, Mein Pfad ist schlecht]; R 4, vv. 11 f.).

Dieser Lebensweg geht letztlich über in ein 'Fließen' in die Transzendenz: "I plyniem w nicośc jutra" (lund war flieben in 
das Nichts des Morgen]: $R 33, v, 15)$, meist als Wunschvorstellung: "plynąc i plynać do krain czystych" ([flieben und flieben zu reinen Gefilden]; $R 36$, vv. 16 f.l: "Musze plynać w dal" ([Ich muB in die ferne flieBen]; $R$ 49, V. 9); "Wiecc tam, gdzie sie stawa / 2 tego nicestwa - Coś, plynie ma dusza" ([Also dorthin. wo / Aus diesem Nichts - ein Etwas entsteht, flieBt meine seele]: R 14, vv. 11 f.). Schließlich dient 'plynać' zur Bezeichnung der Bewegungsformen in dieser transzendenten Sphäre: "w nieskończoności lazurach plynacy" ( $\mathrm{im}$ Himmelblau der unendlichkeiten (liebend]; R 54, V. 33).

\subsubsection{Himmelskörper und mit innen verbundene Naturphänomene}

Ebenfalls direkt mit der 'Transzendenz' verbunden ist der Begriff 'planeta' [Planet]: "te zjawy ze sfer niewidzialnych <...> nle zejda ze swych planet dalnych" ([diese Traumbldor aus unsichtbaren sphären (...) werden von ihren fernen planeten nicht heruntersteigen]: R 58, vv. 9 und 11): "I nie wiem, 2 jakiej planety / Tutaj na ziemie dotarly / Tajemnicze alfabety, / Co tak rychlo tu wymarly!" ([Und ich weis nicht, von welchem planeten / Hierher auf die Erde / Die geheimnisvollen Alphabete gekommen sind, , Die hier so schnell zugrunde gingen!]; R 64-3. vv. 17-20). Konkreter steht 'planeta' für die verschwommenen Erinnerungen des lyrischen Ichs an frühere Existenzen: "Tysiace we mnie planet blądzi eterycznych. I skąd jesteście, umarle gwiazdy?" ([In mir irren Tausende von atherlschen planeten. woher seid ihr, tote sterne?]: $R 28$, vv. 3 f.: vgl. auch $R 37$, vv. 1 und 10 ).

Funglerte $1 \mathrm{~m}$ letzten Textbeisplel 'gwlazda' [stern] ausnahmsweise als synonym für 'planeta'. so besitzt es gewönnlich den gleichen metaphorischen Wert wle 'slońce' [sonne], nämlich den erstrebenswerten 'Glückszustand": "Atlantyda nadzlemska <...> Jako najwyzsza gwiazda - cala z snów utkana" ( [Ein viberirdisches Atlantis <...> Als höchster stern, ganz aus traumen gewebt]; R 42, vv. 9 und 12); "Ze slońc edenów - w księzyce hadesów" ([Von den Sonnen der Garten Eden - bis zu den Monden der Totenreiche]; R 27, v. 8): "Za jakimś slońcem, które jest pozorem, / Dni twe niepewne - jako ćmy - lopoca" ( Hinter irgende1ner sonne, die nur schein lst, f flatern deine unsicheren tage 
we Nachtfalter her]; $R$, vv. $15 \mathrm{f} .1$; im Sinne einer ganz konkreten Lebenssituation: "O, chcialbym iśc z powrotem / za mlodości slońcem zlotem" ( 00 , ich würde gerne zurückkehren, I Der goldenen sonne der Jugendzeit nach]: R 49, vv. $13 \mathrm{f.:} v g l$. auch R 5, v. 3).

Ganz ihnlich ist der symbolgehalt von 'tęcza' [Regenbogen] (dazu 'tęczowy' [regenbogenfarben]), das insbesondere die Schönheit dieses Glückszustands unterstreicht: "Hesperyjski wid jakiś proroczy, / Swiat zmieniajacy w tęcze i krysztaly" l(Eine prophetische Hesperidenvision, / Die die Welt in einen Regenbogen und in Kristalle verwandelt]; $R 56$, vv. 15 f.). Die Begriffe 'tęcza' und 'gwiazda' werden im übrigen in den gleichen zusamnenhängen gebraucht: "duch nasz <...> Na niebiosach by tecze zapalal" (lunser Geist <... w würde on den Himmeln Regenbogen entzunden]: R 23, vv. 13 und 16, bzw. 19) und: "Chcialbym na nuebie zapalic / Gwiazd meteory" ([Ich wurde gerne am Himmel entzunden / sternenmeteore]; R 64-1, vv. 7 f.).

Neben dem erhofften 'Glückszustand" selbst symbolisieren die synonymen Substantive 'zorza' und 'jutrznia' [Morgenrot] (dazu adjektıvisch 'jutrzniany') sowie 'świt' [Morgendämmerung] (dazu 'zaświtać' [dämmern]) insbesondere auch deren Beginn: "Wstańcie. Wenedy, w nowej zorzy swiatów!" ([steht auf, Weneder, in der neven Morgenröte der Welten!]: DP 18, v. 14); "Moze wejdzie zorza laski, / Moze szczęście blyśnie znów" ([vielleicht wird sich ein Morgenrot der Gnade erheben, / Vielleicht wird das Glück wleder leuchten]: Sw 7, vv. 19 f.): "Gdziekolwiek jesteś, chcialbyś odejść precz <...> Rojąc, ze w jutrznię los twój się przechyli / Na innym miejscu..." ([wo duch immer du bist, würdest du gerne fortgehen <...> Wähnend, das sich dein schicksal zu einer Morgenröte hin neigt, An einem anderen ort...J: $R$, vv. 1 und 3 f.): "nowych świtów Panie" ([Herr neuer Morgendämmerungen]; DP Epi., v. 4).

Im gleichen Bildzusammenhang werden schließlich die von den genannten Gestirnen ausgehenden 'Strahlen' ('promienie'; dazu 'promiennośc' [das strahlen], 'promienny'. 'promienisty' [strahlend], 'promienic sie'. 'zapromieniec'. 'wypromieniac' [(er)strahlen]) verwendet: " $z$ mojej mogily / Nowe promienie zycia wyplyna blekitnie" ([aus meinem Grab / werden neue strahlen des Lebens himmelblau hervorflieben]: R 10, vv. $13 \mathrm{f.l:}$ "Niegdyś 
zylem daleko <... N Na jakichs wyspach zlotych, w promienistych switach" ([Einst lebte lch ferne <...) Auf irgendwelchen goldenen Inseln, in strahlenden Morgendammerungen]; $R 28$, vv. 9 und 111 .

\subsubsection{Farbsymbol lk}

wie u.a. das letzte Textbeispiel zeigt, dient die von LANGE sehr häfig verwendete Farbe 'golden' ('zloty' und 'zlocisty'; dazu 'zloto' [cold], 'wyzlacac (sle)'. 'zlocic (sie)' (tsich) vergolden]. '(0)zlocony' (vergoldet]) durchwegs zur positiven Charakterisierung verschiedener Sachverhalte. Sie steht deshalb oft in Verbindung mit den zuletzt angefürten Metaphern für erhoffte 'Glückszustände" oder den 'Traum" davon:

"Mów, gdzıe jest czarodziejska two\}a zorza zlota?" ([sag, wo ist delne zauberhafte goldene Morgenröte?]; R 50, v. 58): "Przeczuwany w zlocistej nieokresinej zorzy - / Tajemniczy - nieznany - nowy ksztalcie bozy" ([Vorgeahnt in einer unbestimmten goldenen Morgenröte - / Geheimnisvolle - unbekannte - neue göttiche Gestalt]; DP Epi., vv. 5 f.l: "I nowa, zlota, nieokresina / Porywa mie ku sobie wizja wnlebowzieta" ([und eine neue, goldene, unbestimmte, Himmlische Vision reiBt mich hin]; R 42, vV. 7 f.): "O szczéscie! Snie mój zloty. śnie mój bezpowrotny!" ([o Gluck! Mein goldener Traum, mein unwiederbringlicher Traum!]: DP $11, v .11$.

Den diametralen Gegensatz zum 'Gold' bildet in LANGES poet 1scher Sprache die 'schwarze' Farbe ('czarny'), die zunächst zur Bezeichnung von Negativem ganz allgemein dient: "zycla czarne kaluze" ([die schwarzen Pfutzen des Lebens]; $R$ 2, v. 8); "I nie przebijem oka przez zbyt czarne chmury" ([und wir können die zu schwarzen wolken nicht mit dem auge durchdringen]; Swemu pokoleniu, v. 4). Plastisch vor Augen geführt wird die genau entgegengesetzte Bedeutung von 'golden' und 'schwarz' in "R 50":

w morzu clemności duch mój toczy sie bez końca

Po czarnych jakichs falach, spienionych w kedzlory:

A blask nıewldzialnego - dalekıego slońca

Czasem mrok uludnymi wyzlaca kolory.

Ale ta kropla zlota w przestrzenl hebanach

Znikoma jest - jak ziarno, rzucone na piaski:

I duch mój w czarnej nocy wije sie tumanach

I na prózno wyglada za promieniem laski. (vv. 1-8) 
[In einem Meer von finsternis treibt mein Geist ohne Ende Aut lrgendwelchen schwarzen wellen, die mit gekräuselten [schaumkronen versehen sind;

Und der schein einer unsichtbaren - fernen Sonne vergoldet manchmal die Dunkelheit mit tauschenden Farben.

Aber dieser goldene Tropfen im Ebenholz der Raume Ist winzig klein - wie ein auf sandflachen geworfenes Korn: Und mein Geist windet sich in den Schwaden der schwarzen Nacht Und hält vergebens Ausschau nach elnem strahl der Gnade.]

Daneben wird 'schwarz' in Verbindung mit dem nega $t$ i $v$ gewerteten Tod gebraucht, wie schon die symbolik der 'schwarzen Rosen' gezeigt hat. Das deutlichste Beispiel einer solchen Assoziation stellt " $R$ 21" dar, in dem die füfmalige verwendung von 'czarny' das 'Memento mori' der Zentralaussage deutlich unterstreicht. Weitere Beispiele: "Skrzydlo śmierci czarne" ([Der schwarze flügel des Todes]: R 63-1, v. 18): "Ty zaś plyń $z$ swym czarnym znakiem" ([Du <der Tod> aber fliebe mit desnem schwarzen zeichen dahin]: R 64-2, v. 15).

Am wenigsten konventionell ist LANGES symbolische Verwendung der Farbe 'weiß' ('bialy': dazu 'blalośc'. 'blelizna' [WeiB]). Sie erscheint fast durchweg in metaphysisch-transzendenten $\mathrm{zu}-$ sammenhängen: So werden der in " $k$ " beschworene "Astralleib" ("cleń") als mit einem atherlschen, weiken Gewand bekleidet ("eterowa strojny szata biala": v. 15) und der in "R 27" erweckte Urgeist ("Duch plerworodny": v. 5) des lyrischen Subjekts als mit weiken flugeln rauschend ("skrzydlami szumiacy bialemi": $v .3$ l beschrieben oder jenes 'höhere Leben" in den Tiefen unserer Seele mit elner weiben, mystischen lilie ("biala mistyczna lilija": R 57, v. 28) verglichen. Schließlich steht dre tote Geliebte an Gottes Thron im reinen weis der wadergeburt ("w przeczystej odrodzin bieliznie": R 12, v. 14).

Vor diesem Hintergrund wird deutlich, warum die in " $R$ 54" geschilderten, ob ihrer quasi jenseitigen, ewig unveränderlichen Harmonie benesdeten Marmorstatuen von Göttern und Heroen insgesamt zehnmal (!) als 'weiß' gekennzeichnet werden, z.B.: "Swiat marmurów tak bialych jak pióra labedzie, / Jako zimowe śniegi, bialościa promienny" ([Elne welt von Marmor, so weib wie Schwanengefieder, / wie wanterschnee, der vor weibe strahlt]: vv. $3 \mathrm{f.}$.

Dieses 'transzendente', positiv markierte 'WelB' wird, ähnlich wie das 'Gold', dem negativen 'Schwarz' entgegengestellt: 
A patrzac, na cóz patrza wasze biale oczy.

Gdy u stóp waszych czarny, bezksztaltny lud zywy. olśniony ich potega. zmęczony sie tloczy -

I upada omdlaly, drzacy i trwozliwy?... (R 54, vv. 41-44)

[Und blickend, auf was denn blicken eure weiben Augen,

Wenn zu euren fuBen das schwarze, unfömige lebendige volk, Geblendet von ihrer <sic!> Macht, erschopft sich drangt Und ermattet, zitternd und angstlich hinfallt?...]

Oberflächlich betrachtet, bezeichnet 'czarny' hier den Schmutz und das Elend der Menge (ganz ähnlich auch: "ta czarna cliba" (diese schwarze Menge]; v. 65). Im Lichte der Farbsymbolik jedoch wird es zum Repräsentanten des von Tod und Unglück geprägten 1 rdischen Daseins, im Gegensatz zur makellosen Reinheit der 'weißen' Ewigkeit.' Der Gegensatz von 'Schwarz' und 'Weiß' kommt am deutlichsten in Verbindung mit dem Motiv des Todes zum Ausdruck: Mit dem negativ gesehenen Vernichter-Tod, der 'schwarz' gefärbt lst (vgl. oben!), kontrastiert der weskgeflugelte ("bialoskrzydla": vgl. R 10, v. 2: DP 21, v. 6) Erlöser-Tod, der auf diese Weise zum Sinnbild der Transzendenz verklärt wird.

Eine sinnfällige Verbindung der drei für LANGE charakteristischen Farben mit einer Reihe wichtiger Schlüselwörter weist

das Sonett "DP 12. Vaisseau-fantôme" auf:

Senna - zlocista wyspa. Na niej śród zieleni

Zamek. Na baszcie - jasna królewna - w okienku $z$ oddali mie przyzywa biala chusta w reku Pójdí - śpiewa - pójdź tu cisze znajda potepieni.

Lecz morze wokól huczy, lecz morze sie pieni.

Okręt mój opętany plynie w dzikim lęku.

slysze echa okropne wszechistnienia jęku Peadze w dal, precz od wyspy, we mgly, po bezdeni.

Widma gonie nieznane, kresy bezpromienne. Królewna mi zniknęla jak marzenie senne Którego wiec juz nigdy - nigdy nie zobacze!

Okręt mknie: maszty czarne jak krzyze cmentarne, A zagle ma $z$ purpury niby krew. A gwarne Szaleja dokola morskich burz rozpacze.

(Eine goldene Trauminsel. Auf ihr im Grun

Ein SchloB. Aut dem Turm - elne blonde Prinzessin - $2 m$ fenster[chen

Ruft mich aus der ferne mat einem weiben Tuch in der Hand [heran -

Komm - singt sie - komm! hier werden die Verdammen Ruhe finden.

"Ganz ähnlıch verkörpert die 'welße' Marmorstatue der Venus in "Posag l dzlewczyna" die ewlge (platonische) "Idee" der Liebe in inrer Absoluthelt, während das vorüberkommende Madchen $f u ̈ r$ ihr irdisch-vergängliches Abbild steht. 
Aber das Meer dröhnt ringsum, aber das Meer schäumt. Mein verwunschenes Schiff schwimmt in wilder Angst dahin. Ich höre die schrecklichen Echos des Klagegestöhs des All[seins Ich Jage in die Ferne, weg von der Insel, in Nebel, uber [ Abgründe.

Ich jage unbekannte Phantome, dustere Grenzgefilde.

Die Prinzessin ist mir entschwunden wie ein eitler Traum Den ich also nie, nie mehr erblicken werde!

Das schiff jagt dahin: Masten hat es schwarz wie friedhofs-

Und segel aus purpur wie Blut. Und [kreuze, Ringsumher rasen die lärmenden Verzweiflungen der Meeres[sturme.]

Die Glücksvision der goldenen Trauminsel mit ihrer metaphysisch reinen ("biala chusta") stille kann der 'Verdammte" auf seiner Jagd nach den ewigen Geheimnissen, die hinter den Schrecken der irdischen Existenz verborgen liegen, nie erreichen.

4.4. Zusammenfassung

Das zuletzt zitierte Gedicht zeigt beispielhaft die quantitative und qualitative Bedeutung der Schlüsselwörter für LANGES Lyrik. Sie pragen den Sprachstil nicht unwesentlich und liefern in ihren spezifischen semantischen Relationen das Grundgerust für eine angemessene Textinterpretation.

Wenig typisch für LANGE ist im Falle des zitierten Sonetts allerdings der relatıv konkrete Wortschatz, der sich aus dem bildhaften Charakter des Gesamttextes ergibt. Im allgemeinen weist LANGES Lyrik, wie die analysierte Lexik zeigt, einen höheren Anteil an abstrakten Begriffen auf, der dadurch noch gestelgert wird, daß elne große Anzahl von ursprünglich konkreten Substantiven durch (konventionelle) Metaphoriszerung ebenfalls zu abstrakten umfunktioniert wird. Es dominiert bel LANGE dementsprechend die explizite Bezeichnung von Stimmungen und Gedankengängen über eine Schılderung inrer konkreten Manifestationen, woran der reflexiv-diskursive Grundcharakter seines lyrischen werks zusätzlich deutlich wird.

Stilistısch gesehen, ist ein erheblicher Tell gerade dieses unanschaulichen Vokabulars in der 'jungpolnischen' Sprachmanier verankert. So finden sich fast alle von M. JASTRUN ('1967:LXVI) als typisch 'jungpolnisch' angefühtten Ausdrücke bei LANGE als Schlüsselwörter. Es sind dies die Substantive 'zorza', 'śwlt'. 
'czar'. 'kwlat', 'gwiazda': 'duch', 'dusza', 'serce'. 'nieskończoność, 'otchlań', 'glabb', 'wiecznośc'; 'mrok'.

Doch fügt sich auch dieser Tell seines wortschatzes, der vor allem den 'Grundbegriffen' und 'bildhaften Naturelementen' zuzurechnen ist, bruchlos in die Gesamtstruktur seiner poetischen Welt":

Die in der ersten Gruppe (4.1.) zusammengestellten Begriffe, die den Bereich von absolutum und Geist verbalisieren, dienen gleichsam als philosophischer Hintergrund für die eigentlichen Probleme der Lyrik. Das zeigt sich unter anderem daran, daß diese Begriffssphäre nur selten zum Thema von Gedichten wird und dann unpersönlich-allgemelngültig gehalten ist (meist Monologtyp IIId).

Das wlrkliche persönliche Rlngen des Dichters basiert auf dem Wortschatz der Gruppe 4.2. So wird der Schlüselbegriff 'Tod' zugleich zum wichtigsten Zentralthema der Lyrik. Das wechselvolle Reflektieren kommt in den diametral entgegengesetzten Wertungen zum Ausdruck, denen der Begriff in den verschiedenen Kontexten unterliegt. Die entsprechenden Wandlungen erfährt bezeichnenderweise das antonyme Wortfeld 'Leben' unter umgekehrtem Vorzeichen (4.2.1.).

Die glelche Dialektik der Betrachtung weisen die stilistischen Felder 'Geheimnis' und 'Abgrund' auf: Einerseits bergen sie in sich das 'wahrhafte Sein', das Absolutum, dessen Erkenntnis zum höchsten ziel wird, andererseits aber verdammen sie eben dadurch den Menschen zu dauerndem, letztlich zum Scheitern verurteiltem Streben (4.2.2.).

Dieses Grunddilemma äußert sich im konkreten Leben einerseits als Sphäre der 'Finsternis' und des 'Leidens' (4.2.3. - 4.2.5.). andererseits in 'Sehnsüchten' und 'Träumen' (4.2.6. - 4.2.7.).

In diesen 2 wiespalt fügen sich 'bildhafte Naturphänomene" und 'Farbsymbolik' organisch ein (4.3.): 'Blumen' und 'Blüte' (4.3.1.), der Bereich der Himmelskörper (4.3.4.) sowie die Farben 'golden' und 'weiß' (4.3.5.) als positive, Wltterungsphänomene (4.3.2.) und die Farbe 'schwarz' (4.3.5.) als negative Metaphern. Der Bereich 'Meer' und 'Wellen' (4.3.3.) schließlich stellt in seiner Dialektik die synthese dieser beiden wertungspole dar, ähnlich wle 'Tod' und 'Geheimnis' in der expliziten Begriffswelt. 
LANGES Schlüsselwörter gehören also zwel großen, semantisch kontraitierenden Sphären an. Dementsprechend läßt sich eine dialektische Betrachtungsweise als charakteristisches Grundprinzip von LANGES lyrischem Werk feststellen.

$K$. WYKA gelangt bei der Untersuchung der Schlüsselwörter von $T$. GAJCY $z$ dem Ergebnis, daß ihre Einheitlichkeit - im Gegensatz etwa zur Differenziertheit bei K. K. BACzYNSKI in Forn elner unveränderlichen, ausschlieblichen und übermabigen Unterordnung unter ein einziges Motiv, den Katastrophismus, einen Mangel ("wada") darstellt (1969:229). Entsprechend kann man für LANGES Lyrik feststellen, daß die Gespaltenheit von Wortschatz und Weltsicht dieser eine innere spannung verleiht. die sicher einen ihrer Vorzüge darstellt. 


\section{Literarische Bezugnahmen}

Schon in den vorangegangenen Kapiteln wurde des öfteren auf verschiedene literarische Ansplelungen oder Anknüpfungen an kulturelle Traditionen durch den Lyriker LANGE hingewiesen. So bringen die Gedichtzyklen "Sonety wedyckie" und "Kslegi proroków" östliches Gedankengut und der zyklus "Logos" die philosophischen Konzeptionen polnischer Dichter und Denker in die strenge Form des Sonetts bzw. der Sestine. Einige den Schlüsselwörtern zuzurechnende Begriffe verweisen auf die antike bzw. blblisch-chrlstliche Kultur. Auch Anspielungen aus dem Bereich von Versifikation und Strophik waren zu verzeichnen.

Daruber hinaus mag der zyklus "Ze starych legend" beispielhaft Spannweite und Funktionsweise dleses dichterischen Verfahrens bei LANGE zelgen: All die Paraphrasen des Glelchnisses von den 'klugen und törichten Jungfrauen' aus der Bibel (Matth 25. 1-13, etc.: in 2SL 2; zitiert oben in Abschnitt 2.2.3.1), einer Stelle aus der "Ilias" (Gesang 24, vV. 448-456; in ZSL 7), des "Prisoner of Chillon" von BYRON (in 2SL 4), eines Bildes aus KRASINSKIS "Przedświt" (vgl. 1973:160, vv. 175 f.: in 2SL 5), der Schlußszenen von WYSPIANSKIS "Wesele" (1927, Akt III, Szenen 34-37; in 2SL 3) sowie der Anfangsworte der polnischen $\mathrm{Na}-$ tionalhymne (in 2SL 8), eines Volkslieds (vgl. PRZYBOS 1957: 221; in 2SL 12) oder eines geflügelten Worts (in 2SL 6) dienen zunächst dem Zweck, die Geschichte des von der Landkarte verschwundenen und wiedererstandenen Polen bildhaft, teilweise allegorisierend darzustellen. Zugleich mögen diese Paraphrasen auf engere und weitere Inspirationsquellen des polnischen volks und des Dichters selbst in dieser schwierigen Lage verweisen." Vor allem aber zeigen sie LANGES tiefe Verwurzelung in nationalen und übernationalen Kulturtraditionen.

\footnotetext{
\#Vgl. LANGES explizite Aussage in seinem Poem "Pleśn o slowle" (VIII, vV. 25-28): "Díwiecznymi struny budzili narody, / Szekspıry. Danty. Homery, Shelley'e: / Wino miloścl 1 ogleń swobody / wlewall w ludów bratobójcze dzieje." [Mlt klangrollen saiten erweckten die völker / Die shakespeares, Dantes, Homere. shelleys; / Den Wein der liebe und das Feuer der Freihelt/gossen sie in der volker brudermorderische Geschlchte.].
} 
Sehr viel weitgehender noch ist die Verwendung von vorgegebenen Traditionen etwa im Falle von "Pog 8": Dem agitatorischen Zweck des Gedichts entsprechend, ist es als Collage aus den Anfangsworten bekannter, meist revolutionärer oder patriotischer Lieder des 19. Jahrhunderts gestaltet (vgl. HERTZ 1965:329-331). In ähnlicher Weise könnte man die Versdramen "Wenedzi" und "Atylla" als Pastiche nach SKOWACKI bzw. eine Art Cento mit nationalen wie allgemeineuropäischen Vorbildern charakterisieren (EUSTACHIEWICZ 1965:383; vgl, auch JAKUBOWSKI 1960:8 und KRZYŻANOWSKI $1963: 57$ f.).

Aber LANGE beschränkt sich nicht auf Bezugspunkte außerhalb seines Werkes. Wie etwa die beiden Sonette "DP 18 . Wenedzi" und "DP 19. Atylla" zeigen, knüpft er in seiner Lyrik auch an eigene Werke mehr oder weniger explizit an. Selbst in solchen Fällen verzichtet er nicht auf den Einbau von fremden zitaten, wie etwa zu Beginn von "DP 18": "Sromota wieczna i nienagrodzona / Szkoda, Wenedzi!" ( Ewige Schande und nicht wiedergutzumachender / schaden. Weneder!]: vv. 1 f.l. Es ist dies der fast wört$1 \mathrm{lch}$ übernommene Anfang von KOCHANOWSKIS aufruttelnd-patriotischer "Pleśń II, 5" (21953:317 f.), die LANGE beschwort, um die Aussage seines eigenen Gedichts wirkungsvoll zu unterstreichen und außerdem den Cento-Charakter der durch das Gedicht beschworenen Tragödie "Wenedzi" deutlich zu machen.

All die angefürten Beispiele belegen die Bedeutung von Bezugnahmen jeglicher Art für das Werk Antoni LANGES." Es ist dies ein wichtiger Gestaltungsfaktor seiner poetischen Sprache. der elne eingehendere Untersuchung lohnt.

Zunächst erscheint dabel die Frage interessant, aus welchen kulturellen Hauptquellen er schöpft. Zum elnen lassen sich auf diese Welse ubergreifende geistesgeschichtllche Bezuge und Ausel nandersetzungen erfassen, zum anderen können so kulturelle

"Hierauf ist im ubrigen schon mehrfach verwiesen worden, etwa von M. PODRAZA-KWIATKOWSKA: Lange verwandte gerne Elemente der Kulturtradition, indem er an diese allein schon in den Titeln anknupfte ("Pogrzeb shelleya", "Ksiggl proroków", zahlrelche beruhmte Gestalten im zyklus "Logos"), indem er literarlsche Ansplelungen einfuhrte, lndem er st 1 lisierungen verwandte $(1971: 486)$. Vgl. auch KRZYŻANOWSKI 1963:57 f.! S. LICHANSKI charakterisiert LANGE seiner intensiven Rezeption und Verarbeitung jeglicher Art von petrifizierter Kulturtradition wegen sogar als buchhalterischen schriftsteller ("plsarz-klerk": 1962:96). 
"Färbungen" bestimmter Gedichte oder zyklen herausgearbeltet werden, wie es der antike, der biblische, der mittelalterliche und besonders deutlich der orientalische Bereich nahelegen. (La letzterer aber schon ausfürlich von $F$. MACHALSKI untersucht worden 1st (1937, vgl, besonders 30-80), klammere ich diesen bei der Zusammenstellung kultureller Bezugssphären aus.)

Ebenso wichtig ist die Frage nach den konkreten Funktionen der Bezugnahmen im Aufbau der einzelnen Texte. Diese Funktionen können von sehr verschiedener Art und von unterschiedlichem Gewicht sein, wie im folgenden zu zeigen ist.

Es kann in diesem Kapitel wohlgemerkt nicht der versuch unternommen werden, a 11 e Bezugnahmen in LANGES lyrischem Werk nach den angefürten Kriterien erschöpfend aufzuschlüsseln. Es sollen lediglich die großen Haupt-Inspirationsquellen (unter Beibringung einiger Belege) charakterisiert sowie die grundlegenden Textfunktionen der Bezugnahmen bel LANGE exemplarisch aufgezeigt werden.

\subsection{Die griechisch-römische Antike}

Als Musterbeispiel für eine Bezugnahme auf die antike Kultur kann das schon erwähnte (vgl. oben Abschnitt 3.1.1.) "R 48" dienen: Ein Motiv aus der homerischen Proteus-Episode ("Odyssee". 4. Gesang, besonders vv. 384-461) wird philosophisch umgedeutet; das antike 'Kolorit' wird dadurch iber das gesamte Gedicht hin aufrechterhalten, daß die sich wandelnden Gestalten des ('maskierten') lyrischen Ichs - soweit sie nicht als allgemelngültige Phänomene beschrieben werden - ausschließlich der griechischen Kultursphäre entnommen sind, z.B.: Sirene, Harpyie. Gorgone, Eumenide, Chimare, Tritonen; Akteon, Endymion, orest.

Diese und andere Begriffe der antiken Mythologie erscheinen bei LANGE häufig in den verschiedensten Zusammenhängen als Metaphern und Vergleiche. Die rächenden Eumeniden lauch Erinnyen oder - lateinisch - Furien) etwa stehen für die innere Zerrissenhelt des Menschen (DP 2, vv. 4 und 10; Son 21, v. 2 ) ebenso wle für die Schrecken des Krieges (Sielanka II, $v$. $\varepsilon$ ) oder für die Sonnenstrahlen, die geheimnisvolle Melodien aus dem Unterbewußtsein zum Ersterben bringen ( $R 1$, vv. $10 \mathrm{f.}$ ). Zahlreiche mit der Unterweltsvorstellung verbundene Ausdrücke iHades, Tar- 
taros, Erebos, Lethe, Kokytos, styx, Charonl erscheinen zur Bezeichning des Todes ( $8, v, 10 ; R 21$, vv. 18-20) oder auch der tiefsten Abgründe des Lebens (R 60, v. 18 ).

wichtiger jedoch als solche eher ornamentalen Verwendungen isolierter Begriffe sind Fälle einer echten Integration antiker Mythen in den geistigen Gesamtzusammenhang eines Gedichts, wie ich es (im Bereich 'Hades") für das Gedicht "R 33" (vgl. oben Abschnitt 3.1.2.: ähnlich auch R 63-1) oder am uminterpretierten Proteus-Mythos von " $R$ " 24 zeigen versucht habe. Dies gilt insbeosondere auch für den - ebenfalls uminterpretierten Mythos vom Jäger Akteon, dessen Gestaltung bei LANGE von MACHALSKI ausfühlich untersucht wurde (1937:69-74), sowie für das Prometheus-Motiv (vgl. Son 16, vv. 9-14 und Son 17, vv. 5-8 sowle R 61 , vV. $15 \mathrm{f.l}$.

Einen hervorragenden Platz in LANGES antikem Beziehungsgefuge nehmen die homerischen Epen ein, an deren Verbreitung in Polen er selbst beteiligt war."0

Neben den schon erwähnten Episoden verdient das Kirke-Motiv ("Odyssee". 10. und Beginn des 12. Gesangs) Beachtung: "Smierci [... czy znajde w twym królestwie czarowna Eeje, / Gdzie Cyrce niewidzialna leczy duchów jeki?..." ( $\operatorname{Tod}(\ldots)$ Werde ich in deinem Reich ein zauberhaftes Aiaia finden, / Wo eine unsichtbare Kirke der Geister Klagegestöhn heilt?...]: R 32,vv. 3 f.: vollständig zitiert im Abschnitt 3.4.2.!). Geschickt wird durch dieses knappe Bild ein komplexer Tatbestand evoziert: Wie die Insel Alaia dem Odysseus und seinen Gefährten zunächst zum Unglücksort zu werden droht (Verwandlung in erdaufwülende schweine), dann aber einen glücklichen Aufenthalt gewährt, so bietet das Reich des grundsätzlich zunächst abschreckenden Todes vielleicht die ersehnte Erholung: "Czy znajde zapomnienie to i ukojenie. / Które. go tak potrzeba duchom umeczonym" ([werde ich das vergessen und die Linderung finden., Die den müden Geistern so nötigist]; vv. $5 \mathrm{f.l}$.

Doch dann setzt die zweite Hälte des Gedichts mit ihrer erschreckenden Gegenerwägung ein, ob das nicht alles Täuschung ist:

- V Vl.: HOMER: Ilıada. Stréscll l opracowal A. WRZESIEN [= A. LANGE]. Warszawa 1904 ; HOMER: Odysseja. Stréscil A. WRZESIEN. Warszawa 1904 : Epos. Zbiór arcydziel poezjl eplckiej wszystkich czasów 1 narodów w streszczeniach 1 wyciagach. Ulozyl A. LANGE. Bd. 5. Epos greckie: HOMER: Illada. Brody 1912. 
"Moze smierć - to najwyższe zludzenie" ([Viellescht ist der rod die höchste rauschung]: v. 8). Und hier wird die weitergrelfende Dimension des Kirke-Bildes deutlich: Der Aufenthalt auf Aiaia steht in unmittelbarem Zusammenhang mit der Fahrt in den grauenerregenden, eindeutig negativ gesehenen Hades: eine Episode, die In der "Odyssee" (Gesang 11) vom Bericht über Aiaia (Gesänge 10 und 12 ) übrigens ebenso umschlossen wird, wie der fragende Haupttell des Gedichts " $R$ " von den refrainartigen Anfangsund Schlußzeilen ( $v v .1$ f. und 12 ), die die positive Grundeinstellung dem Phänomen Tod gegenüber zum Ausdruck bringen: "Smierci - a jam cie przybral w zloty plaszcz bezcenny!" ([ rod - und ach tabe dich in einen goldenen, unschätzbar wertvollen Mantel gekleidet 1]: v. 12).

Die homerischen Epen werden aber auch in ihrer Gesamtheit als Metaphern verwendet: "Rzeklbys, milionami powstali Atrydzi“" / I jakas oblakana zaczeli Iliade" ([Gleichsam sind die Atrlden millionenfach auferstanden / Und haben eine verruckte Ilis begonnen]: Sielanka II, vv. 12 f.). Diese bildhafte Fassung des I. Weltkriegs wird im Gedicht "Iliada i Odyseja" zum thematischen Vorwurf ("Szal Askaniuszów rozpoczal krwawa ostatnia Iliade" [Der wahnsinn der Ascaniusse <Askanier!> hat die letzte blutige Ilias begonnenl: v. 5), allerdings erweitert um die sich anschließende Odyssee der aus allen Himmelsrichtungen in das wiedererstandene Land heimkehrenden polnischen Kämpfer. u.a. aus der Magdeburger Gefangenschaft ("z Magdeburskiej niewoli", d.h. Pilsudski: v. 26).

Auf ganz ähnliche Weise wird die "Orestie" zum Bild für die Selbstzerfleischung der Menschheit: "Jutro zakończym nasza krwawa Oresteje" ([Morgen werden wir unsere blutige orestie beenden]; Prz 5, v. 8). Bezeichnenderweise entstammt - nicht nur des Reimes wegen - auch der Gegenbegriff dem griechischen Kulturberelch: "Jutro zdobedziem szturmem zlote Elizeje" ([Morgen werden wir goldene Elysien im sturm nehmen]; v. 5). Die beiden Begriffe symbolisieren so die Kontinultät der Menschheltsgeschichte, das sich ständig wiederholende Streben nach dem Idealzustand, das schon bel den Griechen vergeblich war.

- I Ich verbessere das sicher als Druckfehler zu wertende "Atryd" des Textes zu "Atrydzi", wie auch vom Reimpartner "widzi" (v. Ii) nahegelegt wird. 
Der spezifisch römische Bereich ist bei LANGE sehr viel schwächer als der griechische repräsentiert: So polemisiert er mit dem bekannten Proöm zum 2. Buch von LUKREZENS "De rerum natura" (List do redaktora, vv. 13-20) oder knüpft mit dem Titel eines Gedichts (Exegi...) an HORAZENS Ode III, 30 an, grenzt sich aber von ihm dadurch ab, daß er in dieser (Zwischen-lBilanz für sich das Schaffen einer geheimen, inneren Phantasiewelt konstatiert, im Gegensatz zum nach außen gerichteten Ruhmesstolz des Römers:

Swiat zbudowalem sobie jasny i promienny -

W tajemnicy przed ludzmi, nieznany nikomu:

Swiat na pól rzeczywisty - i na poly senny,

I zyje w nim i kraze jak po wlasnym domu. (vv. 1-4)

[ Ich habe mir eine helle und strahlende welt erbaut Verhelmlicht vor den Menschen, niemandem bekannt:

Elne Welt, halb wirklich - und halb traumaft, und ich lebe und bewege mich in ihr wie im eigenen Haus.]

LANGES Sympathie und Interesse gehören vor allem dem weiBen (!) Griechenland, weniger dem elsernen Rom ("biala Grecja i Roma zelazna"; R 37, v. 3).

\subsection{Dle Welt der Blbel}

Neben den schon erwähnten spezifischen Begriffen (vgl. die Abschnitte 4.1.5. und 4.2.7.) sowie den paraphrasierten Gleichnissen aus der Bibel (vgl. R 33 und $R$ 63-1 sowie ZSL 2) verwendet LANGE häufig Anspielungen auf biblische Geschehnisse zu den verschiedensten $\mathrm{Zwecken:}$

So werden in "Prz 3" der 'Sündenfall' (1. Mose 3, 1-7; vgl. Prz 3, vv. 9-11) und der 'Turmbau zu Babel' (1. Mose 11, 1-9; vgl. Prz 3, v. 12) - ebenso wie der versuch der antiken Giganten, den Himmel zu stürmen (vgl. Prz 3, v. 13) - als Manifestationen des personifizierten stolzes ("Duma") interpretiert: der Rückgriff auf die Bilder der jüdischen - und griechischen Mythologie unterstreicht dabei die altehrwirdige Tradition dieser (approbierten) Lebenshaltung.

Vor allem der pathetischen Ausdruckssteigerung sollen Anspielungen auf den 'Durchzug durch das Rote Meer' (2. Mose 14) oder die Wirkung des Moses-Stabs (2. Mose 17, 5-7) dienen: "Mówla, ze za tym strasznym, za Czerwonym morzem - / Sa jakieś Atlantydów pola Elzzejskie" ( [Man sagt, dab hinter diesem schreck- 
lichen, hinter diesem Roten Meer - / Eleusische Atlantzs-Felder sind]; Sielanka II, vv. 48 f.. ahnlich v. 62; vgl. auch Pog 12. v. 61; das Blutmeer des $I$. Weltkrlegs muB also durchschritten werden, um das "Gelobte Land" zu erreichen); "Chcesz rozjaśnic te mroki? napelnić tę próznie? / W glazach obudzı́́ wode - jak laska Mojzeszowa?" ([willst du <die Geliebte> diese Finsternisse erhellen? diese leere ausfüllen? / In Felsen wasser erwekken - wie ein Mosesstab?]; Impromptu, vv. 26 f.).

Auch die Eucharistie (vgl. Matth 26, 26-28; etc.) wird zum Symbol der Auferweckung durch die Geliebte: "Roztopilem sie w duszy twej winle i chlebie $<\ldots .$. zmartwychwstanie / Wzeszlo ml w blyskawicy nagle, niespodzianie" (ll lch bin in wein und Brot deiner seele zerflossen $<\ldots$. Die Auferstehung/Ging mir in elnem Blitz plotzlich, unerwartet am Himmel aufl; Son 20. vv. 8 und 12 f.l.

Polemisch umgewendet schließlich werden ein Wort Jesu aus dem Neuen (Matth 22, 21: etc.) und die Paradiesesgeschichte aus dem Alten Testament (1. Mose 2, 8; 3, 1-24): Das bekannte Zitat "Wiec oddawajcie Cesarzowi, co jest Cesarskiego" I in der übersetzung des Jakub WUJEK. Bei LUTHER: "So gebet dem Kaiser. was des Kaisers ist") wird von LANGE unter Ausnutzung der Mehrdeutigkeit des polnischen verbs "oddawać" ([abgeben] vs. [zurückgeben]) zu elner rhetorisch wirksamen sozlalrevolutionären Aussage umgestaltet:

Cezarom oddaj wszystko to, co jest cezarów:

Oddaj im widma gwaltów, zabójstw i grablezy:

oddaj meczarnie glodu i hanbe pregierzy.

oddaj im spustoszenia 1 luny pozarów. (Cezarom oddaj.... vv. $1-4$ )

laib den casaren alles, was der cäsaren ist:

Gib ihnen die Gespenster von Gewalt, Totschlag und Raub,

Glb die Hungerqualen und die schande an den Prangern,

Gib zhnen die Verwüstungen und den Feuerschein der Brände [zurück.]

Außerdem wird das (frühe) Gedicht zu elner Kampfansage an die obrigkeitshörige und zugleich auf das Jenselts vertröstende Aussage des Originalsatzes, dessen zweiter Tell bekanntlich lautet: "und Gott, was Gottes ist" (LUTHER).

In "R 50" dient die "Vertrelbung aus dem Paradies" als symbolisches Aquivalent für das gelstige Meer der Finsternis, in dem das lyrische Ich umherirrt: 
Sam raje sobie stwarzam - i sam siebie kusze,

By zerwać z drzewa wiedzy owoc zakazany -

Sam mieczem archaniola wypęzam swa dusze

Z Edenów - i tak blądze, z Edenów wygnany. (vv. 9-12)

[selbst erschaffe ich mir Paradiese - und selbst fuhre ich

[mich in versuchung,

Die verbotene frucht vom Baum der Erkenntnis zu reiben -

Selbst vertreibe ich meine seele mit dem Schwert des Erzengels

Aus den Eden-Gärten - und so irre ich umher, aus den Eden-

[Garten verjagt.]

Zugleich verweist hier die Umkehrung des religiösen Mythos darauf, daß die Religion keine geistige Geborgenheit mehr vermitteln kann; das lyrische Ich ist auf sich selbst zurückgeworfen und letztlich auch selbst verantwortlich für seine spezifische Rezeption der Erscheinungen des Lebens.

\subsection{Christliches Mittelalter und europälsche Neuzelt}

Neben der welt der Bibel findet auch das christliche Mittelalter Niederschlag in LANGES lyrischem Werk. Am repräsentativsten ist hier wohl die Bezugnahme auf die bekannte, dem THOMAS VON CELANO zugeschriebene Totenamtssequenz "Dies irae", die den Tag des Jünsten Gerlchts in dusteren Farben malt:

Dies irae, dies illa

Solvet saeclum in favilla

Teste David cum Sibylla.

(DREWES/BLUME/BANNISTER 1915:269)

Die (auch formale) Anlehnung an dieses Vorbild soll den Schrecken unterstreichen, den zum elnen die unweigerlich kommende soziale Revolution hervorruft, obwohl sie vollkommen gerechtfertigt ist:

Dies irae - dies illa

Z mroku czasów sie wychyla!

Swladkiem Chrystus i Attyla! (Pog 11, vv. 1-3)

Lies irae - dies illa

Neigt sich aus dem Dämmer der zeiten!

zeuge sind christus und Attlia!l.

und der zum anderen die wiedergeburt des geteilten Polen begleitet:

Dies glorlae, dies illa

Jak poczwarka w ksztalt motyla,

$z$ mroku w spazmach sie wychyla.

$w$ porodowych wstaje mękach,

w Iun czerwieni, w zelaz szczekach,

w krwi, rzęzeniu, glodach, jękach. (Dies illa, vv. 1-6) 
[Dies gloriae, dies illa neigt sich, wie eine larve in die Gestalt eines schmetterlings, In Krämpfen aus dem Dämmer.

Dieser Tag ersteht in Geburtsqualen, Im Rot der Feuerscheine, im Klirren der Eisen,

In Blut, Geröchel, Hungersnöten, Klagerufen.]

Ganz ähnlich wird der (politische) Lebensweg von LANGES Generation durch eine - auch formale - Paraphrase des DANTEschen Wegs von der Hölle über das Purgatorium bis zum Paradies anschaulich gemacht:

U schylku drogi naszego zywota -

Rzucamy okiem wstecz, gdzie nas wirgili

Prowadzil milczac za piekielne wrota. (Boska komedia, vv. (1-3)

LAn der Neige unseres Lebensweges -

Werfen wir den Blick dorthin zurück, wo uns vergil

schweigend durch die Höllenpforte hineingeführt hatte.]

Im früheren "Sonet [1]" vergleicht LANGE seinen (persönlichen) Lebensweg hingegen mit dem realen DANTE ("Jestem w dniach, kiedy Dante schodzil w piekiel progi" ( $I$ ch bin in den Tagen, in denen Dante zu den Schwellen der Hölle hinunterstiegl; v. 10). um die Nichtigkeit des bisher von ihm vollbrachten, gleichzeitig aber auch seinen - unerreichbaren - literarischen Anspruch zu unterstreichen.

Der Stellenwert DANTES in LANGES Traditionsbezügen wird überdies an mehreren Anspielungen auf die göttliche Beatrice ("Triumfalnie podYość sie uśmiecha", vv. 31 f.: "Starozytnym Gallów obyczajem", v. 19) und vor allem am "Vita nova" betitelten zyklus von Liebesgedichten deutlich, der an seine eigene "Beatrice' gerichtet ist und inr so die Aureole der berümten Vorgängerin verleiht, wobei zugleich an das idealisierende, metaphysisch verklärende Bild der Geliebten bei DANTE angeknüpft wird.

stellt hier LANGE seine Liebesbeziehung in den Rahmen DANTEBeatrice, so ist es im Gedichtzyklus "XXVII sonetów" auf ganz ähnliche Weise das Renaissance- 'Paar' MICHELANGELo und Vittoria Colonna: "Zjawilaś mi sie niby Vittoria Colonna, / Niespodziana zwiastunka nowych wiosen rózy" ([Du bist mir erschienen wie eine Vittoria Colonna, / Eine unerwartete Kunderinder Rosen neuer Fruhlinge]; Son 4, vv. 1 f.). Der zyklus stellt sich damit bewUßt in die Tradition von MICHELANGELOS "Rime" und der darin zum Ausdruck gebrachten idealen Auffassung von Llebe und Geliebter: bei LANGE wird dies etwa so formuliert: 
I stanelismy nagle w wyze uniesieni -

Nad ziemie - jak niebieskich dziedzin wyslannicy.

W dali - pod nami - ziemskie zostaly tumany.

Objawienie nam śpiewać naraz piéśn zaczęlo -

Az duch rozkolysany i ukolysany

Tworzyć jal jakieś nowe i nieznane dzielo.

W jednej chwili rozszerzyl nam sie w bezgraniczny

Wszechświat - ten promienisty prześwit blyskawiczny. (Son 19. vv. 7-14)

[Und wir standen plötzlich in Höhen erhoben -

Uber die Erde - wie Gesandte himmlischer Gefilde.

In der ferne - unter uns - blieben die irdischen Nebel zurück.

Die offenbarung begann uns zugleich ein Lied zu singen -

Bis der Geist, in schwung gebracht und eingewiegt,

Ein neues und unbekanntes Werk zu schaffen begann.

In einem Augenblick erweiterte sich uns in ein grenzenloses

weltall - dieser strahlende Blitzesschimmer.]

Aus dem Bereich der späteren europäischen Kulturgeschichte sind vor allem SHAKESPEARE, die englische Romantik und Richard WAGNER als Anknüpfungspunkte für LANGE hervorzuheben:

So wird ihm die handlungsunfähige Hamletgestalt zum Negativsymbol, von dem er sich explizit abgrenzt: "A ty, dusz truciclelu, idź mi precz, Hamlecie <...> oto nadszedl dzień czynu, co watpiace zmiecie" ([und du, seelenvergifter, geh mir weg, Hamlet <... Der Tag der tat ist angebrochen, der die Zweifelnden hinwegfegt]: $R$ 55, vv. 1 und 4): andererseits sind ihm Macbeth und Macduff die Repräsentanten einer 'romantischen' Lebenshaltung, die der technikgläubigen, vermassten Moderne entgegengestellt wird (Romantyczność; vgl. oben die Abschnitte 3.1.1. und 3.2 .1 .1 .

Neben dem schon erwähnten "Prisoner of Chillon" findet auch BYRONS "Manfred" Eingang in LANGES Lyrik. Unter anderem GOETHES Faust an die Seite gestellt, wird diese Gestalt in all ihrer Zerrissenheit zu einem der Wegbereiter des neuen, besseren Zeitalters: "Z marzeń Faustów, co patrza w bytu kolowroty - / 2 Manfredów nieugiętej za śmiercia tessknoty - <... plynie duch nowej Godziny" ([Aus den Träumen der Fauste, die in das Durcheinander des seins blicken, / Aus der unbezwingbaren sehnsucht der Manfreds nach dem tode <...> fliebt der Geist der Neuen stunde]; DP 20 , vv. 2 f. und 8 ).

Dem Lobpreis SHELLEYS, des zweiten großen Vertreters der englischen Romantik, ist ein eigenes Poem gewidmet (Pogrzeb Shelley'a), wobei SHELLEYS eigene literarische schöpfungen in das 
Werk eingefüht werden (vgl. LORENTOWICZ 1908:85). Auf dieses verweist "DP 5" in seiner Gesamtheit (vgl. auch Abschnitt 5.5.) und $f a B t$ die dort breit entwlckelte Aussage prägnant zusanmen: SHELLEY wird zum Seher stilisiert, der goldene Mittagsstunden / In den ungeborenen zeiten sonniger At lantis-Inseln erblickt hat ("co widzial zlote poludnia godziny / w nieurodzonych czasach Atlantyd slonecznych": vv. 3 f.l.

Ebenfalls zunächst als (balladeskes) Poem ist von LANGE der durch die WAGNER-Oper bekannt gewordene "Holländer"-Stoff verarbeitet" 2 und schließlich im bereits zitierten "DP 12 "kondensiert und interpretiert worden (vgl. oben Abschnitt 4.3.5.). Hier und in anderen fällen (vgl. etwa: Rien que pour vous III, $v$. 12) steht die irrende Seefahrergestalt für die gesstige unbehaustheit, das vergebliche streben nach Erkenntnis und der daraus resultierenden 'Ruhe'.

Neben dem "Holländer" bezieht sich LANGE auch auf die Gestalt Lohengrins:

Posluchaj mie! Ja w sobie mam coś z Lohengrina:

Nie lubie, by kto nazbyt mi zazieral w dusze.

Bezimiennym dla świata być chce i być musze -

I znikam, gdy mój Graal krwawić sie zaczyna. (Son 24, vv. 1-4; vgl. auch Bezsenna noc, vv. 102-104)

[Höre mir zu! Ich habe etwas von Lohengrin an mir:

Ich liebe nicht, daB mir jemand zu sehr in die seele hinein-

[schaut.

Namenlos möchte und muB ich für die welt sein -

und ich verschwinde, wenn mein Gral sich zornrot zu färben

[beginnt.]

Ebenfalls durch WAGNER dürfte schließlich der Gebrauch des Begriffs Götterdammerung ("zmierzch bogów": auch als "Ragnaröck") inspiriert sein. LANGE verwendet inn zur Bezeichnung der Schrekken des I. Weltkriegs (Mickiewicz II, V. 4: Sielanka II, V. 64).

\subsection{Der polnische Kulturbereich}

Zu Beginn des Kapitels 5 wurde bereits eine Reihe von Bezugnahmen LANGES auf die polnische Kulturgeschichte erwahnt, angefangen bei Jan KOCHANOWSKI über den 'Marsch' der polnischen Legio-

" 2 Das Poem paraphrasiert Sentas "Ballade" aus dem 2. Aufzug unter fast wörtlicher Übernahme der Wendung "blutrot die Segel. schwarz der Mast": "maszty ma czarne <...> A zagle ma z krwawej purpury": Latajacy holender I, vv. 32 f. u.ö.: ähnlich DP 12 , vv. $12 \mathrm{f}$. 
nen und die polnische Romantzk bis hin zu LANGES unmittelbarem Zeitginossen Stanis $x$ aw WYSPIANSKI.

Wie schon diese Beispiele gezeigt haben, macht sich LANGE vor allem die patriotisch-politische Komponente der nationalen Kulturtradition in seiner Lyrik zunutze. Insbesondere ist hierbei auf die messianistischen Konzeptionen der drei "großen" Romantiker $z$ verweisen, die quasi als Einheit betrachtet werden. was u.a. auch in der Zusammenstellung der von ihnen geschaffenen literarischen Gestalten zum Ausdruck kommt: "Sny Irydionów, Konradów, Anhellich" ([Die Träume der Irydions, Konrade, Anhel1is]; We śnie, v. 27: ähnlich: Mickiewicz IV, v. 46).

Besonders häufig bezieht sich LANGE auf MICKIEWICZ' "Ksiegl narodu polskiego i pielgrzymstwa polskiego" und KRASINSKIS "Przedświt" als zwei zentralen Werken des polnischen Messianismus. So geht der Titel des 1925 erschienenen Bandes "Trzeci dzien", der vor allem politische Lyrik enthält, auf diese beiden Quellen zurück, wie LANGE auch durch die dem Buch vorangestellten Motti deutlich macht (TD:6): "A trzeci dzień wnijdzie, ale nie zajdzie" (lund der dritte Tag wird heraufkommen, aber nicht untergehen]; vgl. MICKIEWICZ 1952:17) sowie: "Dnia trzeciego się rozwidni / I na wleki bedzie rano" ([Am dritten Tage wird es hell werden / und fur immer wird Morgen seinl: vgl. KRASINSKI 1973:161, vV. $216 \mathrm{f} .1$. Wie die beiden 'Seher' prophezeit hatten, war Polen - gleichsam ein Christus der Völker - am dritten Tage wlederauferstanden. Diese Anspielung wird auch sonst mehrfach verwendet und bezeichnet das ersehnte (Mickiewicz I. v. 10) oder schon eingetretene Wiedererstehen Polens (Nowa pléśn I, v. 9: Pochwala zycia, v. 21).

Eine weitere Stelle aus MICKIEWICZ" "Ksiegl" paraphrasiert LANGE in " $\mathrm{L}$ " ( vgl, oben Abschnitt 2.3.1.), in dem er des 'Sehers" geschichtsphilosophisches system darlegt: "Dzis o wojne wszechludów blagamy cie, Panie!" (lHeute flehen wir dich um den Krieg aller Volker an. Herrj; v. 14. Vgl. MICKIEWICZ 1952:58: "O wo jne powszechna za wolność ludów / Prosimy cię, Panie" [Um den allgemesnen krseg fur die freiheit der völker/ Bitten war dich, Herr]). MICKIEWICZ' Vision eines - allerdings nahen allgemeinen Volksbefrelungskrlegs betrachtet LANGE als durch die Ereignisse des I. Weltkriegs erfült (vgl. auch das langere Gedicht "z poza chmury"). 
Der Gedanke, daß Polens Befreiung durch einen blutigen Krieg erkauft werden muß, wird von LANGE schon früher, in "Sw 8 ". dargelegt: Der Tagesanbruch zeigt sich zunächst in einer "blutigen" Morgenröte, bevor die Sonne, die z.B. auch in "ZSL 2 " als Metapher für das wiedererstandene Polen dient ( $v$. 9), strahlend am Himmel steht (vollständig zitiert im Abschnitt 2.2.3.). Deutlich wird die Anspielungsebene insbesondere an den " $K r i e g s^{\prime}$ Metaphern, die den ersten Teil des Textes pragen (vv. 1, 3 f.. $6)$, bis der feuerschein des blutes erlischt und die goldene schonheit der Sonne alle Dinge vergoldet ("Kuna krwi zagasa <...> I wszystkie rzeczy zloci jego zlota krasa": vv. 9 und 11). So $f u ̈ g t ~ s i c h$ das scheinbar vordergründige "Naturgedicht" organisch in den MICKIEWICZ geweinten "Switez"-zyklus ein Ivgl. dazu oben Abschnitt 4.1.5.1.

Auch die Tradition von KRASINSKIS "Przedświt" nimmt LANGE durch weitere Anknüpfungen auf. So stellt er an den Beginn seines zyklus "Przekleństwa" folgendes $z_{1}$ tat aus KRASINSKIS Poem als Motto:

Ale w sercu jest pogarda.

Co ma takze swe panienstwo. I nie zechce - nadto harda -

Roznamietnic sie w przekleństwo.

(vgl. KRASINSKI 1973:163, vv. 297-300)

laber 1 m Herzen ist verachtung,

Die auch ihre Jungfraulichkeit hat,

und sich - zu stolz - nicht

zu einem fluch erhitzen will.]

Im ersten Gedicht der "Przekleństwa" rechtfertigt LANGE dann, daß er dennoch diesen Zyklus von fluchen geschrieben hat: Wie KRASINSKI vorzugehen vermöchten nur Engel oder steine: manchmal könten eben nur fluche Erleichterung bringen (Prz 1, vv. 8-14). Durch den demonstrativen Bezug auf das große Vorbild versucht der Dichter zum einen, seinem zyklus die nötige Autorität zu verschaffen, zum anderen stellt er seine fluche, die vor allem den politischen und sozialen Unterdrückern gelten, in den historischen Kontext von KRASINSKIS geistiger Abrechnung mit den Teilungsmachten und ihren Handlangern $1 \mathrm{~m}$ entsprechenden Abschnitt seines Poems (KRASINSKI 1973:161-163, vv. 218-281).

Auch das berelts 21 tierte Gedicht "Boska komedia" knüpft indirekt an "Przedświt" an, denn schon KRASINSKI hatte seinen Lebensweg mit der Wanderung durch die Hölle verglichen ("Jak Dant - 
przez pieklo przeszedlem za zycia" [wie Dante - habe ich zu Lebzezten die Hölle durchschritten]: 1973:153 f., v. 5 und etwas modifiziert $v .25$ ), wodurch LANGES Werk eine zusätzliche Deutungsdimension erhält.

Weitere Bezüge zu KRASINSKI stellen etwa das auf die "Boska komedia" unmittelbar folgende Gedicht "Nieboska komedia" allein schon durch den Titel sowie der antikisch stilisierende Dialog "Herakles $i$ Achilles" in Anknüpfung an sein Drama "Irydion" her.

An SKOWACKI erinnert LANGE vor allem durch zwei von diesem mehrfach in seinen Werken (vgl, besonders "Beniowski". "Ksiadz Marek" und "Sen srebrny Salomei") gestaltete Personen: "Moze proroctwa Marka, Wernyhory / Wydzieraja sie w zycie z tych tumanów?" ([Vielleicht resBen sich die Prophezeiungen Mareks, Wernyhoras / Aus diesen Nebeln ins Leben?]; List do redaktora, vv. 71 f.l: "Czy ten świat sie ubarwi w zmartwychwstań kolory / Podyug slów księdza Marka i wrózb Wernyhory?" ([wird sich diese Welt mit Auferstehungsfarben farben / Gemab den worten des Priesters Marek und den Prophezeiungen Wernyhoras?]; Mickiewicz I. vv. $25 \mathrm{f.l}$.

Aber LANGE bezieht sich nicht nur auf die von den drei traditionellen 'Sehern' gestalteten Zukunftsvisionen Polens, er zitiert auch NORWIDS "Fortepian Szopena": "Gdzie jest ta przemienionych kolodziejów/Polskazlotopszczola?" ([wo ist dieses - verwandelter stellmacher/goldbienlge Polen?]; Blyskawice XXIII, vv. 3-4; Sperrungen im Original!); exn Bild (vgl. NORWID 1971:144f., 147), von NORWID der Musik CHOPINS entlauscht, das LANGE nicht mit der Wirklichkeit des wiedererstandenen Polen in Einklang bringen kann.

In anderen als politischen Kontexten der angefürten Art bedient sich LANGE sehr viel seltener eines Bezugs auf die nationale Kulturtradition. Eines der wenigen Beispiele stellt "Fragment [1]" dar, in dem er zwei zitate aus M. SĘP SZARzYNSKIS "Sonet $V$. O nietrwalej milości rzeczy świata tego" (1973: 11) seiner Gedankenführung zugrunde legt. Zunächst zitiert er SĘPS Gedıchtanfang: "I nie mi lować cięzko, i milować / Nędzna pociecha" lsowohl nicht zu lieben ist schwer, als auch zu lieben / Ist eine erbärmliche freude] und entwickelt diese Aussage in den ersten drel Strophen. Die Strophen 4-7 sind dann der Dar- 
legung der entschieden negativen Folgen des 'N1chtliebens' gewidmet, während Strophe 8 im Anschluß an das zweite 2 itat "Milośc jest wlasny bieg zycia naszego" ([Die Liebe ist der eigentliche Cang unseres Lebens]: vgl. SĘP, v. 5) eine Hymne auf die 'Liebe' singt: die restlichen sechs Strophen schildern schließlich am persönlichen Beispiel Freude und Leid, die diese mit sich bringt, um am Ende zu resümieren: "Kto znal milości wieńce i kajdany: / Ten wiecznych cierpıen poznal siew rózany" (lwer die Kranze und ketten der liebe gekannt hat: / Der hat die Rosensad ewiger Leiden kennengelernt]: vv. $83 \mathrm{f}$. ).

So kommt LANGE zwar insgesamt zum gleichen Ergebnis wie der als Vorbild zitierte SZARZYNSKI, daß nämlich die liebe trotz aller inrer Leiden schließlich doch vorzuziehen lst; sein Gedicht bleibt jedoch (scheinbar) auf dieses Abwägen einer praktischen' Lebensfrage beschränkt, wahrend jener mit der Pointe schließt, daß eine wirkliche Befriedigung des Liebesverlangens nur im religiösen Bereich möglich ist. Durch die bewußte Ausklammerung dieses religiösen Aspekts hebt aber LANGE unauffällig seine SĘP diametral entgeqengesetzte Zentralaussage in der - zentralen - 8. Strophe hervor: "W niej jest modlitwa, w niej bytu calego / Prawda najwyzsza i jedyne slowo, / Chwala i rozkosz" (l In ihr <der Liebe> ist ein Gebet, in ihr ist des ganzen seins, Hochste wahrheit und der einzige Logos, / Ist Ruhw und wonne]: vv. 45-47).

Erwahnenswert sind im Bereich der 'nichtpolitischen' Bezugnahmen schlleßlzch noch die zahlrelchen LANGES zeitgenössischen Schriftstellerkollegen gewidmeten Gedichte, die eine würdigung von deren Schaffen versuchen (Pieśni dla przyjaciól: Pamieci Marii Grossek-Koryckiejl.

\subsection{Bezugnahmen innerhald von LANGES Gesamtwerk}

Neben den Anknüpfungen an verschledene Kulturtraditionen splelen - wie erwähnt - in LANGES Lyrik auch Bezüge auf eigene werke elne gewisse Rolle.

Am deutlichsten wird dies am Beisplel des Zyklus "Deuteronomion czyli Powtórzenie". Wie schon der Titel (Deuteronomion, oder: Wlederholungl zum Ausdruck bringt, handelt es sich hierbei um eine Art poetischer (Zwischen-)Bilanz von LANGES Origi- 
nalschaffen bis in die ersten Jahre des 20. Jahrhunderts hinein." Diese Sonette nehmen entweder ganz bestimmte, größere werke (Poeme, Gedichtzyklen, Dramen) wleder auf oder aber bezlehen sich auf elnen größeren thematischen Elnzelbereich aus LANGES Lyrikschaffen (vgl. auch LORENTOWICZ 1908:97 f.).

So resümert er in "DP 11. Lilla" seine Llebesgedichte, in "DP 14. Las" seine Naturlyrik, in "DP 17. Napiersk 1 "seine politisch-soziale Dichtung sowle in "DP 8. Nirwana" und "DP 21. Smierć" das zentrale Motiv selner Reflexionslyrik.

Beziehen sich die Sonette hingegen auf ein westimmtes Einzelwerk. so fassen sie oft dessen Inhalt oder zumindest einen Teilaspekt prägnant zusammen: "DP 5. Cor cordium" etwa kann als Kurzfassung des Poems "Pogrzeb Shelley'a" (PS) und "DP 15. Jezioro" als Resumee des zyklus "Na Switezi" betrachtet werden. Mit "DP 6. Ewolucja" ist das zusammenfassende Einleitungsgedicht der "Sonety wedyckie" unverändert übernommen, und "DP 22 . Palingeneza" paraphrasiert das zentrale Geschehen des gleichnamigen Poems.

In manchen Fällen wird aber auch das Thema des entsprechenden Werks frei variiert: So fügt LANGE etwa mit "DP 13. Upojenie" den fünf säuferballaden ("Ballady pijackie"), die den Getranken Absinth, Kaffee, Punsch und Champagner sowie dem Haschisch gewidmet sind, einen Lobpreis des Weines hinzu oder er interpretiert in "DP 10. Lllith" die Titelfigur des gleichnamigen Poemfragments als Urbild des weiblichen Wesens uberhaupt.

Aber auch außerhalb des "Deuteronomion"-2yklus verwendet LANGE Ansplelungen auf elgene Werke, wie etwa in " $R$ 61" auf sein revolutionär und blasphemisch gestimmtes politisches Jugendschaffen, dem er nun distanziert gegenübersteht: "Niejedno gorzkle slowo, które niegdyś rzeklem, / Pewnie bym dziś przekresill na swych ksiag stronicach" ([so manches bittere wort, das ich einst gesprochen habe, / wurde lch heute sicher auf

"Der "Epllog" dieses Zyklus ist auf 1902 datlert, elnzelne Sonette mögen aber auch noch in der zeit bis zur Veröfentlichung im Band "Rozmyślanıa" (1906) entstanden sein. Diese Unsicherheit der Datierung erschwert die Dechiffrierung der Bezugnahmen jedoch nur in elnigen wenigen fällen. in denen nicht auf ein ganz bestimmtes werk angesplelt wird (vgl. besonders "DP 21. Smierć", das nicht genau erkennen läßt, welche der "Rozmyślania" mit Todesthematik zeitlich noch miteinbezogen sind). 
den Sezten meiner Bucher durchstreichen]: vv. I f.l. Insbesondere aber wird die struktur vieler zyklen durch wechselseitige Bezüge unter den sie bildenden Gedichten mitbestimmt, was zu untersuchen einen elgenen - den Rahmen dieser Arbeit sprengenden - Abschnitt uber 'zyklenstrukturen' erfordern würde.

\subsection{Zusammenfassung}

Wie dieses Kapltel gezelgt hat, knüpft LANGE in selner Lyrik explizit an verschiedene kulturelle Traditionsstränge an. Hervorzuheben sind insbesondere die griechisch-römische Antike. die welt der Blbel, das christliche Mittelalter einschlleßlich DANTES, SHAKESPEARE, die englische Romantik und Richard WAGNER sowie der polnische Messianismus; nicht $z$ u vergessen auch der - hier ausgeklammerte - orlentalische Kulturraum. All dies zeugt von einem Universalismus des Gelstes, einem Universalismus, dem die elgene Erfahrungswelt zu- und untergeordnet wird.

Selnem lyrischen Werk insgesamt verleint die ausglebige verwendung des Gestaltungsmittels 'Bezugnahme' ein stark intellektuelles Gepräge: der reflexive Grundcharakter der Lyrik kommt hler ähnlıch wie bei der schluisselwortstruktur deutlich zum Ausdruck.

In elnigen Gedichten mit übertrlebener Häufung von Bezügen. zumal wenn diese ihrer Herkunft nach bunt gemischt sind und unmotiviert wirken, kann allerdings der Elndruck elnes gewissen Manierismus entstehen: Man vergleiche etwa "Boska komedıa", in der - wie erwähnt - durch Paraohrase von DANTES "Göttlicher Komödie" die jüngere polnische Geschichte sinnfällig gemacht werden soll, LANGE dem Text aber schelnbar wahllos Begriffe aus ganz anderen Bereichen aufpfropft (Atessa, v. 22: Gog und Magog. v. 25: Myrmidonen, v. 36 ).

Meist jedoch wird das durch Anspielungen erzeugte 'Kolorit" elnes Gedichts durchgehalten: es ergibt sich quasi eine geschlossene 'Bildebene'.

Gelstesgeschichtliche Einflüsse, die in LANGES Lyrik zum Tragen kommen, lassen sich anhand der hier zur Diskussion slehenden expliziten Anknüpfungen vor allem für den Bereich des polnischen Messianismus sowie fur eine idealistisch-romant 1sche Grundhaltung im allgemeinen feststellen, wie dies fur 
einen der 'jungpolnischen' Geistesformation zuzurechnenden Autoren ja auch nicht verwunderlich ist. Dienen die messianistischen Konzeptionen der großen Romantiker als Interpretationsmuster und Wertungskriterien für die neuere polnische Geschichte, so verweisen die Anknüpfungen an SHAKESPEARE (Romantycznośc!), die englische Romantik und Richard WAGNER (sowie die indische Philosophie: vgl. MACHALSKI 1937) einerseits und an das idealisierende Frauenbild bei DANTE und MICHELANGELo andererseits auf eine ganz spezifische Geistes- und Lebenshaltung. die LANGES Gedichte grundlagend prägen lauch wenn erst ein studium seiner theoretischen Schriften die genauere Rekonstruktion eines rational formulierten philosophischen systems des A U tors (!) ermöglicht; vgl. SZYMANSKA 1979).

Dagegen dienen Antike und Bibel in erster Linie als 'steinbruch für Mythen und Bilder, die von LANGE auf seine eigene Lebenserfahrung bezogen und dementsprechend uminterpretiert werden. of $t$ verbindet sich damit eln Unterstreichen von uralten Traditionen und der Kontinuität der Menschheitsgeschichte.

Allen Bezugsbereichen gemeinsam sind einige generelle Verwendungsformen: Anspielungen werden zur autoritativen stüzung und Aufwertung der eigenen Aussage oder aber zur kritischen bis polemischen Auseinandersetzung mit nicht geteilten Ansichten genutzt: sie können bewußten Bezug auf bestimmte Traditionsstränge ebenso wie eine explizite Distanzierung von solchen bezwecken. Häufig dienen sie der rhetorischen Ausdruckssteigerung.

Im eigentlichen Textaufbau schließlich werden den Bezugnahnen ebenfalls die unterschiedlichsten Funktionen zugewiesen: Sie können als isolierte Metaphern oder Vergleiche auftreten, durch inr zusammenwirken eine locker gefügte, aber homogene 'Bildebene' für einen größeren Abschnitt bzw. das Gesamtgedicht schaffen, oder schließlich die Gesamtkomposition eines Textes dadurch bestimmen, daß das konkrete Baumaterial dem vorgegebenen Muster entsprechend geformt wird (vgl. die zyklen "Ze starych legend" in TD und " $Z$ nowej serii" in OZP I). Dementsprechend ist ihre Gestaltungskraft und Bedeutung im Rahmen des jewelligen Gesamttextes sehr unterschledlich.

zum Abschluß sei noch auf LANGES Selbstbezüge verwiesen (5.5.) die bilanzierenden Charakter tragen oder - in unauffalligerer Form - zur inneren strukturierung von Gedichtzyklen beitragen. 


\section{Schlul3}

Wie ich in der vorliegenden Arbeit $z$ u zeigen versucht habe, können durch eine systematische Untersuchung der Gestaltungselemente 'Iyrischer Monolog". 'Versbau'. 'Schlüsselworter" und "literarische Bezugnahmen" wichtige Einblicke in die Wirkungsmechanismen von LANGES Dichtungssprache und damit letztlich in die Struktur seiner Lyrik insgesamt gewonnen werden.

Die an dieser stelle aus praktischen Grüden nicht durchführbare Analyse we iterer Gestaltungsprinzlpien (wie z.B. Reimstruktur und Strophik, Textkomposition, Bildsprache, lyrische Gattungen, Zyklenstrukturen, etc.l bliebe für die zukunft zu wüschen, verspräche sie doch zusatzliche Gesichtspunkte für elne adäquate Interpretation und Charakterisierung des untersuchten Werkkomplexes.

Eine Elnordnung der hier für LANGES Lyrik gewonnenen Aussagen in den Rahmen der literarischen Epoche oder gar in größere literaturgeschichtliche Evolutionsstränge konnte nicht unternommen werden, da die nötigen Vorarbeiten bisher fehlen (vgl. oben Abschnitt 1.2.). Wlchtig wäre aus diesem Grunde zunächst eine systematische Untersuchung we 1 terer Ly $1 k$ er der "Mloda Polska" auf die in dieser Arbeit behandelten oder ähnliche Prinzipien der Gestaltung inrer poetischen Sprache hin. um so einerseits $z u$ einer grundlegenden Charakteristik der 'Jungpolnischen' Dichtungssprache insgesamt zu gelangen, andererseits vor diesem Hintergrund die Individuellen züge der einzelnen Autoren (einschließlich LANGES) klarer herausarbeiten zu können. Dabei wäre nicht nur zu fragen, wie die jeweiligen Gestaltungselemente realislert werden, sondern auch, welchen stellenwert sie bel den elnzelnen Lyrikern jeweils einnehmen.

Erst ein solcher vergleichender Zugang könnte die hier für LANGE erarbeiteten - tellweise gleichsam provisorischen - Er gebnisse in ihren wahren Relationen erscheinen lassen und zu einer endgultigen Charakterislerung seiner individuellen Dichtungssprache im literarhistorischen Kontext füren. 


\title{
7. Literaturverzeichnis
}

\subsection{Verwendete Ausgaben von LANGES Werken}

\author{
AT = Atylla. Tragedia. Warszawa 1910. \\ FRAG = Fragmenta. Poezje wybrane. Warszawa 1901. \\ OzP = Ostatnl zbiór poezyj. [I] Gdzıekolwıek jestés... Roz- \\ myślania. Wlersze rözne. [II] Malczewski i kilka \\ erotykow. Hg. v. A. TOM. Warszawa 1931. \\ P I I Poezje. Cześć I. Kraków 1895. \\ PII = Poezje. Częśc II. Kraków 1898 . \\ PDS = Pierwszy dzien stworzenla. Piésnl spoleczne. Kraków \\ 1907 . \\ POC = Pocalunki. Warszawa 1925 . \\ POG = Pogrobowcom. Kraków 1901 . [unter dem Pseudonym "Napier- \\ ski" erschienen.] \\ PS = Pogrzeb Shelley'a. Warszawa 1890 . \\ PW = Poezje wybrane. Hg. V. J. Z. JAKUBOWSKI. Warszawa 1960. \\ RIIW = Rozmýslania 1 inne wiersze. Hg. v. J. PORADECKI. War- \\ szawa 1979. \\ ROZ = Rozmyślania. Kraków 1906. \\ SON = XXVII sonetow. Warszawa [1914; anonymerschienen]. \\ TD = Trzecl dzien. Wiersze plsane r. 1915-1923. Warszawa \\ 1925 . \\ WEN = Wenedzi. Tragedia. Paryz 1909. \\ WP $=$ Wybór poezyj. Lwów [1899].
}

\subsection{Quellen der zitierten Gedichte}

Ich zitiere LANGES Gedichte grundsäzlich nach der ersten Buchveroffent 1 l chung, da sonst oftmals auf spatere - wenlger zuverlassige - Auswahlausgaben (WP, FRAG) zuruckgegriffen werden muBte, bzw. die Geschlossenheit ursprünglicher zyklen (vgl. z.B. $E Z$ ) wegen solcher Auswahlbände zu zerstören wäre. (wurde jedoch eln zunächst unabhänglges Gedicht später in einen geschlossenen zyklus integriert, lege ich der Einfachhelt halber die rassung dieses zyklus zugrunde, zumal der Autor - in solchen (sehr seltenen) Fällen. wie auch sonst - kaum mehr veränderungen an einmal gedruckten Texten vornimmt.) soweit die Gedichte in durchnumerlerten zyklen erschienen sind, gebe ich sie in der Arbeit nach dem entsprechenden zyklus und der Nummer in diesem an, andernfalls nach titel bzw. Incipit lletzteres immer in "Anfuhrungszeichen", die anderen falle nur bel vorkommen im laufenden $T e x t)$. Die bei Angaben nach dem zyklus verwendeten siglen und lhre Auflosung sind in der folgenden Aufstellung an ihrem alphabetischen Platz zu finden. Zu den siglen fur die Textquellen vgl. oben Abschnitt 7.1.!

Akteon (z "Ksıegl bogów")

OZP I: $125-132$
OZP I: $148-155$
OZP I $111-118$
TD:62-65
OZP I:167 f.

Apollo I Muzy

Bezsenna noc

BIyskaw z ce

Boska komedia

OZP I:167 f. 
BP $1-5=$ Ballady pijackie I $-V$

"Bywaja czasem slowa, które - rzeklbyś - plyna"

Cesarz wilhelm

Cezarom oddaj...

Chcialbym...

Choreodaktyl

Chrabaszcze

cienie

Cyfra i slowo

Dab

Dies illa

DP Pr., 1-22, Epl. = Deuteronomion czyli Powtórzenie: Prolog. I-XXII, Epllog

Exegi...

Ez $1-9=$ Echa zimowe I-IX

Fragment [1] ("I nie milować ciezko, I milowac")

Fragment [2] ("My sie nie mozem kochać, Jak golębie")

Fragment [3] ("Blada te] duszy, która nazbyt tkliwa")

Herakles 1 Achilles

Il 1 ada I Odyseja

Impromptu

Inwokac ja

Kolysanka ( $z$ pleśnı o nędzy)

Kopernik

KP $1-6=K s i e g 1$ proroków I-VI

L $1-10=$ Logos $I-X$

List do redaktora

Kuk i arfa

Mlckiewicz

Mlynareczka

Mogila

Nad stawem

Na roll

Nieboska komedia

Nie, Jam. wcale nie kochal

Nowa pleśn

Pamięi Mar 1 Grossek-Koryckiej

"Pamietasz te noc cicha - l ten lazur czysty")

Pieśni dla przyjaciól I-V

Pieśni o pocalunkach. Scherzo I-II

Piéśn Hunnów ( $Z$ tragedil Atylla)

Pléśn o slowle

Pochwala zycia

Pog $1-12$ = Pogrobowcom I-XII

Posag I dziewczyna

Prz $1-16=$ Przekleństwa I-XVI

Przebacz...

Pytanie

$R 1-56$ = Rozmyślania I-LVI

R 57-64 = Rozmyślania LVII-LXIV

Rien que pour vous I-III

Romantycznośc

Rym (Do Jednej pani, która ganila moje rymy zbyt prostel

Samotność

Sielanka

P II $: 19-30$

OZP II $: 115$

TD $: 41-45$

PDS : 15

$P \quad I: 40$

$P$ I I : 174

P II:246 F.

$P$ I:56-59

$P \quad I: 157-163$

P II:77 f.

TD : 58-61

ROZ : $101-126$

WP : 107-111

P II:79-92

P I : 21-24

P I:41-43

OZP II: $105 \mathrm{f}$.

TD:25-31

OZP I:165 f.

$P$ I:54 f.

OZP $1: 174 \mathrm{f}$.

PDS : $|8-2|$

TD: 66

P I : $127-140$

TD : $91-100$

TD: $9-12$

P I I : 187-190

TD: $21-24$

P I I : 248

OZP I I : 107-109

$P$ II:55 $\mathrm{f}$.

P I: $13-15$

OZP I:169 f.

$P \quad I: 49$

OZP $1: 171$

OZP I: $172 \mathrm{f}$.

OZP II $: 116 \mathrm{f}$.

$P$ II : $31-43$

$P I: 38 \mathrm{f}$.

WP:106 f .

P I:141-156

OZP I: 176

POG: 9-42

$P$ I: $25 \mathrm{f}$.

PDS : $22-37$

P I:50 f.

P I: 47

ROZ : $1-81$

OZP $1: 85-104$

OZP II $118-120$

OZP $I: 156-164$

P I I : 165-170

P I : 48

TD $: 32-35$ 
Skowronki

Son 1-?7=XXVII sonetów I-XXVII

Sonet [1] ("Czasami śród kochanków tak plynie rozmowa")

Sonet [2] ("Nieujezdzonym żrebcem bylo zycie moje")

Sosna

"Starozytnym Gallów obyczajem"

Strofa alcejska

Sw Pr., 1-7 = Sonety wedyckie [prolog], I-VII

Swemu pokoleniu

Sw $1-10=$ Na Switezi I-X

Topola

"Triumfalnie podlość się úsmiecha"

Villanella

Vita nova $I-X I$

Wenecja $1-6$

We śnie

W imionniku R. D.

Wiosenna pieśn

W lesie I-III

Zachód slońca

2 erotyków ("Cóz bym ja zyskal, gdybyśs sie wznios la")

2 poza chmury

ZSL $1-12=$ Ze starych legend I-XII
P II:53 f.

SON : $5-31$

P I: 31

P II: 240

P II:57 f. OZP II:112-114

P II:171-173

P I: $117-126$

PDS : 86-88

P II:93-109

P II:67 f. OZP II:110 f.

P I: 53

$P$ I I : 209-228

OZP I : 119-124

TD: $36 \mathrm{f}$.

P II:241

P I: $29 \mathrm{f}$.

P II: 74-76

P I : 16-18

P I: 37

TD: $13-15$

TD : 69-88

\subsection{Weltere zitierte Literatur}

BOROWY, W.: Antoni Lange jako poeta. In: ders.: Dziś i wczoraj. warszawa 1934:196-215. [zuerst in: Pamietnik Warszawski 1929, H. $1: 250-263$.

CHRZASTOWSKA, B. und S. WYSKOUCH: Wladomości z teorii literatúry w analizie literackiej. Warszawa 1974.

DREWES, G.M.. C. BLUME, H.M. BANNISTER (Hg.): Analecta Hymnica Medii Aevi. Bd. 54, Leipzig 1915.

DRZEWICKA, A.: Z zagadnień techniki tlumaczenla poezji. Studia nad polskimi przekladami liryki francuskiej w antologiach 2 lat 1899-1911. Kraków 1971. (= Zeszyty Naukowe Uniwersytetu Jagiellońskiego. 255; Prace Historycznoliterackie. 18.)

EUSTACHIEWICZ, L.: Typologia dramatu Mlodej Polski na tle porównawczym. In: J. KWIATKOWSKI und 2 . ŻABICKI (Hg.): 2 problemów literatury polskiej XX wieku. Bd. 1: MLoda Polska. Warszawa $1965: 370-385$.

HERTz. P. ( $\mathrm{Hg}$.$) : Zbiór poetów polskich XIX w. Bd. 4, Warszawa$ 1965.

JAKUBOWSKI, J.Z.: Wstep. In: PW:5-16.

JASTRUN, M.: Wstęp. In: ders. (Hg.): Poezja Mlodej Polski. Wroclaw usw. '1967:III-LXXXII. (= Biblioteka Narodowa. I-125.)

KOCHANOWSKI, J.: Dziela polskie. Hg. v. J. KRZYŻANOWSKI. Bd. 1 , Warszawa 21953.

KOPCZYNSKA, Z. Und M.R. MAYENOWA (Hg.): SYlabizm. Wroclaw 1956. $l=$ Poetyka. Zarys encyklopedyczny. Tl. 3: Wersyfikacja: Bd. 3.)

KOPCZYNSKA, Z, und M.R. MAYENOWA (Hg.): M. DKUSKA und T. KURYS: Sylabotonizm. Wroclaw 1957. (= Poetyka. Zarys encyklopedyczny. Tl. 3: Wersyfikacja; Bd. 4.) 
KRASINSKI, Z.: Dzlela literackie. Hg. v. P. HERTZ. Bd. 1, Warszawa 1973 .

KRZYŻANOWSKI, J.: Neoromantyzm polski. 1890-1918. Wroclaw usw. 1963.

KRZYŻANOWSKI, J.: Wstep. In: K. TETMAJER: Poezje wybrane. Hg. v. J. KRZYŻANOWSKI. WrOCI aW USW. "1968:III-CIV. ( $=$ Biblioteka Narodowa. I-123.)

KRZYŻANOWSKI, J.: Dzieje literatury polskiej. Warszawa '1979.

LICHANSK1, S.: "Polscy parnasiśc1". In: Twórczość 1962, 6:87-98. [Erneut in: ders.: Cienie i profile. Studia i szkice literackle. Warszawa 1967:99-120.]

LORENTOWICZ, J.: Antoni Lange. In: ders.: Mloda Polska. Bd. 1 , Warszawa 1908:69-100.

kos, J.: Wiersze polskie w ich dziejowym rozwoju. Warszawa usw. [1920].

MACHALSKI, F.: Orientalizm Antoniego Langego ( 2 zarysem bibliograf 11). Tarnopol 1937. (= Prace Podolskiego Towarzystwa Przyjaclól Nauk w Tarnopolu. 2.l

MAYENOWA, M.R. (Hg.): Strofika. Wroclaw usw. 1964 (a poetyka. Zarys encyklopedyczny. Tl. 3: Wersyfikacja: Bd. 6.)

MARKIEWICZ, H.: Glówne problemy wledzy o literaturze. Kraków 1980 .

MICKIEWICZ, A.: Dziela. Wydanze narodowe. Bd. 3: Utwory dramatyczne. Warszawa 1948 und Bd. 6,2: Pisma proza. Warszawa 1952.

NAPIERSK1, S.: Zapomniany polski modernista. Warszawa 1936.

NORWID, C.: Pisma wszystkie. Hg. v. J.W. GOMULICKI. Bd. 2: Wiersze. Czéśc druga, Warszawa 1971 .

PODRAZA-KWIATKOWSKA, M.: WaClaw RollCz-Lieder. Warszawa 1966. $l=$ Historia i Teoria Literatury. Studia. Historia LiteraturY. 16.)

PODRAZA-KWIATKOWSKA, M.: Ideal jednóscl doskonalej. O Antonim Langem jako krytyku. In: dies.: Mlodopolskie harmonie i dysonanse. Warszawa 1969:42-95.

PODRAZA-KWIATKOWSKA, M.: Antoni Lange. In: Polsk 1 Slownik B10graficzny. Bd. 16. Wroclaw usw. 1971:485-487.

PODRAZA-KWIATKOWSKA, M.: Symbolizm i symbolika w poezji Mlodej Polsk1. Teoria 1 praktyka. Kraków 1975.

PORADECKI, J.: Wstep. In: RIIW:5-28.

PROKOP, J.: Antoni Lange. 1861-1929. In: Obraz literatury polskiej XIX $i$ XX wieku. Seria 5: Literatura okresu MYodej Polski. Bd. 1, Warszawa 1968:421-445.

PRZYBOS, J. ( Hg.): Jabloneczka. Antologla polskiej piéśni ludowej. Warszawa 1957 .

SEEP SZARZYNSKI, M.: RYtmy abo wiersze polskie oraz cykl erotyków. Hg. V. J. KRZYŹANOWSKI. Wroclaw usw. 1973. l= Biblioteka Narodowa. I-118.)

SIEROTWINSKI, S.: Maryla Wolska. Srodowisko, życle, twórczośc. Wroclaw 1963. (= Prace Komisji Historycznoliterackiej. 10.)

SKAWINSKI, J. (Hg.): Slownik terminów literacklch. Wroclaw usw. 1976.

SMUSZKIEWICZ, A.: Zaczarowana gra. Zarys dzlejów polskiej fantastyk 1 naukowej. Poznań 1982 .

SzYMANSKA, B.: Poeta i Nieznane. Poglady fllozoficzne Antoniego Langego. Wroclaw usw. 1979. ( = Prace Komisji Historycznoliteraskiej. 40.1

WEISS, T.: Modernizm. In: M. STĘPIEN und A. WILKON (Hg.): Historia literatury polskiej w zarysie. Warszawa 1978:322-384. 
WYKA, K.: slowa-klucze. In: ders.: O potrzebie historii literatury. Szkice polonistyczne z lat 1944-1967. Warszawa 1969: $198-234$.

WXKA, K.: Modernizm polski (struktura i rozwój). In: ders.: Mloda Polska. Bd. 1. Kraków 1977:9-306.

WYSPIANSKI, S.: Dzlela. Hg. V. A. CHMIEL Und T. SINKO. Bd. 4: Dramaty, Warszawa 1927.

ŻELENSKI (BOY), T. (Hg.): MYoda Polska. Wybór poezji. Wroclaw 21947 . ( = Biblioteka Narodowa. I-125.) 


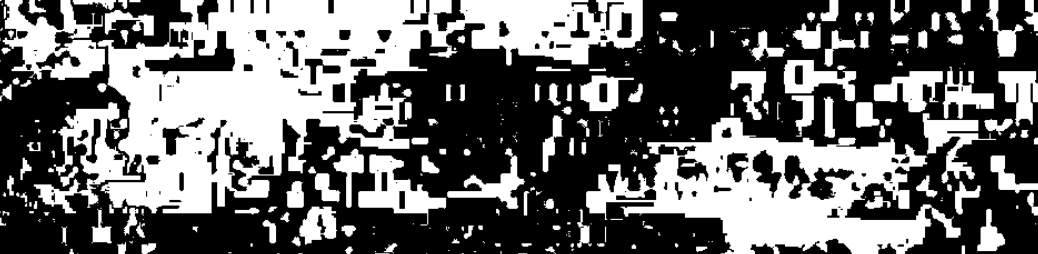
Nots is

$y=1+5=8$ 


\section{SLAVISTISCHE BEITRAGE}

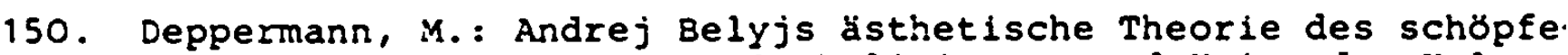
rischen BewuBtseins. Symbolisierung und Krise der Kultur un die Jahrhundertwende. 1982. X, $256 \mathrm{~S}$.

151. Meichel, J.: Zur Entfremdungs- und Identitatsproblematik in der Sowjetprosa der 60er und 70er Jahre. Eine literatursoziologische Untersuchung. 1981. $217 \mathrm{~S}$.

152. Davydov, S.: "Teksty-Matreški" Vladimira Nabokova. 1982. VI, $252 \mathrm{~S}$.

153. Wallrafen, C.: Maksimilian Vološin als Künstler und Kritiker. 1982. IV, $273 \mathrm{~S}$.

154. Dienes, L.: Russian Literature in Exile: The Life and Work of Gajto Gazdanov. 1982. XII, 224 S., 7 Abb.

155. Bulgarien 1300. Referate der Sektion "Sprache und Literatur" des Symposiums "Bulgarien in Geschichte und Gegenwart", Hamburg 9.-17. Mai 1981. Herausgegeben von Peter Hill. 1982. $97 \mathrm{~s}$.

156. Bock, I.: Die Analyse der Handlungsstrukturen von Erzählwerke am Beispiel von N.V. Gogol's "Die Nase" und "Der Mantel" 1982. VIII, $168 \mathrm{~S}$.

157. Pihler, M.: Die, Progressive, Borm des englischen Verbs und ihre Ubersetzungsmöglichkeiten im Slowenischen. 1982. $170 \mathrm{~s}$.

158. Sesterhenn, R.: Das Bogostroitel'stvo bei Gor'kij und Lunačarskij bis 1909. Zur ideologischen und literarische Vorgeschichte der Parteischule von Capri. 1982. VIII, $366 \mathrm{~s}$.

159. Kunstmann, H.: Vorläufige Untersuchungen uber den bairischen Bulgarenmord von 631/632. Der Tatbestand. Nachklänge im Nibelungenlied. 1982. $104 \mathrm{~S}$.

160. Slavistische Linguistik 1981. Referate des VII. Konstanzer Slavistischen Arbe1tstreffens Mainz 30.9.-2.10.1981. Herausgegeben vor Wolfgang Girke. 1982. $264 \mathrm{~S}$.

161. Stobbe, P.: Utopisches Denken bei V. Chlebnikov. 1982. VIII, $157 \mathrm{~s}$.

162. Neureiter, F.: WeiBrussische Anthologie. Ein Lesebuch zur weibrussischen Literatur (mit deutschen Ubersetzungen). 1983. $230 \mathrm{~S}$.

163. Witte, G.: Die sowjetische Kolchos- und Dorfprosa der funfziger Jahre. Zur Evolution einer literarischen Unterreihe. 1983. X, $292 \mathrm{~S}$.

164. Timroth, W.v.: Russische und sowjetische Soziolinguistik und tabuisierte Varietäten des Russischen. 1983. VIII, 194 !

165. Christians, D.: Die Sprachrubrik in der itieraturnaja gazeta von 1964 bis 1978. Dokumentation und Auswertung. 1983. 266 \%.

166. Koschmal, W.: Das poetische System der Dramen I.S. Turgenevs Studien $z u$ einer pragmatischen Dramenanalyse. 1983. X, $453 \mathrm{~S}$. 
167. Hofmann, T.: Das Bauerntum in der sowjetrussischen P:osa der 20er Jahre. Konzeptionen, Konflikte und F:giren. N983. $434 \mathrm{~S}$.

168. Morsbach, P.: Isaak Babel' auf der sowjetischen Bihie. 1983 . $\mathrm{X}, 255 \mathrm{~S}$.

169. Tutschke, G.: Die glagolitische Druckerei von Rijeia und imr historiographisches Werk Knizice od zitié r.mikih arhierèov i cesarov. 1983. $373 \mathrm{~S}$.

170. Lam, A.: Mainzer Vorlesungen iber die polnische Li:e:atur seit 1918. 1983. IV, $280 \mathrm{~S}$.

171. Pratt, S.: The Semantics of Chaos in Tjutčev. 1983. IIII, $149 \mathrm{~S}$.

172. Slavistische Linguistik 1982. Referate des VIII. Konitanzer Slavistischen Arbeitstreffens Kiel 28.9. - 1.10.1982. Herausgegeben von Hans Robert Mehlig. 1983. $252 \mathrm{~S}$.

173. Dingley, J.: The Peripheral Plural Endings of Nouns in Petrine Sermons. 1983. VIII, 388 S.

\section{Bayerisctio}

Staatstibliothok

Münchien 